Leandro Falconi Filippi

\title{
ESTIVAGEM DE UNIDADES DE CELULOSE VIA MODELO DE CORTE E EMPACOTAMENTO
}

São Paulo 
Leandro Falconi Filippi

\section{ESTIVAGEM DE UNIDADES DE CELULOSE VIA MODELO DE CORTE E EMPACOTAMENTO}

Dissertação apresentada à Escola Politécnica da Universidade de São Paulo para obtenção do Título de Mestre em Ciências

Área de concentração: Engenharia de Sistemas Logísticos

Orientador: Prof. Dr. Miguel Cezar Santoro

São Paulo 


\section{Agradecimentos}

Ao Prof. Dr. Miguel Cezar Santoro, primeiramente pela inestimável paciência e por acreditar no potencial do trabalho, mesmo quando as ideias eram incipientes e confusas. Além disso, por toda ajuda e apoio durante o desenvolvimento da pesquisa, pelas inúmeras contribuições técnicas e por toda experiência a mim disponibilizada.

À Luciana, por todas compreensão e, principalmente, pelo apoio nas horas mais difíceis. Sem essa parceria a conclusão deste trabalho não seria possível.

Aos meus pais e irmão, que sempre apoiaram e incentivaram meu desenvolvimento, incluindo o início e conclusão dessa jornada.

Ao Carlos Saias, que deu todas as condições iniciais para que esse projeto saísse do papel, disponibilizando o tempo necessário para as aulas, trabalhos e pesquisas.

À Silvia Krueger Pela, que mesmo nos momentos mais difíceis e complicados da rotina do dia-a-dia, permitiu que o trabalho continuasse a ser desenvolvido.

À Marina Negrisoli, por disponibilizar os dados e instâncias reais que foram utilizados em parte da pesquisa.

Aos amigos e colegas, que direta ou indiretamente contribuíram para esse projeto. 
"Caia sete vezes, levante-se oito" (Provérbio Japonês) 


\section{Resumo}

Este trabalho propõe a aplicação de dois diferentes conceitos para a resolução do Problema de Estivagem de Unidades de Celulose - PEUC, que de acordo com Ribeiro e Lorena (2008) pode ser definido como um problema que busca alocar a máxima quantidade de unidades de celulose ao porão de cargas de um dado navio, respeitando as restrições físicas de dimensões, de posicionamento, de não-sobreposição das unidades e de capacidade máxima do porão do navio.

Esse tipo de problema se encaixa, no contexto da Pesquisa Operacional, na classe de Corte e Empacotamento (Cutting and Packing - CEPP) e pode ser classificado, de acordo com a tipologia de Wäscher, Haußner e Schumann (2007), como sendo um Single Large Object Placement Problem (SLOPP).

Em última instância, o objetivo do PEUC é definir o melhor plano de estivagem para o carregamento de unidades de celulose em um dado porão de um navio, maximizando a área ocupada pelas unidades de celulose.

Trata-se de um problema NP-Completo (DOWSLAND; DOWSLAND, 1992; BISCHOFF; WÄSCHER, 1995; MALAGUTI; DURáN; TOTH, 2013) e por isso foram propostas duas abordagens para buscar a melhoria das soluções encontradas e/ou redução do tempo computacional necessário.

As abordagens propostas, o Modelo Matemático Modificado e o Método Iterativo de Solução, apresentaram bons resultados para instâncias experimentais, confirmando a efetividade de suas aplicações. Os resultados foram melhores tanto na qualidade das soluções (ocupação total do objeto), como no tempo computacional necessário.

Também foram avaliadas quatro instâncias reais, com a comparação dos planos de estivagem resultantes da aplicação dos modelos matemáticos com os planos reais, elaborados manualmente por especialistas. Em três dos quatro casos os resultados das abordagens aqui propostas se mostraram melhores que os planos reais.

Palavras-chave: Corte e Empacotamento. Método Iterativo. Formulação Disjuntiva. Estivagem. Celulose. 


\section{Abstract}

This work proposes the application of two different concepts to tackle the Woodpulp Stowage Problem - WSP, that according to Ribeiro e Lorena (2008) can be defined as a problem that seeks the allocation of the maximum quantity of woodpulp units inside the hold of a cargo vessel, always respecting the physical constraints, positioning constraints, non-overlapping of units and also the hold capacity.

This kind of problem fits, in the context of Operational Research, into the class of Cutting \& Packing and can be classified, according to Wäscher, Haußner e Schumann (2007) typology, as a Single Larga Object Placement Problem (SLOPP).

Ultimately the objective of the WSP is to define the best stowage plan for the loading of woodpulp units inside a given hold of a given cargo vessel, maximizing the total area occupied by the woodpulp units.

As it's a NP-Complete problem (DOWSLAND; DOWSLAND, 1992; BISCHOFF; WÄSCHER, 1995; MALAGUTI; DURáN; TOTH, 2013) two approaches were proposed to improve the quality of the resulting solutions and/or the reduction of the computational time needed. The proposed approaches, the Modified Mathematical Model and the Iterative Solution Method, showed good results for experimental instances, confirming the effectiveness of these approaches. The results were better regarding the quality of the solutions (total occupied area of the object) and also regarding the computational time needed.

Also, four real instances were evaluated, comparing the results of the mathematical models with the real stowage plans, manually created by specialists. In three of the four instances, the proposed approaches showed better results than the real stowage plans.

Keywords: Cutting and Packing. Iterative Method. Disjunctive Formulation. Stowage. Woodpulp. 


\section{Lista de ilustrações}

Figura 1 - Representação esquemática de um navio de celulose (Fonte: G2 Ocean) 14

Figura 2 - Navio Gantry Crane . . . . . . . . . . . . . . . . . 14

Figura 3 - Navio Jib Crane . . . . . . . . . . . . . . . . . . . . 14

Figura 4 - Exemplo de unidade (unit) de celulose (esquerda) e fardo (bale) (Fonte: $\mathrm{UPM}) \ldots \ldots \ldots \ldots \ldots \ldots \ldots$

Figura 5 - Lingada de celulose sendo posicionada no porão do navio . . . . . . . . 16

Figura 6 - Formação de uma lingada de $32 \mathrm{t} \ldots$. . . . . . . . . . . . 17

Figura 7 - Exemplos de padrões de lingadas que podem ser formados . . . . . . 18

Figura 8 - Exemplo real de plano estivagem para porão de $250 \mathrm{~m}^{2}$. . . . . . . . 18

Figura 9 - Exemplo real de plano estivagem para porão de $450 \mathrm{~m}^{2}$. . . . . . . . . 19

Figura 10 - Consolidação do plano de carga do navio Star Louisiana . . . . . . . . 20

Figura 11 - Exemplo de plano de estivagem resultante do MIS . . . . . . . . . . . . 43

Figura 12 - Fluxograma conceitual do MIS . . . . . . . . . . . . . . . . 45

Figura 13 - Representação gráfica do plano de estivagem, iteração 1 . . . . . . . . . 49

Figura 14 - Representação gráfica do plano de estivagem, iteração 2 . . . . . . . . . 49

Figura 15 - Representação gráfica do plano de estivagem, iteração 3 . . . . . . . . . 50

Figura 16 - Representação gráfica do plano de estivagem, iteração 4 . . . . . . . . . 51

Figura 17 - Instância 1, Grupo 1 . . . . . . . . . . . . . . . . . . . 54

Figura 18 - Instância 6, Grupo $2 \ldots \ldots$. . . . . . . . . . 54

Figura 19 - Instância 11, Grupo $3 \ldots \ldots$. . . . . . . . . . 54

Figura 20 - Instância 16, Grupo 4 . . . . . . . . . . . . . . . . 55

Figura 21 - Representação gráfica do plano de estivagem real da instância 1 . . . 77

Figura 22 - Representação gráfica do plano de estivagem gerado pelo modelo para a instância real $1 \ldots \ldots$. . . . . . . . . . . . . . 77

Figura 23 - Representação gráfica do plano de estivagem real da instância 2 . . . 78

Figura 24 - Representação gráfica do plano de estivagem gerado pelo modelo para a instância real $2 \ldots \ldots$. . . . . . . . . . . . . . . . . . 79

Figura 25 - Representação gráfica do plano de estivagem real da instância real 3 . . 80

Figura 26 - Representação gráfica do plano de estivagem gerado pelo modelo para a instância real 3 . . . . . . . . . . . . . . . . . . . . . 80

Figura 27 - Representação gráfica do plano de estivagem real da instância real 4 . . 81

Figura 28 - Representação gráfica do plano de estivagem gerado pelo modelo para a instância real 4 . . . . . . . . . . . . . . . . . . . . . . 82 


\section{Lista de tabelas}

Tabela 1 - Exemplo de matriz de alocação dos itens . . . . . . . . . . . . . . . 41

Tabela 2 - Exemplo de dados de controle das iterações . . . . . . . . . . . . . 43

Tabela 3 - Detalhamento das instâncias experimentais construídas . . . . . . . . . 46

Tabela 4 - Matriz de itens disponíveis para a iteração . . . . . . . . . . . . 47

Tabela 5 - Matriz de com os resultados da iteração . . . . . . . . . . . . 48

Tabela 6 - Dimensões máximas e mínimas dos itens para construção das instâncias 53

Tabela 7 - Detalhamento das instâncias experimentais construídas . . . . . . . . 54

Tabela 8 - Dimensões, em metros, dos porões dos navios . . . . . . . . . . . 56

Tabela 9 - Detalhamento dos resultados do experimento $1 \ldots \ldots$. . . . . 58

Tabela 10 - Detalhamento dos resultados do experimento $2 \ldots \ldots$. . . . . . 58

Tabela 11 - Detalhamento dos resultados do experimento $3 \ldots \ldots$. . . . . . . 59

Tabela 11 - Detalhamento dos resultados do experimento $3 \ldots$. . . . . . . . 60

Tabela 11 - Detalhamento dos resultados do experimento $3 \ldots$. . . . . . . 61

Tabela 11 - Detalhamento dos resultados do experimento $3 \ldots$. . . . . . . . . 62

Tabela 11 - Detalhamento dos resultados do experimento $3 \ldots$. . . . . . . 63

Tabela 11 - Detalhamento dos resultados do experimento $3 \ldots$. . . . . . . 64

Tabela 12 - Detalhamento dos resultados do experimento $4 \ldots \ldots$. . . . . . . 64

Tabela 12 - Detalhamento dos resultados do experimento 4 . . . . . . . . . . 65

Tabela 12 - Detalhamento dos resultados do experimento $4 \ldots$. . . . . . . 66

Tabela 12 - Detalhamento dos resultados do experimento $4 \ldots \ldots$. . . . . . 67

Tabela 12 - Detalhamento dos resultados do experimento $4 \ldots \ldots$. . . . . . . 68

Tabela 12 - Detalhamento dos resultados do experimento 4 . . . . . . . . . . 69

Tabela 13 - Sumário dos resultados experimentais - Ocupação do Objeto . . . . . . 69

Tabela 14 - Sumário dos resultados experimentais - Tempo Computacional . . . . . 70

Tabela 15 - Experimentos adicionais - Tempo Computacional máximo 30 segundos 72

Tabela 16 - Experimento adicional - Tempo Computacional similar . . . . . . . . 75

Tabela 17 - Resultados das instâncias reais . . . . . . . . . . . . . . . 76

Tabela 18 - Detalhamento dos resultados da instância real 1 . . . . . . . . . . 76

Tabela 19 - Detalhamento dos resultados da instância real 2 . . . . . . . . . . . 78

Tabela 20 - Detalhamento dos resultados da instância real 3 . . . . . . . . . . 79

Tabela 21 - Detalhamento dos resultados da instância real 4 . . . . . . . . . . 81 


\section{Sumário}

INTRODUÇÃO $\ldots \ldots \ldots \ldots \ldots \ldots \ldots \ldots$

$1.1 \quad$ Organização do Trabalho $\ldots \ldots \ldots \ldots \ldots \ldots$

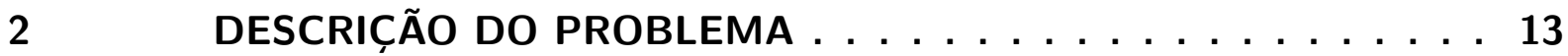

2.1 Caracterização da Operação $\ldots \ldots \ldots \ldots \ldots$

$2.2 \quad$ Características da Carga . . . . . . . . . . . . . . . . . . 14

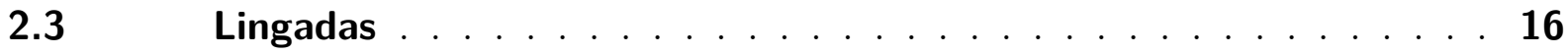

$2.4 \quad$ Exemplos Reais . . . . . . . . . . . . . . . . . . 18

2.5 Objetivos do Problema de Estivagem de Unidades de Celulose . . . 20

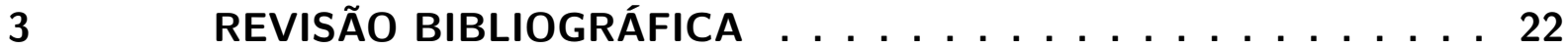

3.1 Problemas de Corte e Empacotamento . . . . . . . . . . 23

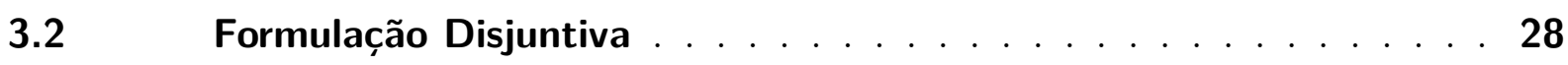

$3.3 \quad$ Heurísticas . . . . . . . . . . . . . . . . . 31

4 MODELOS E MÉTODO DE SOLUÇÃO $\ldots \ldots \ldots \ldots$

4.1 Modelos Matemáticos . . . . . . . . . . . . . . . . 34

4.1.1 Modelo Matemático Base . . . . . . . . . . . . . . . . . 35

4.1.2 Modelo Matemático Modificado . . . . . . . . . . . . . . . 36

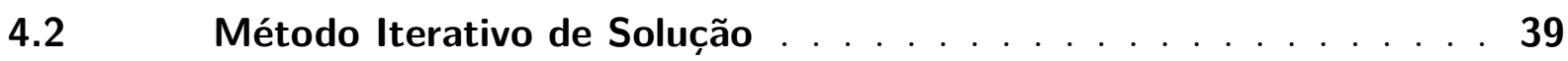

$4.2 .1 \quad$ Conceito do MIS . . . . . . . . . . . . . . . . . . . . . . . . . . 39

4.2 .2 Detalhamento do MIS . . . . . . . . . . . . . . . . . . 40

4.2.2.1 Determinação da quantidade de itens disponíveis . . . . . . . . . . . . . 40

4.2.2.2 Geração da matriz de itens disponíveis para alocação . . . . . . . . . . . . . . 42

4.2.2.3 Resolução do modelo matemático . . . . . . . . . . . . . . . . . . . 42

4.2.2.4 Gravação dos resultados e plano de estivagem resultante . . . . . . . . . . . . 42

4.2.2.5 Avaliação da qualidade da solução gerada . . . . . . . . . . . . . 43

4.2.2.6 Avaliação da continuidade ou encerramento do processo iterativo . . . . . . . . 44

$4.2 .3 \quad$ Fluxograma Conceitual do MIS . . . . . . . . . . . . . . . . . . 44

4.2 .4 Exemplo de Aplicação do MIS . . . . . . . . . . . . . . . . 45

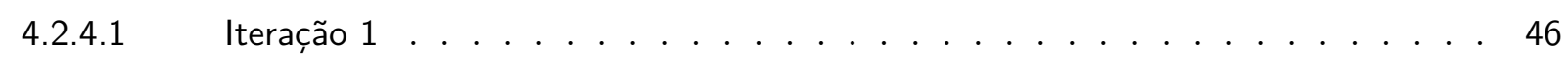

$4.2 .4 .2 \quad$ teração $2 \ldots \ldots \ldots \ldots$

4.2 .4 .3 Iteração $3 \ldots \ldots \ldots \ldots \ldots$

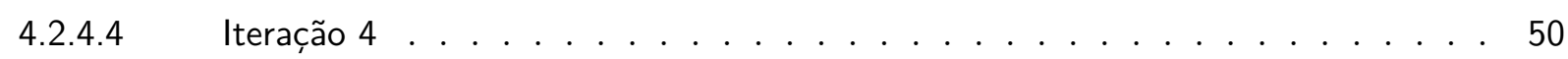

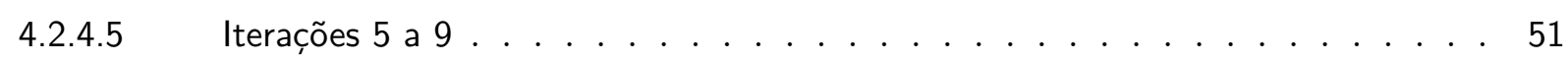


PROCEDIMENTO EXPERIMENTAL . . . . . . . . . . . 52

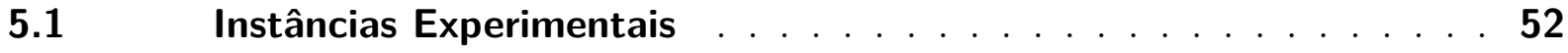

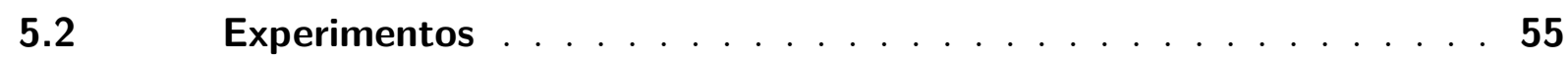

5.3 Experimentos com Dados Reais . . . . . . . . . . 56

$6 \quad$ RESULTADOS . . . . . . . . . . . . . . 57

6.1 Detalhamento dos Resultados . . . . . . . . . . . . . . 57

6.1.1 Experimento 1 - Modelo Matemático Base, sem MIS . . . . . . . . . 57

6.1.2 Experimento 2 - Modelo Matemático Modificado, sem MIS . . . . . . . 58

6.1.3 Experimento 3 - Modelo Matemático Base, com MIS . . . . . . . . . . . 59

6.1.4 Experimento 4 - Modelo Matemático Modificado, com MIS . . . . . . . . 64

6.2 Sumário dos Resultados . . . . . . . . . . . . . . . . . 69

6.3 Discussão dos Resultados . . . . . . . . . . . . . . . 70

6.3.1 Análise dos resultados dos modelos matemáticos . . . . . . . . . 70

6.3.1.1 Experimentos adicionais . . . . . . . . . . . . . . . 71

6.3.2 Análise dos resultados dos MIS . . . . . . . . . . . . . . 73

6.3.2.1 Experimentos adicionais . . . . . . . . . . . . . . . . . 74

$6.4 \quad$ Resultados de Instâncias Reais . . . . . . . . . . . . . . 75

6.4 .1 Instância real $1 \ldots \ldots \ldots \ldots \ldots$

6.4 .2 Instância real $2 \ldots \ldots \ldots \ldots 77$

$6.4 .3 \quad$ Instância real $3 \ldots \ldots$. . . . . . . . . . . . . . . . . 79

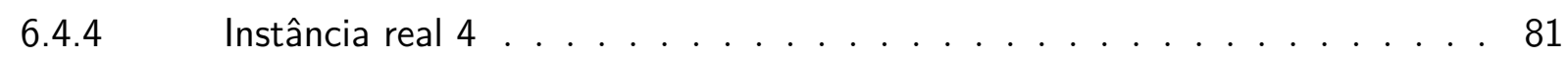

$7 \quad$ CONCLUSÕES $\ldots \ldots \ldots \ldots$

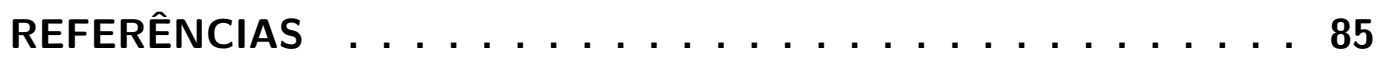

$\begin{array}{ll}\text { APÊNDICES } & 88\end{array}$

APÊNDICE A - IMPLEMENTAÇÃO DO GERADOR DE INSTÂN-

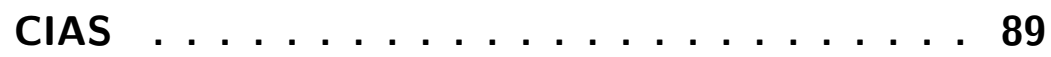

APÊNDICE B - IMPLEMENTAÇÃO DO MODELO MATEMÁTICO

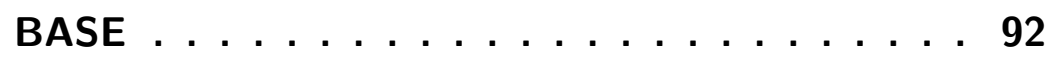

APÊNDICE C - IMPLEMENTAÇÃO DO MATEMÁTICO MODI-

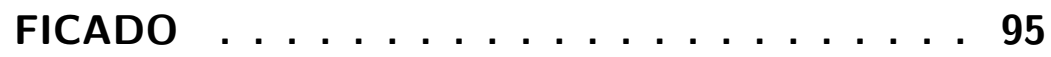

APÊNDICE D - IMPLEMENTAÇÃO DO MÉTODO ITERATIVO DE SOLUÇÃO . . . . . . . . . . . 99 


\section{Introdução}

O Problema de Estivagem de Unidades de Celulose - PEUC (RIBEIRO; LORENA, 2008) pode ser definido como um problema que busca alocar a máxima quantidade de unidades de celulose ao porão de cargas de um dado navio, respeitando as restrições físicas de dimensões, de posicionamento, de não-sobreposição das unidades e de capacidade máxima do porão do navio.

Esse tipo de problema, que a rigor é um problema tridimensional, pode ser reduzido a um equivalente bidimensional (MORALES; MORABITO; WIDMER, 1997; RIBEIRO; LORENA, 2008). Essa redução é possível devido às restrições físicas e operacionais de estivagem das unidades de celulose, que determinam que as camadas de unidades de celulose estivadas em um mesmo porão podem possuir configurações idênticas. Essa determinação busca atender, principalmente, aos requisitos de estabilidade das pilhas formadas pela sobreposição sucessiva das unidades (um porão de cargas típico pode comportar entre 8 e 10 camadas de unidades de celulose).

Carlsson et al. (2009) apresentam em seu trabalho uma matriz com problemas típicos da cadeia de Papel e Celulose. De acordo com os autores, tais problemas podem ser classificados em três níveis (estratégico, tático e operacional) e relacionados a quatro diferentes dimensões da cadeia do setor de Papel e Celulose (suprimentos, produção, distribuição e vendas). De acordo com a matriz proposta por Carlsson et al. (2009) o PEUC pode ser considerado um problema de nível operacional de distribuição.

Dentre os diferentes tipos de celulose produzidos no Brasil, a celulose branqueada de fibra curta (Bleached Hardwood Kraft Pulp - BHKP) é aquela com maior apelo para exportação, devido principalmente à alta produtividade das florestas brasileiras e ao menor custo de produção comparado a outros países produtores (VIDAL; HORA, 2012; HORA; MELO, 2016). A produtividade média das florestas plantadas de Eucalipto no Brasil (principal insumo na produção de celulose no país), por exemplo, passa dos $35 \mathrm{~m}^{3} / \mathrm{ha} \cdot a n o$, sendo maior do que qualquer outro país no mundo (IBÁ, 2017). Em alguns casos essa produtividade pode chegar a $44 \mathrm{~m}^{3} / \mathrm{ha} \cdot a n o$, dependendo das condições locais, espécie plantada e manejo florestal empenhado (SPEROTTO, 2014).

A indústria de celulose é um importante ator na pauta comercial brasileira. Em 2016, 12,9 milhões de toneladas de celulose, cerca de $70 \%$ do total produzido, foram destinadas ao mercado externo, totalizando US\$ 5,6 bilhões em exportações (IBÁ, 2017). De acordo com dados do setor, estima-se que o consumo mundial de celulose de fibra curta seja de aproximadamente 32 milhões de toneladas por ano, sendo que desse total, cerca de 23 milhões de toneladas são especificamente produzidas à partir de fibras de Eucalipto 
(Fibria S.A., 2017).

De acordo com IBÁ (2017), o setor de árvores plantadas como um todo, que inclui a indústria de celulose no Brasil, foi responsável por 0,9\% de toda arrecadação tributária brasileira em 2016 (considerando as esferas federal, estadual e municipal), gerando $\mathrm{R} \$$ 11,4 bilhões em receitas para o estado. Além disso, o setor foi responsável por 1,1\% do Produto Interno Bruto (PIB) do país nesse mesmo ano.

A celulose de fibra curta exportada pelo Brasil tem como principais destinos os países Europeus e Asiáticos (IBÁ, 2017), que a utilizam principalmente como matéria prima na fabricação de papéis sanitários (tissue, papel-cartão e papéis especiais (VIDAL; HORA, 2012).

Levando-se em consideração a importância do setor para e economia brasileira e o peso das exportações no resultado das produtoras brasileiras da commodity, as operações de transporte oceânico, modo pelo qual a celulose é exportada para consumo na Europa, Ásia e América do Norte, ganham importância, já que representam parte significativa dos custos das empresas (VIDAL; HORA, 2012).

Neste contexto, o presente trabalho apresenta uma formulação exata para a resolução do PEUC, com a aplicação de conceitos de formulação disjuntiva. Além disso, o trabalho propõe também uma formulação que leva em conta a ocorrência de itens idênticos e busca reduzir o total de variáveis binárias na resolução do problema. Por fim, é proposto um Método Iterativo de Solução (MIS) que busca a redução do tempo computacional necessário para obtenção de soluções de qualidade.

\subsection{Organização do Trabalho}

Este trabalho é composto por sete capítulos, estruturados conforme detalhamento a seguir:

No capítulo 2 é apresentada uma descrição detalhada do problema, incluindo os conceitos que baseiam o carregamento de navios e suas implicações.

No capítulo 3 é apresentada uma revisão dos problemas de Corte e Empacotamento (C\&E), com especial interesse nas formulações exatas para problemas que abordam o empacotamento retangular. No mesmo capítulo é apresentada uma revisão dos conceitos e aplicações das formulações disjuntivas aos problemas de C\&E e ainda uma revisão sobre heurísticas aplicáveis à essa classe de problemas.

O capítulo 4 detalha o modelo matemático desenvolvido e o Método de Solução Iterativo proposto, bem como a formulação com base em itens idênticos.

Os capítulos 5 e 6 apresentam, respectivamente, os procedimentos experimentais e os resultados computacionais obtidos para os experimentos realizados. 
Por fim, as conclusões e considerações finais sobre o tema são apresentadas no capítulo 7 . 


\section{Descrição do Problema}

Dado um navio e, no interior desse navio, um porão de cargas de área retangular, com comprimento e largura definidos, com uma quantidade suficientemente grande de unidades de celulose (também com comprimentos e larguras definidos) disponíveis para carregamento deste porão, o Problema de Estivagem de Unidades de Celulose - PEUC - consiste na determinação do melhor padrão de estivagem das unidades de celulose a serem carregadas nesse porão, buscando maximizar a área ocupada pela carga.

A seguir são apresentadas as características da operação de carregamento e estivagem das unidades de celulose no porão de cargas de um navio, bem como detalhes e particularidades do problema.

\subsection{Caracterização da Operação}

A exportação de celulose é realizada através de navios oceânicos de longo-curso. Diferentes classes, tipos e tamanhos de navios são utilizados na realização desse transporte, de acordo com a quantidade de celulose a ser transportada, a infraestrutura dos portos de origem e destino, rota de navegação, mercado de destino, custos envolvidos, sinergia com outras cargas e operações, entre outros aspectos. Um navio típico utilizado no transporte de celulose, por exemplo, apresenta comprimento total (LOA - Length Overall)na faixa de 180 a 200 metros e porte bruto (DWT - Deadweight Tonnage variando entre 40.000 e 70.000 toneladas, com capacidade líquida para transporte de 30.000 e 50.000 toneladas de celulose.

Recentemente, buscando a otimização de suas operações e o aumento de competitividade, algumas empresas assinaram acordos para a construção e operação de navios especializados no transporte dos fardos celulose. As brasileiras Fibria (FIBRIA, 2017) e Suzano Papel e Celulose (SEATRADE, 2017), duas das maiores empresas do setor, são exemplos dessa tendência.

Os navios que usualmente realizam o transporte de celulose possuem diversos porões de carga, onde as unidades de celulose são efetivamente armazenadas durante as viagens. A Figura 1, a seguir, apresenta de forma esquemática de um navio típico, com oito porões de carga.

De acordo com a classe ou tipo do navio, os porões de carga possuem diferentes configurações e dimensões. Essas diferenças, que podem existir até mesmo entre porões de um mesmo navio, interferem diretamente na quantidade de celulose que pode ser carregada em cada um deles. Além disso, e de especial interesse para o presente trabalho, o arranjo 


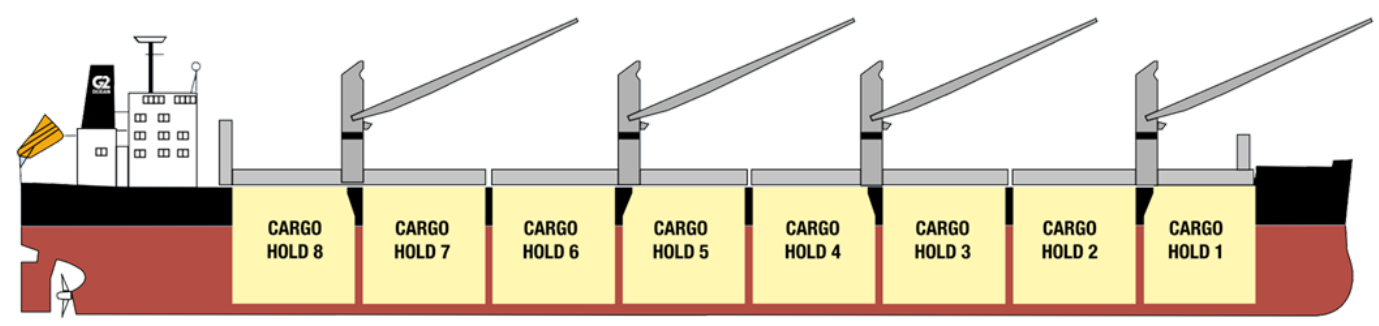

Figura 1 - Representação esquemática de um navio de celulose (Fonte: G2 Ocean)

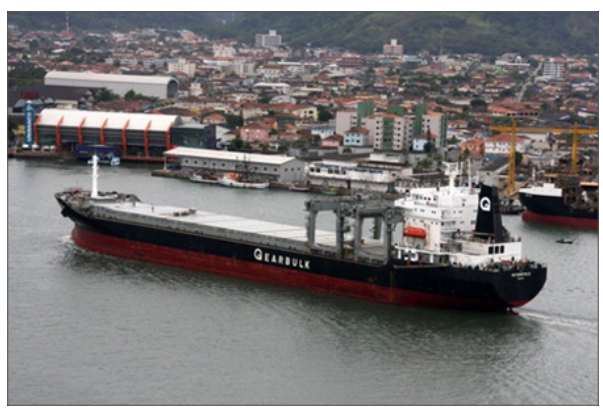

Figura 2 - Navio Gantry Crane

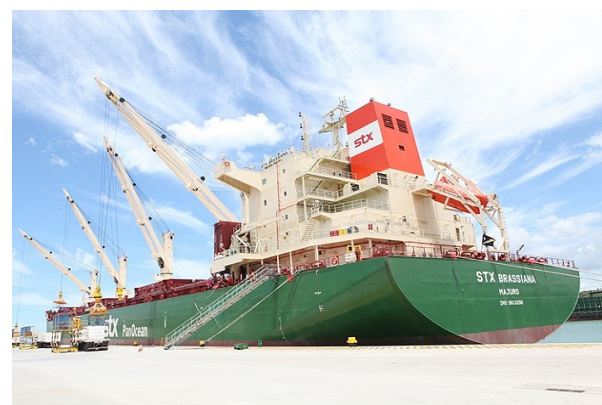

Figura 3 - Navio Jib Crane

das unidades de celulose dentro de cada porão deve ser customizado caso a caso, de forma a maximizar a quantidade total de celulose transportada.

O carregamento das unidades de celulose no porão dos navios é realizado, usualmente, por equipamentos de bordo do próprio navio. Os navios que transportam celulose são do tipo carga geral e podem contar com equipamentos do tipo Gantry Crane (Figura 2) ou Jib Crane (Figura 3). Os navios do tipo Gantry Crane tem operação similar a pontes-rolantes, enquanto os navios Gantry Crane podem ser comparados a guindastes convencionais.

\subsection{Características da Carga}

Uma unidade de celulose é o lote mínimo de movimentação e transporte, desde a saída das linhas de secagem e unitização até o carregamento dos navios. A unidade de celulose é composta por 8 fardos, cada um com $250 \mathrm{~kg}$, agrupados através de arames de aço. Um fardo de celulose, por sua vez, é formado pelas folhas de celulose que saem das linhas de secagem da fábrica.

Com pequenas variações, uma unidade de celulose apresenta peso total de 2.000 $\mathrm{Kg}$, possui aproximadamente $90 \mathrm{~cm}$ de largura, $150 \mathrm{~cm}$ de comprimento e $180 \mathrm{~cm}$ de altura. Essas configurações são definidas durante a fase de especificação e compra dos equipamentos para a implantação da fábrica, de acordo com o fornecedor selecionado e eventuais particularidades do processo produtivo. É importante destacar que essas medi- 
das não podem ser facilmente alteradas após a implantação dos equipamentos na fábrica. A Figura 4 mostra um exemplo de unidade (unit) e fardo (bale) de celulose, nesse caso fabricados pela empresa finlandesa UPM .

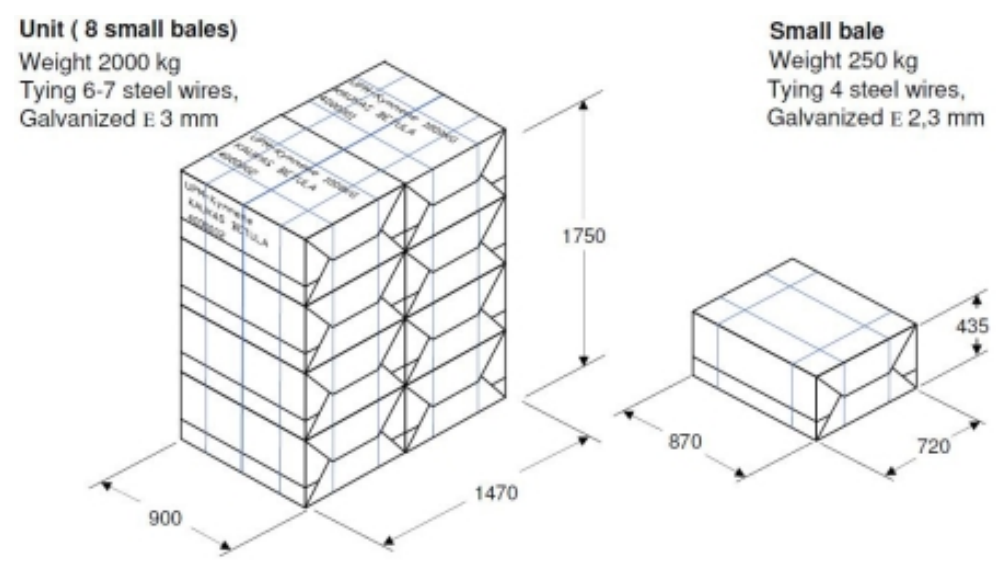

Figura 4 - Exemplo de unidade (unit) de celulose (esquerda) e fardo (bale) (Fonte: UPM)

O conceito de unidade de celulose é mundialmente adotado pelas fabricantes, sejam elas brasileiras, chilenas, finlandesas, norte-americanas ou asiáticas, e impactou diretamente na disseminação e consolidação da celulose como uma commodity.

Ao longo da cadeia logística da celulose, desde a saída das linhas de secagem até o carregamento dos navios, as unidades podem ser movimentadas individualmente ou de maneira agrupada. Na saída das linhas, por exemplo, a unidades são geralmente movimentadas por empilhadeiras duas a duas, ou seja, em lotes de 4 toneladas.

No carregamento dos navios a movimentação precisa ser ainda mais eficiente, já que os custos envolvidos na operação dos navios são superiores a qualquer outro da cadeia logística. Desta forma, as unidades são movimentadas em lotes maiores (usualmente variando entre 16 e 40 toneladas).

A esse agrupamento de unidades utilizado no carregamento dos navios dá-se o nome de lingada. Uma lingada, como já mencionado, é composta por diversas unidades de celulose (geralmente números pares, para evitar desequilíbrios durante o içamento e posicionamento da celulose no porão do navio). Os equipamentos de bordo dos navios, Gantry ou JIB Cranes, são preparados para içar as lingadas através dos arames de amarração que são utilizados nas unidades de celulose para agrupamento dos fardos. Os arames de amarração são colocados em cada unidade de celulose ainda nas linhas de produção e enfardamento. A Figura 5 mostra um exemplo de carregamento de uma lingada celulose no porão de um navio.

Uma das particularidades do Problema de Estivagem de Unidades de Celulose, como tratado no presente estudo, é a utilização de diferentes configurações de lingadas. Como cada lingada é formada pelo agrupamento (temporário) das unidades de 2 toneladas, 


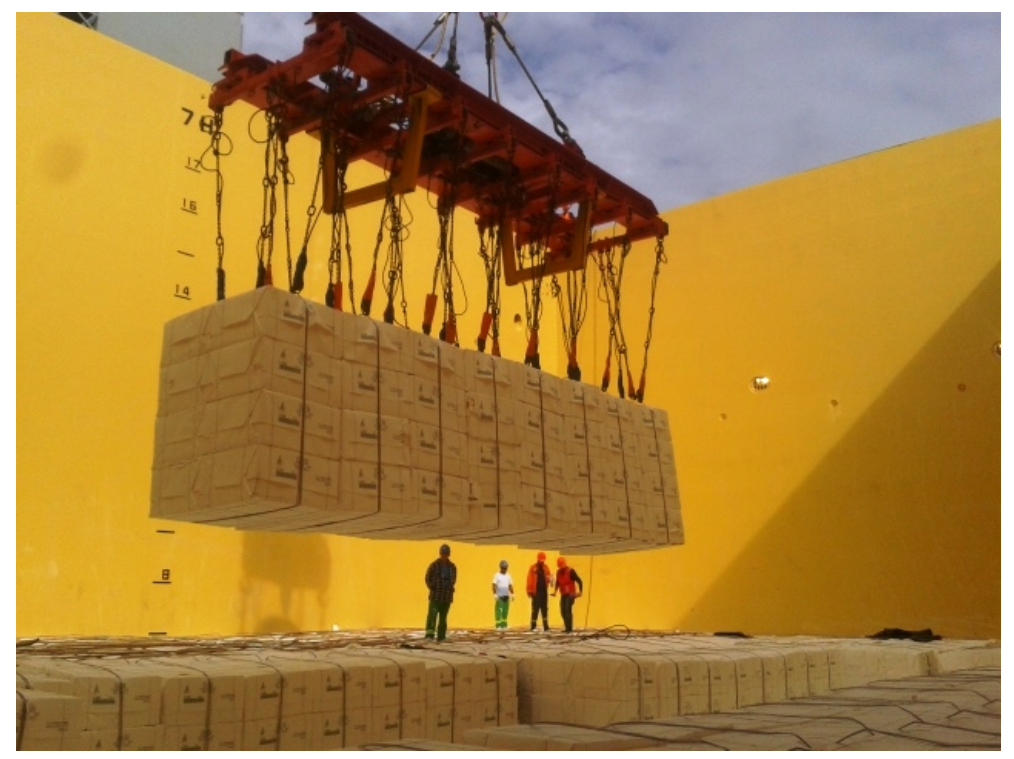

Figura 5 - Lingada de celulose sendo posicionada no porão do navio

diversas configuração são possíveis. A Figura 6 mostra a formação de uma lingada de 32 t à partir das unidades de 2 toneladas. Já a Figura 7 apresenta esquematicamente diversas famílias de lingada que podem ser formadas para o carregamento do navio.

\subsection{Lingadas}

Planos de estivagem reais para carregamento de unidades de celulose são desenhados por especialistas levando em conta, entre outros fatores, as diferentes lingadas que podem ser formadas.

A utilização de diferentes padrões de lingada no carregamento de um navio é influenciada por uma série de diferentes fatores, como por exemplo as dimensões do porão de carga, quantidade total de celulose a ser carregada no navio, cargas previamente carregadas (que podem afetar o trim da embarcação), a ordem de descarregamento das unidades de celulose nos portos de destino e as próprias dimensões da unidade de celulose.

A formulação do PEUC utilizando o conceito de lingadas marca uma das principais diferenças entre o presente trabalho e o desenvolvido por Ribeiro e Lorena (2008), que considera as unidades de celulose individualmente.

Outro fator importante a ser considerado nos planos de estivagem é a quantidade de movimentos necessários para realização do carregamento de um navio. A rigor, toda a operação de carregamento de um navio de celulose é dimensionada para que os equipamentos de bordo que realizam os movimentos de transferência das unidades de celulose para dentro do porão de cargas do navio sejam os recursos limitantes da operação. Isso significa que o carregamento do navio será tão produtivo quanto os seus equipamentos de 
carregamento ( $j i b$ cranes ou gantry cranes), garantindo desta forma a maximização no uso do recurso mais caro de toda a cadeia logística de exportação de celulose.

Desta forma, uma das maneiras mais efetivas para se incrementar a produtividade de carregamento dos navios é aumentar a quantidade de celulose movimentada a cada ciclo do equipamento de bordo. Esse fator torna-se ainda mais relevante devido ao fato de que o ciclo total de movimentação do equipamento sofre pouca influência do tamanho e peso da lingada movimentada. Isso significa que o tempo necessário para movimentar uma lingada de 16 toneladas é, na prática, muito próximo ao tempo necessário para a movimentação de uma lingada com 32 toneladas de celulose.

Por isso, o embarcador sempre busca utilizar as maiores lingadas possíveis, dentro das restrições previamente descritas. Com isso, procura minimizar a quantidade total de movimentos necessários para completar o carregamento do navio e, por consequência, reduzir o tempo necessário para o término da operação. Essa economia de tempo leva, por consequência, a uma economia significativa nos custos envolvidos na operação de carregamento e no próprio valor do frete marítimo de transporte. Estima-se que, em um contrato típico de transporte de celulose, cada hora de carregamento de um navio represente, financeiramente, entre de US\$1.000 e US\$2.000.

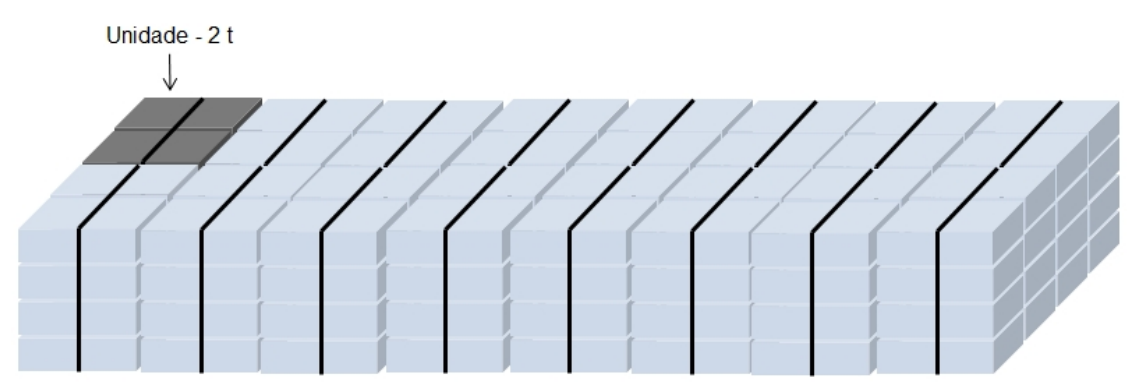

Figura 6 - Formação de uma lingada de 32 t 


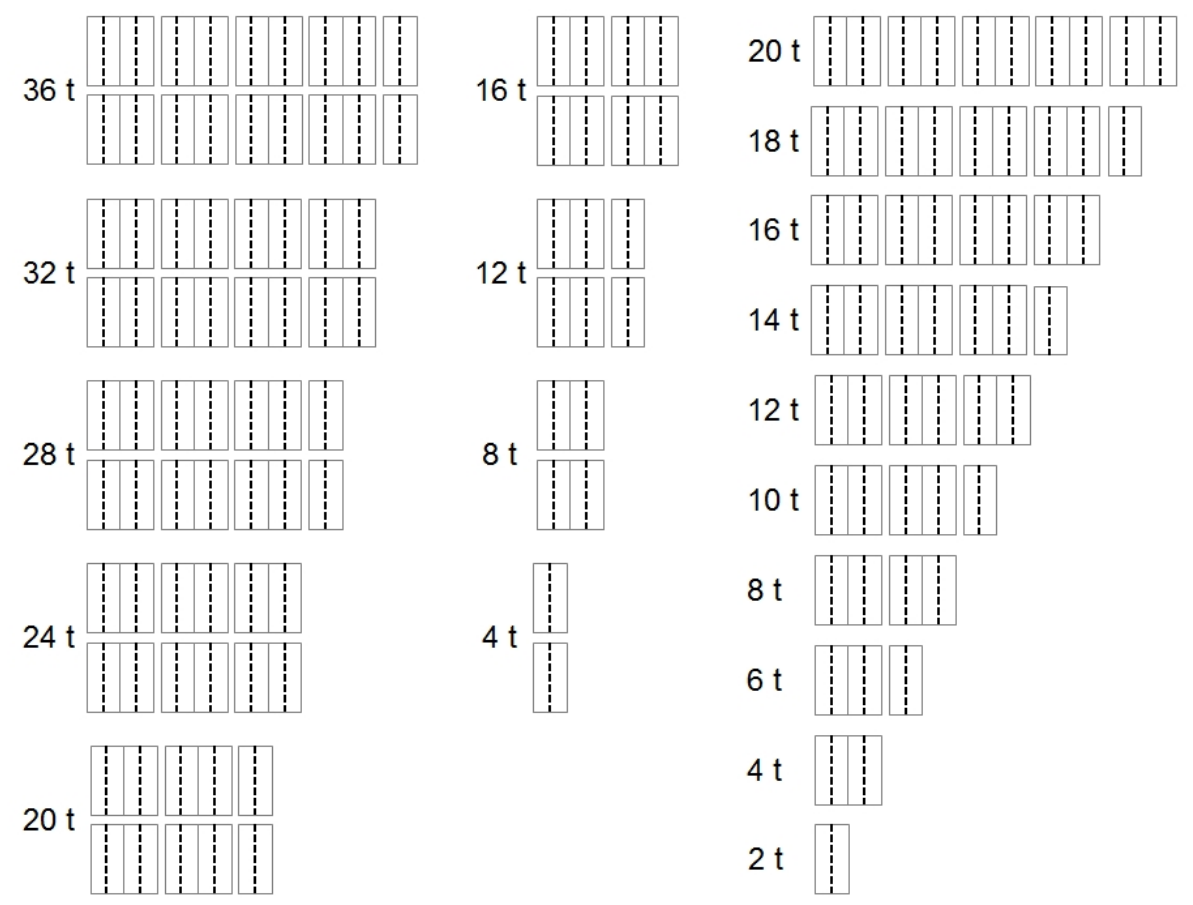

Figura 7 - Exemplos de padrões de lingadas que podem ser formados

É importante ressaltar que as lingadas apresentadas na Figura 7 podem ainda ser rotacionadas ortogonalmente.

\subsection{Exemplos Reais}

Um plano real de estivagem de unidades de celulose em um determinado porão é apresentado na Figura 8. O plano apresenta a disposição das unidades e/ou lingadas de celulose no interior do porão do navio, para cada uma das camadas a ser carregada.

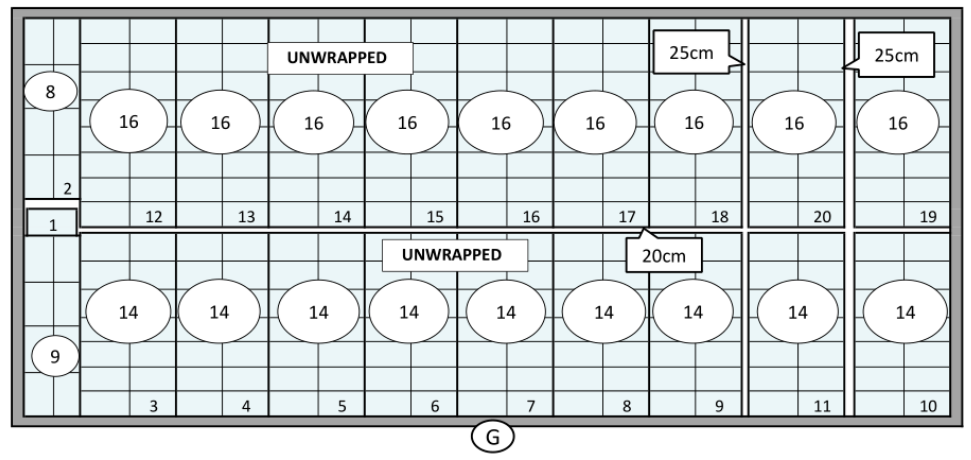

Figura 8 - Exemplo real de plano estivagem para porão de $250 \mathrm{~m}^{2}$

No exemplo apresentado é possível visualizar o plano de estivagem para um porão com 12,80 metros de largura e 19,44 metros de comprimento, ou seja, um porão com 
área total de aproximadamente $250 \mathrm{~m}^{2}$. O plano indica o carregamento de 20 lingadas de celulose, com 4 configurações distintas (lingadas com 8, 9, 14 ou 16 unidades de celulose).

Como já mencionado anteriormente, os planos de estivagem são diretamente afetados pelas dimensões e configurações do porão a ser carregado. A Figura 9, por exemplo, apresenta um plano para um porão com dimensões de 27,37 metros de largura e 16,50 metros de largura (área total de mais de $450 \mathrm{~m}^{2}$ ). Nesse caso é possível verificar o carregamento de 8 diferentes configurações de lingadas (lingadas com 3, 4, 5, 6, 8, 9 e 12 unidades de celulose).

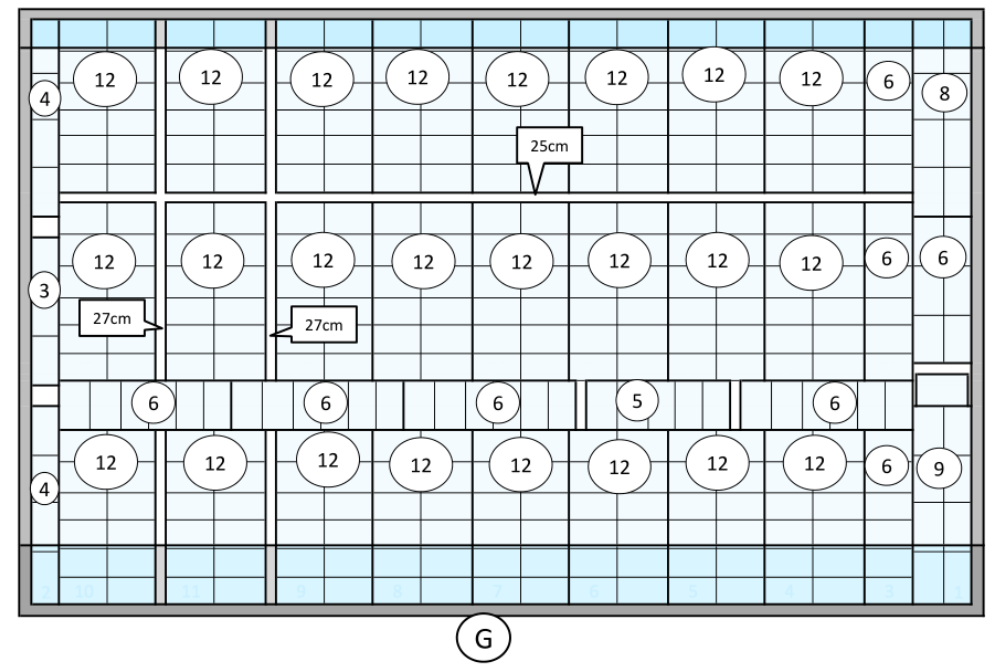

Figura 9 - Exemplo real de plano estivagem para porão de $450 \mathrm{~m}^{2}$

A consolidação dos planos de estivagem para cada camada de cada porão do navio resulta no plano de carga do navio para operação de um determinado terminal portuário. A Figura 10 apresenta um exemplo real do plano de carga do navio Star Louisiana.

No exemplo é possível identificar os porões a serem carregados, destacados em amarelo, verde e azul, de acordo com o tipo de celulose. Também é possível verificar a quantidade de unidades de celulose a ser carregada em cada uma das camadas em cada porão. Esta última informação resulta diretamente dos planos de estivagem, exemplificados nas Figuras 8 e 9. 


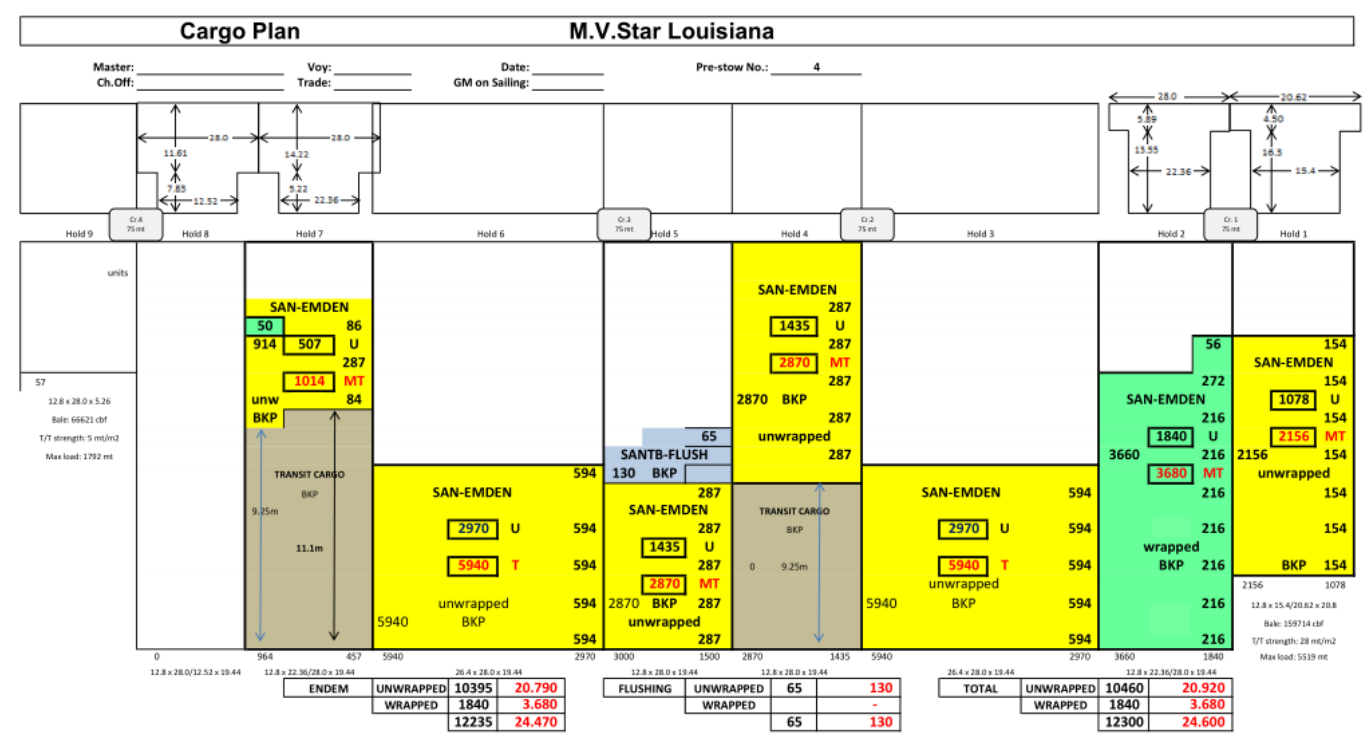

Figura 10 - Consolidação do plano de carga do navio Star Louisiana

A consolidação dos planos de estivagem em um plano de carga do navio é crítica para garantir que a operação de carregamento seja realizada respeitando limitações e características das embarcações. Esse ponto é especialmente sensível quando se leva em consideração o trim da embarcação, ou seja, a inclinação longitudinal do navio. Restrições estruturais do navio podem impedir, por exemplo, que determinado porão seja carregado antes de outro.

A elaboração dos planos de carga do navio não é objeto de estudo do presente trabalho, estando esse limitado apenas aos planos de estivagem.

\subsection{Objetivos do Problema de Estivagem de Unidades de Celulose}

O carregamento dos navios de celulose, assim como qualquer operação que envolva transporte marítimo, é uma operação com diversas partes envolvidas, desde o embarcador da carga (produtor de celulose) até o armador (proprietário da embarcação que realizará o transporte), passando por agenciadores de carga, operadores logísticos, autoridades portuárias, órgãos de fiscalização e controle, trabalhadores portuários e seus respectivos sindicatos. A conciliação dos diferentes interesses de cada parte envolvida é um importante desafio nesse tipo de operação.

Nesse sentido, por exemplo, o embarcador (produtor de celulose), tem interesse em reduzir o valor do frete marítimo sempre que possível. Para tanto, busca reduzir o tempo que o navio leva para ser carregado através da redução no número de movimentos realizados pelos equipamentos de bordo. O armador, por outro lado, busca maximizar a ocupação dos porões de cargas de seus navios, já que seu faturamento está diretamente relacionado ao total de carga transportada em cada viagem do navio. 
Nesse simples exemplo já é possível notar um claro conflito entre os interesses que guiam embarcador e armador. O primeiro busca reduzir a quantidade de movimentos necessários para o carregamento dos navios, através do aumento no tamanho e volume das lingadas. O segundo busca aumentar a ocupação dos porões dos navios, muitas vezes aumentando o número de movimentos necessários para completar o carregamento, já que são necessárias lingadas menores para que tal objetivo seja efetivado.

Sendo assim, a busca pela máxima ocupação do porão do navio utilizando o menor número possível de movimentos demanda a formulação de um plano de estivagem otimizado, que maximize a área ocupada do porão do navio, porém com o menor número possível de movimentos, ou seja, com as maiores lingadas possíveis.

No presente trabalho, como descrito no Capítulo 4, foi priorizado o critério de maximização da área ocupada pelo itens alocados ao objeto. A incorporação de outros critérios e abordagens é discutida brevemente no Capítulo 7, como possíveis extensões do presente estudo.

Até onde se sabe apenas Ribeiro e Lorena (2008) desenvolveram estudos na área de planos de estivagem para unidades de celulose ou mesmo para outros tipos de carga geral solta (break bulk). Por outro lado, trabalhos referentes a planos de estivagem para contêineres ou Roll-on/Roll-off (veículos) podem ser encontrados na literatura disponível com mais facilidade (MONACO; SAMMARRA; SORRENTINO, 2014; ØVSTEBØ; HVATTUM; FAGERHOLT, 2011; SCIOMACHEN; TANFANI, 2007; AMBROSINO; SIRI, 2015). 


\section{Revisão Bibliográfica}

O PEUC, no contexto do campo da pesquisa operacional, se encaixa na classe de problemas de Corte e Empacotamento - C\&E (no inglês Cutting and Packing - C\&PP). As primeiras pesquisas relacionadas aos problemas de C\&E foram publicadas de forma esporádica à partir da década de 1940 (SWEENEY; PATERNOSTER, 1992) e com frequência mais regular após a década de 1960 (DYCKHOFF, 1990).

Um importante impulso as pesquisas relacionadas a C\&E foi dado pelo trabalho publicado por Dyckhoff (1990), que de maneira pioneira apresentou uma tipologia para classificação dos problemas de C\&E. Pela primeira vez foi possível agrupar os diferentes tipos e classes de problemas e suas diversas ramificações, permitindo aos pesquisadores a identificação de problemas similares que anteriormente não eram tratados como tal. Com isso, houve um período de intensa integração e cruzamento de conceitos que, antes, eram tratados e abordados de maneira segregada (WÄSCHER; HAUSSNER; SCHUMANN, 2007).

Apesar de todo pioneirismo no trabalho de Dyckhoff, outros autores, como Wäscher, Haußner e Schumann (2007) argumentam que a tipologia original apresentava algumas lacunas e falhas. Desta forma, propuseram uma tipologia aprimorada, aproveitando os pontos fortes do trabalho original e melhorando-o onde necessário.

De acordo com a nova tipologia proposta por Wäscher, Haußner e Schumann (2007) é possível classificar o PEUC como sendo um problema do tipo Single Large Object Placement Problem (SLOPP). Nesse tipo de problema há apenas um objeto (no caso, o porão do navio), que deve acomodar o maior número possível de itens (unidades de celulose), que por sua vez podem ser de dimensões levemente heterogêneas entre si.

O SLOPP foi abordado pela primeira vez, embora sobre outra denominação, no trabalho de Haims e Freeman (1970). Esse tipo de problema pode ser aplicado em diversas situações comuns na indústria e logística, como, por exemplo, no carregamento de paletes em veículos, estufagem de contêineres e carregamento de caixas em paletes (WÄSCHER; HAUSSNER; SCHUMANN, 2007).

Apesar dos trabalhos de tipologia já consagrados por muitos dos pesquisadores da área, é comum encontrar na literatura problemas classificados de forma diferente daquela recomendada pela tipologia mais atual. É possível, por exemplo, encontrar aplicações do SLOPP sob outras denominações, como por exemplo: Two-Dimensional Cutting Problem, Rectangle Packing Problem (WÄSCHER; HAUSSNER; SCHUMANN, 2007) ou até mesmo como um caso particular de Bin Packing (RIBEIRO; LORENA, 2008). De fato, é possível considerar o SLOPP como uma variação do Bin Packing tradicional, com apenas 
um bin (objeto) disponível para alocação dos diversos itens. Nesse sentido, Dowsland e Dowsland (1992), argumentam que muitas vezes é difícil definir claramente as fronteiras e diferenças entre alguns tipos de problema na área de C\&E.

A seguir são apresentadas as considerações sobre a literatura existente na área de C\&E, com foco nos problemas de empacotamento retangular. São apresentadas também as formulações mais usuais para esse tipo de problema. Na sequência são apresentados os conceitos de formulação disjuntiva, ilustrado com uma formulação exata que utiliza restrições disjuntivas para a resolução de um caso particular de Bin Packing. Por fim, são discutidas heurísticas e meta-heurísticas comumente aplicadas aos problemas de C\&E, especialmente em trabalhos mais recentes da área.

\subsection{Problemas de Corte e Empacotamento}

Devido a alta aplicabilidade em situações reais e nos mais diversos setores da economia e segmentos industriais, os problemas de C\&E são bastante populares e extensamente estudados por pesquisadores de diversas áreas, como pesquisa operacional, computação, matemática aplicada e engenharia industrial (BISCHOFF; WÄSCHER, 1995). Um ponto importante para os pesquisadores é o fato dos problemas de $\mathrm{C} \& \mathrm{E}$, especialmente aqueles que envolvem itens e objetos retangulares, serem classificados como NP-Completos (DOWSLAND; DOWSLAND, 1992; BISCHOFF; WÄSCHER, 1995; MALAGUTI; DURáN; TOTH, 2013), o que dificulta ou até mesmo inviabiliza a obtenção de soluções exatas em tempo computacional razoável para problemas com instâncias consideradas medianas ou grandes.

Os problemas de empacotamento retangular em duas dimensões foram abordados de maneira mais efetiva pela primeira vez por Gilmore e Gomory em 1965 (DOWSLAND; DOWSLAND, 1992), que desenvolveram um método capaz de solucionar rapidamente problemas considerados de razoável complexidade. Problemas de empacotamento retangular, de acordo com Lodi, Martello e Monaci (2002), consideram um conjunto de $n$ itens $i \in I=\{1, \cdots, n\}$, com suas respectivas dimensões $w_{i}$ (largura) e $l_{i}$ (comprimento). Há duas formas tradicionais e distintas de abordagem:

a) Bin Packing: Existe um número ilimitado disponível de objetos retangulares (bins), com dimensões $W$ (largura) e $L$ (comprimento). O objetivo é alocar todos os $n$ itens disponíveis utilizando o menor número possível de objetos (bins).

b) Strip Packing: Nesse caso, há apenas um objeto (bin) disponível, porém com comprimento $L$ ilimitado e largura $W$ fixa. O objetivo é determinar o menor comprimento $L$ necessário para que o bin seja capaz de acomodar todos os $n$ itens disponíveis. 
Nos dois casos é necessário que os itens sejam alocados ortogonalmente, ou seja, as faces correspondentes dos itens e dos objetos devem estar paralelas ( $w_{i}$ paralelo a $W$ ).

Ainda segundo Lodi, Martello e Monaci (2002), uma terceira variação do problema de empacotamento retangular é aquela onde cada item possui um lucro (ou peso) $p_{i}$ associado e o objetivo do problema é maximizar o lucro total dos itens alocados a um único objeto (bin). Esse tipo de problema, como já destacado anteriormente, é uma variação do Bin Packing tradicional e muito se aproxima do conceito do SLOPP definido por Wäscher, Haußner e Schumann (2007), com aplicação direta ao PEUC descrito por Ribeiro e Lorena (2008).

Uma das formulações exatas para resolução do SLOPP é apresentada por Hadjiconstantinou e Christofides (1995). Classificada pelos próprios autores como uma formulação com solução exata para o Knapsack Problem, ela se encaixa nos conceitos do SLOPP apresentados por Wäscher, Haußner e Schumann (2007).

Os autores, conforme formulação apresentada a seguir, abordam um problema bi-dimensional de corte (two-dimensional cutting-stock problem. Nesse problema, peças retangulares menores, cada qual com suas dimensões e valores definidos, devem ser cortadas de um retângulo maior. O objetivo do problema é a maximização do valor das peças cortadas ou a minimização das perdas de material do retângulo maior.

O detalhamento da formulação do problema é apresentado a seguir.

Seja $A_{0}=\left(\alpha_{0}, \beta_{0}\right)$ uma folha retangular de comprimento $\alpha_{0}$ e largura $\beta_{0}$ e $R$ um conjunto de $n$ peças retangulares $R_{1}, R_{2}, \cdots, R_{n}$ com dimensões $\left(\alpha_{1}, \beta_{1}\right),\left(\alpha_{2}, \beta_{2}\right), \cdots$, $\left(\alpha_{n}, \beta_{n}\right)$. Cada uma das peças possui também um valor $v_{1}, v_{2}, \cdots, v_{n}$.

O objetivo do problema é definir um padrão de corte para $A_{0}$ de forma a maximizar o valor total das peças incluídas no mesmo. Existem ainda duas restrições $\left(Q_{i}\right.$ e $\left.P_{i}\right)$ que determinam, respectivamente, as quantidades máximas e mínimas a serem utilizadas de cada peça $R_{i}$ no padrão de corte ótimo.

A definição matemática do problema, formulado como um problema de programação inteira, é apresentada a seguir, onde:

$L_{i}=\left\{x \mid 0 \leq x \leq \alpha_{0}-\alpha_{i}, x\right.$ inteiro $\}$ - é o conjunto de todos os possíveis pontos $x$ ao longo do comprimento de $A_{0}$, tal que qualquer peça $R_{i}$ do conjunto $R$ possa ser cortada de $A_{0}$ com sua largura paralela ao eixo y e seu canto inferior esquerdo em qualquer posição $x \in L_{i}$.

$W_{i}=\left\{y \mid 0 \leq y \leq \beta_{0}-\beta_{i}, y\right.$ inteiro $\}$ - similar ao conceito de $L_{i}$ apresentado acima.

Os conjuntos $L_{i}$ e $W_{i}$ são definidos por $i=1, \cdots, m$.

$x_{i j p}=\{1$ se a $j$-ésima réplica da peça $i$ é cortada com seu canto inferior esquerdo na posição $x p$, onde $j=1, \cdots, Q_{i}$ e $p \in L_{i} ; 0$ caso contrário $\}$. 
$y_{i j q}=\{1$ se a $j$-ésima réplica da peça $i$ é cortada com seu canto inferior esquerdo na posição $y q$, onde $j=1, \cdots, Q_{i}$ e $p \in W_{i} ; 0$ caso contrário $\}$.

$z_{r s}=1$ se o ponto $(r, s)$ em $A_{0}$, onde $r=0, \cdots, \alpha 0-1$ e $s=0, \cdots, \beta_{0}-1$ não foi utilizado por nenhuma peça do conjunto $R$.

$$
\begin{gathered}
M a x Z=\sum_{i=1}^{m} v_{i} \sum_{j=1}^{Q} \sum_{p \in L} x_{i j p} \\
\sum_{s=q} \sum_{r=p}^{q+\beta_{1}-1} z_{r s} \leq\left(2-x_{i j p}-y_{i j p}\right) \alpha_{i} \beta_{i} \\
i=1, \cdots, m, j=1, \cdots, Q_{i}, p \in L_{i}, q \in W_{i} \\
\sum_{p \in L_{i}} x_{i j p} \leq 1, i=1, \cdots, m, j=1, \cdots, Q_{i} \\
\sum_{p \in L_{i}} x_{i j p}=\sum_{q \in W_{i}} y_{i j q}, i=1, \cdots, m, j=1, \cdots, Q_{i} \\
\sum_{i=1}^{m} \beta_{i} \sum_{j=1}^{Q_{i}} \sum_{p=r-\alpha_{1}+1, p \in L_{i}}^{r} x_{i j p}+\sum_{s=0}^{\beta_{0}-1} z_{r s}=\beta_{0}, r=0, \cdots, \alpha_{0}-1 \\
\sum_{i=1}^{m} \beta_{i} \sum_{j=1}^{Q_{i}} y_{p=s-\beta_{1}+1, q \in W_{i}}+\sum_{r=0}^{\alpha_{0}-1} z_{r s}=\alpha_{0}, s=0, \cdots, \beta_{0}-1 \\
x_{i j p}, y_{i j q} \in\{0,1\}, i=1, \cdots, m, j=1, \cdots, Q_{i}, p \in L_{i}, q \in W_{i} \\
z_{r s} \in\{0,1\}, r=0, \cdots, \alpha_{0}-1, s=0, \cdots, \beta_{0}-1
\end{gathered}
$$

A função objetivo (3.1) do modelo busca maximizar o valor total das peças que formarão o padrão de corte ótimo.

A restrição (3.2) garante que cada ponto de $A_{0}$ seja coberto por, no máximo, uma peça. As restrições (3.3) e (3.4), por sua vez, asseguram que cada réplica seja alocada apenas uma vez ao padrão de corte ótimo.

Já as restrições (3.5) e (3.6) garantem que as peças não sejam alocadas fora das áreas permitidas, ou seja, em pontos que excedam as dimensões $\alpha_{0}$ e $\beta_{0}$ da folha retangular.

Por fim, as restrições (3.7) e (3.8) indicam os domínios das variáveis envolvidas no problema.

Interessante notar que, apesar da formulação apresentada por Hadjiconstantinou e Christofides (1995) tratar o problema como sendo um caso específico de corte, é possível 
realizar a aplicação direta de tal formulação a um problema similar que trate do empacotamento retangular. De acordo com Dowsland e Dowsland (1992) os problemas de corte e os problemas de empacotamento, em muitas aplicações, podem ser tratados através de abordagens similares.

Outra formulação exata é apresentada por Ribeiro e Lorena (2008), adaptada como um caso particular do problema tratado por Beasley em 1985.

Trata-se justamente de uma formulação desenvolvida para abordagem do Problema de Estivagem de Unidades de Celulose (PEUC). No trabalho citado, os autores tratam o PEUC como um caso particular do Three-dimensional bin packing problem (3D-BPP).

O objetivo do problema é realizar a alocação de itens (unidades de celulose) a um determinado objeto (porão do navio). No caso abordado pelos autores foram consideradas apenas unidades iguais, sem variações em suas dimensões. Além disso, o problema foi reduzido a uma versão bi-dimensional, considerando-se o conceito de camadas no carregamento dos navios.

O modelo matemático do problema é apresentada a seguir.

Sejam $L$ e $W$, respectivamente o comprimento e a largura do objeto e $l$ e $w$ o comprimento e a largura dos itens.

Além disso, tem-se que as dimensões $l$ e $w$ podem ser permutadas entre si para representar uma alteração na orientação do item (rotação em 90 ). As coordenadas $(p, q)$ definem a posição do canto inferior esquerdo das unidades.

Sejam $X$ e $Y$ dois conjuntos utilizados para definir as coordenadas $(p, q)$ de posicionamento, em relação ao canto inferior esquerdo, dos itens (unidades de celulose) no interior do objeto (porão do navio). Os conjuntos são definidos como:

$$
\begin{aligned}
& X=\left\{p \in Z^{+} \mid p=\sum_{i=1}^{2} l_{i} b_{i}, 0 \leq p \leq L-w, b_{i} \geq 0 \text { e inteiro, } i=1,2\right\} . \\
& Y=\left\{q \in Z^{+} \mid q=\sum_{i=1}^{2} w_{i} b_{i}, 0 \leq q \leq W-w, b_{i} \geq 0 \text { e inteiro, } i=1,2\right\} .
\end{aligned}
$$

Por outro lado, seja $a$ a função que descreve as restrições de não-sobreposição dos itens no interior do objeto, dada por:

$$
a_{\text {ipqrs }}=\left\{0, \text { se } 0 \leq p \leq r \leq p+l_{i}-1 \leq L-1 \text { e } 0 \leq q \leq s \leq q+w_{i}-1 \leq W-1 ;\right.
$$
0 caso contrário\}.

Para a função $a$, apresentada acima, os resultados podem ser obtidos previamente para cada par de vértices $(p, q)$ em relação ao par de vértices $(r, s)$.

Por fim, seja $x_{i p q}$ uma variável binária de decisão, onde $x_{i p q}=\{1$, se uma unidade de celulose é posicionada nas coordenadas $(p, q)$ do porão, com orientação $i$; 0 , caso contrário\}.

Considerando os conceitos e definições apresentados, as equações que formam o 
modelo matemático de Ribeiro e Lorena (2008) são apresentada a seguir:

$$
\begin{gathered}
\operatorname{Max}\left(\sum_{i=1}^{2} \sum_{p \in X \mid p \leq L-L_{i}} \sum_{q \in Y \mid q \leq W-W_{i}} x_{i p q}\right) \\
\sum_{i=1}^{2} \sum_{p \in X \mid p \leq L-L_{i}} \sum_{q \in Y \mid q \leq W-W_{i}} a_{i p q r s} x_{i p q} \leq 1, \forall r \in X \text { e } s \in Y \\
x_{i p q} \in\{0,1\} \forall i=1 \cdots 2, p \in X \text { tal que } p \leq L-L_{i}, q \in Y \text { tal que } q \leq W-W_{i}
\end{gathered}
$$

A função objetivo (3.9) do problema busca maximizar a quantidade de itens alocados ao objeto, dada pela variável binária de decisão $x_{i p q}$.

A restrição (3.10) evita a sobreposição dos itens através da variável binária $a_{i p q r s}$, calculada previamente para todas as possíveis posições de todos os itens. Esta variável assume o valor 1 quanto o item é posicionado dentro dos limites do objeto e sem qualquer conflito com os demais itens, e 0 caso contrário.

Por fim, (3.11) apresenta os domínios da variável de interesse.

No trabalho de Ribeiro e Lorena (2008) os autores trabalham a formulação do modelo apresentado acima como sendo um Problema de Máximo Conjunto de Vértices (PMCIV).

Além das formulações apresentadas anteriormente, Carvalho (2002) oferece uma visão detalhada de outras soluções exatas e formulações baseadas em Programação Linear para esses problemas. Além disso, o EURO Special Interest Group on Cutting and Packing (ESICUP) disponibiliza uma compilação abrangente de estudos publicados na área de C\&E, classificadas de acordo com a tipologia de Wäscher, Haußner e Schumann (2007). Essa compilação mostra, por exemplo, que até o ano de 2012 foram publicados 117 estudos na categoria $S L O P P$, sendo 80 deles bi-dimensionais e os demais tri-dimensionais (ESICUP, 2012).

Apesar de ser possível trabalhar com diferentes formulações para soluções exatas dos problemas de Bin Packing, Strip Packing ou SLOPP, é muito comum que os pesquisadores dediquem seus trabalhos e tempo ao estudo de soluções aproximadas (ex.: heurísticas), já que o fato de serem problemas do tipo NP-Completo limita de forma significativa a aplicação das soluções exatas aos problemas de maior escala e complexidade. A própria compilação apresentada pelo ESICUP (2012) mostra que grande parte dos estudos relacionados ao $S L O P P$ são baseados em heurísticas ou outros métodos que não resultam necessariamente em soluções comprovadamente ótimas.

Desta forma, maneiras de melhorar a capacidade das formulações exatas e de aumentar a robustez dos modelos de otimização, permitindo a resolução de instâncias de 
maior tamanho e/ou complexidade, são assuntos de interesse para pesquisadores da área de C\&E. Uma das maneiras utilizadas pelos pesquisadores para melhorar o desempenho de seus modelos é a utilização de formulações disjuntivas. O item a seguir trata de forma mais detalhada esse tipo de abordagem.

\subsection{Formulação Disjuntiva}

Problemas que fazem uso de uma formulação disjuntiva contêm restrições que são ativadas em apenas algumas situações específicas. Considere, por exemplo, as duas desigualdades a seguir (ARENALES et al., 2007):

$$
\begin{aligned}
& f\left(x_{1}, x_{2}, \cdots, x_{n}\right) \leq 0 \\
& g\left(x_{1}, x_{2}, \cdots, x_{n}\right) \leq 0
\end{aligned}
$$

No caso de uma formulação disjuntiva, deseja-se que somente uma das desigualdades apresentadas seja ativada por vez. Para isso, as desigualdades são reformuladas com a inclusão de uma variável binária $y$ tal que (3.12) seja ativada apenas quando $y=1$

e (3.13) seja ativada apenas quando $y=0$. Desta forma, as desigualdades podem ser reescritas da seguinte maneira:

$$
\begin{gathered}
f\left(x_{1}, x_{2}, \cdots, x_{n}\right) \leq M(1-y) \\
g\left(x_{1}, x_{2}, \cdots, x_{n}\right) \leq M y
\end{gathered}
$$

Sendo assim, quando $y=1$, o termo direito de (3.14) é igual a 0 , enquanto o termo direito de (3.15) é igual a $M$. O comportamento oposto é válido para o caso de $y=0$.

Nas desigualdades exemplificadas acima foi utilizado o método big- $M$ (BM) para transformar uma formulação puramente disjuntiva em uma formulação de Programação Inteira Mista (SAWAYA; GROSSMANN, 2005). Nesse caso, $M$ assume o papel de Big Number, definido de maneira a ser suficientemente grande para manter o sentido matemático das desigualdades do modelo. Outros métodos podem ser utilizados para transformação das disjunções em um problema de Programação Inteira Mista, como Envoltória Convexa (Convex Hull - CH) (SAWAYA; GROSSMANN, 2007).

O conceito de formulação disjuntiva (Disjuctive Formulation - DP) foi proposto originalmente por Egon Balas (RAMAN; GROSSMANN, 1994), quando este pesquisava o papel e função da aplicação de conceitos de lógica em problemas de otimização discreta. 
Ainda de acordo com Raman e Grossmann (1994) o autor propôs a formulação disjuntiva como uma maneira alternativa de representar problemas de Programação Inteira Mista.

Após a publicação dos primeiros trabalhos detalhando o desenvolvimento de modelos e técnicas com a utilização de restrições disjuntivas (BALAS, 1979), o autor deu continuidade ao desenvolvimento e aprimoramento das técnicas de programação disjuntiva em outros trabalhos posteriores (BALAS, 1998). Entretanto, na área de Corte e Empacotamento (C\&E), o trabalho de Chen, Lee e Shen (1995) foi um dos primeiros a lançar mão de restrições disjuntivas em sua formulação.

Chen, Lee e Shen (1995) apresentaram um problema relacionado ao carregamento de contêineres com caixas de diferentes dimensões. A formulação apresentada pelos autores utilizou, entre outras, restrições disjuntivas para garantir a não-sobreposição das caixas alocadas aos contêineres. Trata-se de um problema de Programação Inteira Mista, que pode ser resolvido de maneira trivial com auxílio de softwares matemáticos e de otimização disponíveis comercialmente.

O modelo de Chen, Lee e Shen (1995) lançou as bases para que outros trabalhos na área de $\mathrm{C} \& \mathrm{E}$ pudessem ser desenvolvidos com a aplicação de restrições disjuntivas. Nesse contexto, Hifi et al. (2010) foram alguns dos autores que desenvolveram modelos com conceitos similares ao trabalho citado anteriormente.

Hifi et al. (2010) abordaram o problema do Bin Packing em três dimensões (3D $B P P)$. Nesse tipo de problema busca-se minimizar o número total de bins utilizados para alocar todos os itens disponíveis. Apesar das diferenças entre o problema tratado pelos autores e o problema abordado pelo presente trabalho (PEUC), o modelo de Hifi et al. (2010) pode ser adaptado para o caso do Problema de Estivagem de Unidades de Celulose. Sendo assim, faz-se necessário apresentar de forma mais detalhada o modelo de Hifi et al. (2010).

O problema definido pelos autores consiste na alocação de um grupo de $n$ itens retangulares a um grupo de bins (objetos) idênticos. Cada item $i$ é caracterizado por suas dimensões $l_{i}, h_{i}$ e $d_{i}$ (respectivamente comprimento, altura e profundidade). De maneira análoga, os objetos possuem dimensões $L, H$, e $D$.

Como se trata de um problema tri-dimensional, as referências, em termos de posicionamento relativo dos itens, são feitas em relação aos eixos $x$ (item a esquerda de outro), y (item abaixo de outro) e $z$ (item atrás de outro).

Assume-se, inicialmente, que existe um número suficiente de bins $\bar{\gamma}$ capaz de acomodar todos os $n$ itens do problema $(n \leq \bar{\gamma})$. O vetor $\left(x_{i}, y_{i}, z_{i}, \bar{\gamma}_{i}\right)$ é utilizado para determinar a posição geométrica do item $i, \operatorname{com} x_{i}, y_{i}, z_{i} \geq 0$ e $\bar{\gamma}_{i} \geq 1$. O vetor $\left(x_{i}, y_{i}, z_{i}\right)$ representa a coordenada do ponto esquerdo inferior de trás de cada item, já que, como mencionado anteriormente, trata-se de um problema em três dimensões. Sendo assim, 
assume-se que o caso $(0,0,0)$ representa o ponto esquerdo inferior de trás de cada objeto (bin).

Por fim, define-se $\gamma_{i}$ como o rótulo do objeto onde o item $i$ é alocado. O objetivo do modelo é minimizar o maior rótulo de $\gamma_{i}$ e, por consequência, o número total de bins utilizadas para acomodar a totalidade dos itens disponíveis.

Além das notações já apresentadas, tem-se que:

$l_{i j}=1$ se o item $i$ está à esquerda de $j$.

$u_{i j}=1$ se o item $i$ está abaixo de $j$.

$b_{i j}=1$ se o item $i$ está atrás de $j$.

$c_{i j}=1$ se $\gamma_{i}<\gamma_{j}$.

Desta forma, a formulação matemática do problema é apresentada a seguir:

$$
\begin{gathered}
\min \gamma \\
l_{i j}+l_{j i}+u_{i j}+u_{j i}+b_{i j}+b_{j i}+c_{i j}+c_{j i}=1, i<j=1, \cdots, n \\
x_{i}-x_{j}+W\left(l_{i j}-c_{i j}-c_{j i}\right) \leq W-w_{i}, i \neq j=1, \cdots, n \\
y_{i}-y_{j}+H\left(u_{i j}-c_{i j}-c_{j i}\right) \leq H-h_{i}, i \neq j=1, \cdots, n \\
z_{i}-z_{j}+D\left(b_{i j}-c_{i j}-c_{j i}\right) \leq D-d_{i}, i \neq j=1, \cdots, n \\
(\bar{\gamma}-1)\left(l_{i j}+l_{j i}+u_{i j}+u_{j i}+b_{i j}+b_{j i}+\gamma_{i}-\gamma_{j}+\bar{\gamma} c_{i j}\right) \leq \bar{\gamma}-1, i \neq j=1, \cdots, n \\
0 \leq z_{i} \leq D-d_{i}, i=1, \cdots, n \\
0 \leq y_{i j} \leq H-h_{i}, i=1, \cdots, n \\
0 \leq x_{i j} \leq W-c_{i j} \in\{0,1\}, i \neq j=1, \cdots, n \\
\end{gathered}
$$


As restrições (3.17), (3.18), (3.19) e (3.20) garantem que não existam sobreposições entre os itens.

A restrição (3.21), por sua vez, garante que $c_{i j}=c_{j i}=0$ quando os dois itens comparados estão em um mesmo bin e, portanto, não podem ocupar o mesmo espaço.

A restrição (3.22) determina a característica binária das variáveis.

As restrições (3.23) a (3.25) garantem que as dimensões físicas dos bins são devidamente respeitadas.

Por fim, a restrição (3.26) garante que o número de bins utilizadas não exceda o upper bound do problema.

Esse tipo de formulação pode ser bastante útil ao pesquisador que busca trabalhar com resoluções exatas de problemas de $\mathrm{C} \& \mathrm{E}$ de razoável complexidade. Ao longo do presente trabalho será desenvolvida uma formulação que utiliza como base os conceitos apresentados nas formulações exatas apresentadas anteriormente e utiliza também as vantagens da aplicação dos conceitos de restrições disjuntivas.

Vale destacar que o modelo de Hifi et al. (2010), particularmente, pode ser adaptado ao caso do PEUC descrito anteriormente, com a conversão da formulação de três para duas dimensões e a adaptação do conceito de Bin Packing para o SLOPP.

\subsection{Heurísticas}

Grande parte dos problemas de C\&E, como aqueles encontrados de maneira geral no setor de Papel e Celulose, é do tipo NP-Completo (KALLRATH et al., 2014). De acordo com Cui, Cui e Yang (2014) modelos de Programação Linear não conseguem apresentar bons resultados em instâncias de médio ou grande porte nesses tipos de problemas. Nesses casos, o GAP de otimalidade obtido dificilmente é satisfatório.

Desta forma, buscando obter boas soluções para os problemas de C\&E em um tempo computacional razoável, diversos pesquisadores se concentraram na elaboração e aplicação de métodos heurísticos (HILLIER; LIEBERMAN, 2000). Os métodos heurísticos são utilizados na obtenção de uma rápida, porém não necessariamente ótima, solução para o problema estudado (WINSTON, 2003). Esse tipo de abordagem, de acordo com Kallrath et al. (2014) é muito comum em softwares comerciais, que combinam algoritmos básicos para fornecer soluções consistentes em um tempo computacional aceitável. Nesse sentido, Delgado et al. (2012) informa que, para o caso de planos de estivagem de contêineres, tempos acima de 10 minutos para obtenção das soluções são considerados inaceitáveis pelos planejadores dos armadores e terminais portuários.

Entre as soluções heurísticas usualmente aplicadas aos problemas de C\&E, o SHP (Sequential Heuristics Procedure) é um dos métodos mais utilizados. De acordo com Cui, 
Cui e Yang (2014), essa heurística consiste na geração de um padrão de preenchimento para parte da demanda e a repetição desse mesmo padrão para a totalidade da demanda restante. Além disso, algumas abordagens heurísticas podem envolver a resolução do problema original em diferentes etapas, sendo algumas delas, inclusive, baseadas em Programação Linear (CUI; CUI; YANG, 2014).

Na indústria de Papel e Celulose, Kallrath et al. (2014) discorre sobre alguns métodos comumente aplicados na resolução dos problemas, como métodos heurísticos, MILP (Mixed Integer Linear Programming), Collumn Generation e Branch 8 Price. Um dos métodos descritos pelos autores é o chamado Método Exaustivo. Nesse método, instâncias de pequeno porte são resolvidas através da aplicação de $M I L P$. Já instâncias maiores são abordadas com uma combinação de heurística construtiva e MILP, aplicado quando restam poucas ordens a serem resolvidas na instância. Apesar de serem relatados problemas na área de Papel e Celulose, nenhum deles aborda o Problema de Estivagem de Unidades de Celulose.

Outra forma de buscar soluções consistentes em tempo computacional aceitável é apresentada por Ambrosino e Siri (2015). Os autores adotam a estratégia de prover uma solução inicial factível e não-trivial para o problema do carregamento de contêineres em vagões ferroviários, aplicando posteriormente $M I L P$ na resolução. São apresentados diferentes métodos para definição da solução inicial, entre os quais vale destacar a aplicação de uma heurística construtiva e a resolução de uma versão simplificada do modelo, com menos possibilidades de movimentos no carregamento.

Além da aplicação das heurísticas, um campo crescente e promissor na resolução de problemas de C\&E, e combinatoriais de maneira geral, é o das meta-heurísticas (HILLIER; LIEBERMAN, 2000). De acordo com Lodi, Martello e Monaci (2002), entre os algoritmos meta-heurísticos aplicados aos problemas de C\&E, destacam-se: Simulated Annealing, Algoritmos Genéticos, Busca Tabu e Neighborhood Search Strategy. De maneira complementar, Hopper e Turton (2001) destaca também a aplicação de Bottom Left Heuristics, Hill Climbing e da Näive Evolution.

Nesse sentido, uma aplicação interessante de meta-heurística baseada em Algoritmos Genéticos pode ser encontrada em Lu e Huang (2015), para o caso do corte de telas de cristal líquido, quando outras técnicas de resolução do problema se mostraram ineficientes.

Além disso, outra técnica explorada recentemente por pesquisadores é a das hiperheurísticas. De acordo com López-Camacho et al. (2014), soluções heurísticas e metaheurísticas muitas vezes geram resultados excelentes. Entretanto, podem gerar também soluções ineficazes ou medíocres.

Enquanto as meta-heurísticas focam na exploração do espaço das soluções possí- 
veis, as hiper-heurísticas exploram o espaço de heurísticas (LÓPEZ-CAMACHO et al., 2014). Ainda de acordo com López-Camacho et al. (2014), são dois os tipos de hiperheurísticas:

a) Selection hyper-heuristics: Método para desenvolver ou selecionar diferentes heurísticas que podem ser aplicadas na resolução do problema abordado.

b) Generation hyper-heuristics: Método para geração de novas heurísticas com base em partes ou trechos de heurísticas já existentes.

A utilização de métodos heurísticos ou meta-heurísticos não é o foco principal do presente trabalho. Desta forma, o leitor pode encontrar em Oliveira et al. (2016) e Christensen et al. (2017) dois trabalhos recentes de levantamento sobre métodos heurísticos e similares aplicados a problemas de bin packing. 


\section{Modelos e Método de Solução}

O presente capítulo apresentam os modelos matemáticos desenvolvidos para resolução do PEUC, bem como o método de solução aplicado na tentativa de obter melhores resultados para o problema.

\subsection{Modelos Matemáticos}

Os modelos matemáticos desenvolvidos para a resolução do Problema de Estivagem de Unidades de Celulose foram formulados como um problema de programação linear inteira mista (MILP - Mixed Integer Linear Programming). As formulações apresentadas utilizam o conceito de formulação disjuntiva, apresentado no Capítulo 3 do presente trabalho. A seguir é apresentada a notação utilizada nos modelos matemáticos:

Índices:

$i \quad$ Item a ser alocado ao objeto;

$j$ Item comparado com o item $i$ para garantir não-sobreposição no objeto.

\section{Parâmetros:}

$l_{i} \quad$ Comprimento do item $i$

$w_{i} \quad$ Largura do item $i$

M Big-M, número suficientemente grande utilizado em uma função disjuntiva;

L Comprimento do objeto;

W Largura do objeto.

\section{Variáveis de Decisão:}

$A l o c_{i}$ Variável binária (0-1) que indica se o item $i$ é ou não alocado ao objeto;

$x_{i} \quad$ Coordenada de posição do item $i$ ao longo do eixo $\mathrm{x} ;$

$y_{i}$ Coordenada de posição do item $i$ ao longo do eixo y;

$\alpha_{i j} \quad$ Variável de decisão binária que indica se o item $i$ está à direita do item $j$;

$\beta_{i j}$ Variável de decisão binária que indica se o item $i$ está à esquerda do item $j$;

$\gamma_{i j} \quad$ Variável de decisão binária que indica se o item $i$ está abaixo do item $j$;

$\delta_{i j} \quad$ Variável de decisão binária que indica se o item $i$ está acima do item $j$.

\section{Função Objetivo:}

Z Área ocupada pelos itens (lingadas) alocados ao objeto (porão do navio).

No presente trabalho foram desenvolvidos dois modelos matemáticos. Além do modelo matemático base, apresentado a seguir, foi desenvolvido também um modelo ma- 
temático que leva em consideração o conceito de famílias de lingadas. Esse modelo matemático modificado busca reduzir a quantidade total de variáveis binárias de decisão, buscando otimizar o tempo computacional necessário para obtenção dos resultados.

\subsubsection{Modelo Matemático Base}

A função objetivo do modelo (4.1) é definida por:

$$
\operatorname{Max} Z=\sum_{i=1}^{N} A_{l o c_{i}} * l_{i} * w_{i}, i=1 \ldots n
$$

A função (4.1) busca maximizar a área total ocupada pelos itens (lingadas de celulose) alocados ao objeto (porão de cargas do navio). Na função objetivo, $l_{i}$ e $w_{i}$ representam as dimensões dos itens (lingadas de celulose), enquanto $A l o c_{i}$ é uma variável binária que indica se o item $i$ (lingada) foi alocado $\left(A l o c_{i}=1\right)$ ou não $\left(A l o c_{i}=0\right)$ ao objeto (porão do navio).

As restrições (4.2) a (4.6), apresentadas a seguir, são responsáveis a comparação entre diferentes itens $\left(i\right.$ e $j$ ) potencialmente alocados ao objeto. Nessas restrições $x_{i}$ e $y_{i}$ representam as coordenadas de posicionamento do item $i$ no interior do objeto, tendo como referência o canto inferior esquerdo.

$$
\begin{aligned}
& x_{j}-x_{i}-l_{i}+\left(1-\alpha_{i j}\right) * M \geq 0, i=1 \ldots n, j=1 \ldots n, i<j \\
& x_{i}-x_{j}-l_{j}+\left(1-\beta_{i j}\right) * M \geq 0, i=1 \ldots n, j=1 \ldots n, i<j \\
& y_{j}-y_{i}-w_{i}+\left(1-\gamma_{i j}\right) * M \geq 0, i=1 \ldots n, j=1 \ldots n, i<j \\
& y_{i}-y_{j}-w_{j}+\left(1-\delta_{i j}\right) * M \geq 0, i=1 \ldots n, j=1 \ldots n, i<j
\end{aligned}
$$

As restrições apresentadas em (4.2), (4.3), (4.4) e (4.5) indicam se o item $i$ está, respectivamente, à esquerda, direita, abaixo ou acima do item $j . \alpha_{i j}$ é a variável binária, que indica se o item $i$ está posicionado à direita do item $j\left(\alpha_{i j}=1\right)$. Do mesmo modo, $\beta_{i j}$ indica se o item $i$ está à esquerda do item $j, \gamma_{i j}$ indica se o item $i$ está posicionado abaixo do item $j$ e, por fim, $\delta_{i j}$, indica se o item $i$ está posicionado acima do item $j$.

A não-sobreposição dos itens, no entanto, só é garantida quando a restrição 4.6, a seguir, é satisfeita.

$$
\alpha_{i j}+\beta_{i j}+\gamma_{i j}+\delta_{i j}-A_{l o c}-A_{l o c} \geq-1, i=1 \ldots n, j=1 \ldots n, i<j
$$


A restrição (4.6) garante que o item $i$, uma vez alocado ao porão, satisfaça ao menos uma das condições descritas nas restrições 4.2 a 4.5 .

As restrições (4.7) e (4.8) garantem que o item seja posicionado no interior do objeto, com dimensões $L$ (comprimento) e $W$ (largura), sempre tomando como referência de posicionamento $(0,0)$ o canto inferior esquerdo do objeto.

$$
\begin{gathered}
0 \leq x_{i} \leq L-l_{i}, i=1 \ldots n \\
0 \leq y_{i} \leq W-w_{i}, i=1 \ldots n
\end{gathered}
$$

Por fim, as restrições (4.9) e (4.10) determinam o espaço das variáveis de decisão.

$$
\begin{gathered}
\operatorname{Aloc}_{i}, \text { Aloc }_{j}, \alpha_{i j}, \beta_{i j}, \gamma_{i j}, \delta_{i j} \in\{0,1\} \\
x_{i}, y_{i} \in \mathbb{R}^{+}
\end{gathered}
$$

O código fonte da implementação do Modelo Matemático Base é apresentado detalhadamente no Apêndice B. O modelo foi implementado através do OPL (Optimization Programming Language) do IBM ILOG CPLEX Optimization Studio.

\subsubsection{Modelo Matemático Modificado}

O modelo matemático modificado desenvolvido para a resolução do Problema da Estivagem de Unidades de Celulose, como citado e detalhado no Capítulo 2, considera o conceito famílias de lingadas. Esse conceito incorpora ao modelo o fato de lingadas idênticas serem intercambiáveis quando da elaboração do plano de estivagem das unidades de celulose no porão do navio. Isso significa que, quando se trata de um plano de estivagem de unidades de celulose, não há diferença prática entre lingadas com dimensões idênticas e mesma quantidade de unidades de celulose agrupadas.

Matematicamente, a utilização do conceito de famílias de lingadas tem o objetivo de reduzir a quantidade de variáveis binárias de decisão do problema. Esse tipo de abordagem, que busca reduzir a quantidade de variáveis binárias envolvidas na resolução do modelo matemático, pode ser vista em um trabalho pioneiro de Christofides e Whitlock (1977). No trabalho em referência, os autores demonstram que, para o caso de um problema de corte, a existência de padrões simétricos permite a redução do número de variáveis e, por consequência, a redução das variáveis na árvore de possíveis soluções para o problema.

Trabalhos mais recentes, como o de Martello e Monaci (2015), continuam a utilizar técnicas e abordagens similares com o objetivo de reduzir o espaço de soluções do 
problema. Soluções desse tipo são comuns em problemas de Corte e Empacotamento, justamente por estes serem, normalmente, problemas do tipo NP-Completo (HUANG; HWANG; LU, 2016).

O Modelo Matemático Modificado, que utiliza as mesmas notações já apresentadas, é apresentado a seguir:

A função objetivo do modelo (4.11) é definida por:

$$
\operatorname{Max} Z=\sum_{i=1}^{N} A l o c_{i} * l_{i} * w_{i}, i=1 \ldots n
$$

A função (4.11) busca maximizar a área total ocupada pelos itens (lingadas de celulose) alocados ao objeto (porão de cargas do navio). Na função objetivo, $l_{i}$ e $w_{i}$ representam as dimensões dos itens (lingadas de celulose), enquanto $A l o c_{i}$ é uma variável binária que indica se o item $i$ (lingada) foi alocado $\left(A l o c_{i}=1\right)$ ou não $\left(A l o c_{i}=0\right)$ ao objeto (porão do navio).

As restrições (4.12) a (4.15), apresentadas a seguir, são responsáveis a comparação entre diferentes itens $\left(i\right.$ e $j$ ) potencialmente alocados ao objeto. Nessas restrições $x_{i}$ e $y_{i}$ representam as coordenadas de posicionamento do item $i$ no interior do objeto, tendo como referência o canto inferior esquerdo.

$$
\begin{aligned}
& x_{j}-x_{i}-l_{i}+\left(1-\alpha_{i j}\right) * M \geq 0, i=1 \ldots n, j=1 \ldots n, i<j \\
& x_{i}-x_{j}-l_{j}+\left(1-\beta_{i j}\right) * M \geq 0, i=1 \ldots n, j=1 \ldots n, i<j \\
& y_{j}-y_{i}-w_{i}+\left(1-\gamma_{i j}\right) * M \geq 0, i=1 \ldots n, j=1 \ldots n, i<j \\
& y_{i}-y_{j}-w_{j}+\left(1-\delta_{i j}\right) * M \geq 0, i=1 \ldots n, j=1 \ldots n, i<j
\end{aligned}
$$

As restrições apresentadas em (4.12), (4.13), (4.14) e (4.15) indicam se o item $i$ está, respectivamente, à esquerda, direita, abaixo ou acima do item $j$. $\alpha_{i j}$ é a variável binária, que indica se o item $i$ está posicionado à direita do item $j\left(\alpha_{i j}=1\right)$. Do mesmo modo, $\beta_{i j}$ indica se o item $i$ está à esquerda do item $j, \gamma_{i j}$ indica se o item $i$ está posicionado abaixo do item $j$ e, por fim, $\delta_{i j}$, indica se o item $i$ está posicionado acima do item $j$.

A não-sobreposição dos itens, no entanto, só é garantida quando a restrição (4.16), a seguir, é satisfeita.

$$
\alpha_{i j}+\beta_{i j}+\gamma_{i j}+\delta_{i j}-A_{l o c}-A_{l o c} \geq-1, i=1 \ldots n, j=1 \ldots n, i<j
$$


A restrição (4.16) garante que o item $i$, uma vez alocado ao porão, satisfaça ao menos uma das condições descritas nas restrições (4.12) a (4.15).

Quando são comparadas lingadas de uma mesma família, ou seja, itens idênticos, são ativadas as restrições (4.17) a (4.19), apresentadas a seguir, em substituição as restrições apresentadas no Modelo Matemático Base ((4.12) a (4.16)). Essa novas restrições possuem as mesmas funções das restrições (4.12) a (4.16), com a diferença de trabalharem com apenas duas variáveis de posicionamento, $\alpha_{i j}$ e $\gamma_{i j}$ (item $i$ à esquerda do item $j$ ou item $i$ abaixo do item $j$, tendo como referência o canto inferior esquerdo).

A comparação de itens de uma mesma família é realizada através dos parâmetros $F_{i}$ e $F_{j}$. Esses parâmetros indicam a família dos itens a serem comparados $(i$ e $j$ ) e, caso a comparação indique $F_{i}=F_{j}$, as restrições (4.17) a (4.19) são ativadas. Caso contrário, continuam ativadas as restrições (4.12) a (4.16). A comparação de $F_{i}$ e $F_{j}$ foi implementada diretamente no código fonte do Modelo Matemático Modificado, através da linguagem de programação do ILOG CPLEX Optimization Studio.

$$
\begin{gathered}
x_{j}-x_{i}-l_{i}+\left(1-\alpha_{i j}\right) * M \geq 0, i=1 \ldots n, j=1 \ldots n, i<j \\
y_{j}-y_{i}-w_{i}+\left(1-\gamma_{i j}\right) * M \geq 0, i=1 \ldots n, j=1 \ldots n, i<j \\
\alpha_{i j}+\gamma_{i j}-A_{l o c}-A_{l} c_{j} \geq-1, i=1 \ldots n, j=1 \ldots n, i<j
\end{gathered}
$$

As restrições (4.20) e (4.21) garantem que o item seja posicionado no interior do objeto, com dimensões $L$ (comprimento) e $W$ (largura), sempre tomando como referência de posicionamento $(0,0)$ o canto inferior esquerdo do objeto.

$$
\begin{gathered}
0 \leq x_{i} \leq L-l_{i}, i=1 \ldots n \\
0 \leq y_{i} \leq W-w_{i}, i=1 \ldots n
\end{gathered}
$$

Por fim, as restrições (4.22) e (4.23) determinam o espaço das variáveis de decisão.

$$
\begin{gathered}
\operatorname{Aloc}_{i}, \text { Aloc }_{j}, \alpha_{i j}, \beta_{i j}, \gamma_{i j}, \delta_{i j} \in\{0,1\} \\
x_{i}, y_{i} \in \mathbb{R}^{+}
\end{gathered}
$$

O código fonte da implementação do Modelo Matemático Modificado é apresentado detalhadamente no Apêndice C. O modelo foi implementado através do OPL (Optimization Programming Language) do IBM ILOG CPLEX Optimization Studio. 


\subsection{Método Iterativo de Solução}

Como já definido por Ribeiro e Lorena (2008), o PEUC é um problema NPCompleto e, por isso, a obtenção de uma solução ótima nem sempre é factível em um tempo computacional razoável. Os próprios autores, em seu trabalho, apresentam um modelo de otimização para o PEUC que faz uso do conceito de Relaxação Lagrangiana para que seja possível a resolução do problema (RIBEIRO; LORENA, 2008).

De fato, após testes iniciais com os modelos matemáticos apresentados anteriormente, foi possível notar dificuldade na obtenção de boas soluções para o PEUC, conforme definido no Capítulo 3 e modelagens apresentadas nos itens 4.1.1 e 4.1.2, em tempo computacional razoável, especialmente para casos de instâncias com um maiores número de itens. Esse fato pode ser constatado mesmo em teste iniciais com o Modelo Matemático Modificado, que já contempla uma redução no total de variáveis binárias de decisão.

A dificuldade na obtenção de boas soluções está diretamente relacionada ao número total de itens disponíveis para alocação ao objeto, já que estes impactam diretamente o número total de variáveis de decisão do problema.

Desta forma, buscando viabilizar a solução de instâncias do PEUC em um menor tempo computacional e com resultados mais satisfatórios, o presente trabalho propõe a aplicação de um Método Iterativo de Solução (MIS) aos modelos matemáticos de otimização descritos anteriormente.

O principal objetivo do MIS, como detalhado a seguir, é reduzir tanto quanto possível o número de itens disponíveis para alocação ao objeto na resolução do modelo matemático. Esse conceito considera a premissa de que uma boa solução será possível caso a resolução do problema não utilize todos os itens disponíveis para alocação ao objeto.

A utilização de métodos iterativos para a resolução de problemas de Corte e Empacotamento pode ser encontrada em diversos trabalhos da área, com destaque recente para Huang, Hwang e Lu (2016) e Martello e Monaci (2015).

\subsubsection{Conceito do MIS}

O MIS foi desenvolvido com o objetivo de reduzir ainda mais o número de variáveis de decisão envolvidas na resolução do PEUC. O conceito básico na construção do MIS é a redução, tanto quanto possível, do número de itens disponíveis para alocação ao objeto. Por outro lado, o método deve garantir que a redução do número de itens a cada iteração não prejudique a qualidade ou efetividade da solução encontrada.

Dada uma determinada configuração do objeto (largura e comprimento) e a lista dos diferentes tipos de itens (cada qual com suas respectivas dimensões) que poderão ser alocados ao objeto, o algoritmo do MIS é utilizado para determinar iterativamente a 
quantidade de itens de cada um dos possíveis tipos disponíveis para alocação ao objeto, avaliar a qualidade da solução resultante da aplicação do modelo matemático e determinar se as iterações devem continuar ou podem ser encerradas.

Considerando o exposto acima, o algoritmo do MIS pode ser subdivido em seis grandes blocos:

1. Determinação da quantidade de itens disponíveis;

2. Geração da matriz de itens disponíveis para alocação;

3. Resolução do modelo matemático;

4. Gravação dos resultados e plano de estivagem resultante;

5. Avaliação da qualidade da solução gerada; e

6. Avaliação da continuidade ou encerramento do processo iterativo.

A seguir são apresentados os conceitos específicos e detalhes de cada um dos blocos citados acima. O código fonte da implementação do Método Iterativo de Solução é apresentado detalhadamente no Apêndice D. O método foi implementado através do $O P L$ (Optimization Programming Language) do IBM ILOG CPLEX Optimization Studio.

\subsubsection{Detalhamento do MIS}

\subsubsection{Determinação da quantidade de itens disponíveis}

Trata-se de um dos principais pontos do MIS. Esse bloco do algoritmo é responsável por avaliar, baseado na iteração anterior, quantos itens de cada família de lingada foram, de fato, alocados ao objeto na iteração anterior. Para tanto, avalia-se a matriz de alocação dos itens resultante da iteração imediatamente anterior, calculando a quantidade de itens disponibilizados e os itens efetivamente alocados ao objeto durante a iteração já executada.

Um exemplo da matriz de alocação analisada nesse bloco do algoritmo do MIS é apresentado na Tabela 1. Nela é possível verificar que, do total de 17 itens disponibilizados para alocação na iteração anterior, 13 foram efetivamente alocados ( 6 itens da família de lingadas 1 e 7 itens da família de lingadas 2). Os itens efetivamente alocados, de acordo com a notação apresentada para os modelos matemáticos, é determinada por $A_{l o c}=1$.

Neste exemplo são consideradas duas diferentes famílias de itens na matriz de alocação. O conceito descrito acima, entretanto, é válido para qualquer configuração, independentemente da quantidade de diferentes famílias de itens. 
Tabela 1 - Exemplo de matriz de alocação dos itens

\begin{tabular}{ccccccc}
\hline $\mathrm{n}$ & $x_{i}$ & $y_{i}$ & $l_{i}$ & $w_{i}$ & Aloc $_{i}$ & Família \\
\hline 1 & 0,00 & 0,00 & 2,67 & 7,34 & 1 & 1 \\
2 & 0,00 & 7,34 & 2,67 & 7,34 & 0 & 1 \\
3 & 0,00 & 7,34 & 2,67 & 7,34 & 1 & 1 \\
4 & 2,67 & 0,00 & 2,67 & 7,34 & 1 & 1 \\
5 & 5,34 & 0,00 & 2,67 & 7,34 & 1 & 1 \\
6 & 0,00 & 14,68 & 2,67 & 7,34 & 1 & 1 \\
7 & 9,63 & 0,00 & 2,67 & 7,34 & 0 & 1 \\
8 & 9,63 & 0,00 & 2,67 & 7,34 & 0 & 1 \\
9 & 9,63 & 0,00 & 2,67 & 7,34 & 1 & 1 \\
10 & 4,96 & 7,34 & 7,34 & 2,67 & 1 & 2 \\
11 & 4,96 & 0,00 & 7,34 & 2,67 & 0 & 2 \\
12 & 4,96 & 10,01 & 7,34 & 2,67 & 1 & 2 \\
13 & 4,96 & 12,68 & 7,34 & 2,67 & 1 & 2 \\
14 & 4,96 & 15,52 & 7,34 & 2,67 & 1 & 2 \\
15 & 4,96 & 18,19 & 7,34 & 2,67 & 1 & 2 \\
16 & 4,96 & 20,86 & 7,34 & 2,67 & 1 & 2 \\
17 & 4,96 & 23,53 & 7,34 & 2,67 & 1 & 2 \\
\hline
\end{tabular}

Baseado nesses dados, o algoritmo realiza o cálculo da quantidade de itens de cada uma das famílias que devem ser disponibilizados para a próxima iteração a ser executada.

O conceito utilizado considera que deve sempre haver "folga"de $20 \%$ nos itens de cada família em relação a iteração anterior, com o total de itens arredondados para o maior número inteiro. Considerando o exemplo citado, como foram alocados 6 itens da família 1 na primeira iteração, serão disponibilizados 8 itens dessa mesma família para execução da próxima iteração. De forma análoga, serão disponibilizados 9 itens da família 2.

Ainda no contexto da quantidade de itens disponíveis, quando da aplicação do MIS, o algoritmo verifica a quantidade total de famílias de itens que possuem folgas na alocação dos itens ao objeto. Caso todas as famílias de itens apresentem folga na quantidade de itens efetivamente alocados ao objeto na iteração imediatamente anterior, a mesma disponibilidade de itens é mantida para a próxima iteração, porém com incremento no tempo computacional disponível para resolução do modelo matemático. Com isso, busca-se disponibilizar mais tempo computacional para que uma configuração de itens com bom potencial seja explorada na resolução do modelo matemático.

A utilização dos conceitos de "folga"descritos anteriormente busca garantir que a quantidade de itens disponíveis de cada uma das famílias de lingada não seja um limitante para a a obtenção do melhor plano de estivagem. 


\subsubsection{Geração da matriz de itens disponíveis para alocação}

Com base na quantidade de itens de cada família disponibilizados para alocação, é gerada uma matriz dos itens disponíveis e suas dimensões $l_{i}$ e $w_{i}$ de acordo com as famílias de lingada.

A matriz gerada é utilizada como um dado de entrada para o modelo matemático. Um exemplo de matriz de itens é mostrado no próprio Capítulo 4, na Figura 4.

\subsubsection{Resolução do modelo matemático}

À partir da matriz gerada no bloco anterior e em outros dados de entrada estáticos, como por exemplo as dimensões do objeto, um dos modelos matemáticos é utilizado para a resolução da iteração.

De acordo com o andamento do processo iterativo a resolução do modelo matemático pode apresentar diferentes limites de tempo computacional. Caso seja identificado pelo algoritmo que houve "folga"em todas as famílias de itens na iteração anterior, a iteração atual é executada com um tempo computacional limite bem superior ao padrão, buscando disponibilizar mais tempo para que o modelo matemático encontre uma boa solução para o problema.

Ao ser atingido o tempo limite ou caso seja determinada uma solução ótima para o problema, passa-se ao próximo bloco do algoritmo.

\subsubsection{Gravação dos resultados e plano de estivagem resultante}

Antes que sejam avaliados os resultados obtidos pela resolução do modelo matemático de otimização, o MIS grava os dados obtidos até o momento.

Dois tipos de dados são armazenados: informações gerais sobre a iteração e a matriz de itens, com o plano de estivagem resultados.

Os dados gerais da iteração incluem: identificação das instância, identificação da iteração, a função objetivo resultante, a área do objeto, a ocupação total resultante, tempo computacional, GAP informado pelo solver, indicadores de controle do MIS e outros indicadores de controle do solver. Um exemplo dos dados gerados é apresentado na Tabela 2.

Além disso, são armazenados ainda os dados referentes a alocação dos itens, suas dimensões e posicionamento no interior dos objetos. Com base nesses dados é possível construir graficamente o plano de estivagem resultante, exemplificado na Figura 11. 
Tabela 2 - Exemplo de dados de controle das iterações

\begin{tabular}{cccccccccc}
\hline Instância & Iteração & Objetivo & Área Objeto & Ocupação & Status & Tempo & GAP & Exaustão & Folga \\
\hline 1 & 1 & 209,979 & 216 & 0,972124 & 11 & 98,156 & 0,456124 & 1 & 4 \\
1 & 2 & 207,935 & 216 & 0,962661 & 11 & 185,671 & 0,575105 & 1 & 6 \\
1 & 3 & 209,986 & 216 & 0,972159 & 11 & 393,703 & 0,475587 & 2 & 5 \\
1 & 4 & 209,989 & 216 & 0,972171 & 11 & 482,046 & 0,559734 & 1 & 5 \\
1 & 5 & 206,915 & 216 & 0,957941 & 11 & 570,703 & 0,582915 & 1 & 6 \\
2 & 1 & 203,557 & 216 & 0,942393 & 11 & 1263,89 & 0,446409 & 1 & 4 \\
2 & 2 & 197,733 & 216 & 0,915429 & 11 & 1355,81 & 0,525793 & 1 & 5 \\
2 & 3 & 201,739 & 216 & 0,933976 & 11 & 1448,19 & 0,466623 & 2 & 4 \\
3 & 1 & 180,405 & 216 & 0,835209 & 11 & 2061,28 & 0,473348 & 1 & 2 \\
3 & 2 & 181,664 & 216 & 0,841037 & 11 & 2154,78 & 0,559129 & 1 & 3 \\
3 & 3 & 182,923 & 216 & 0,846864 & 11 & 2248,63 & 0,555281 & 1 & 3 \\
3 & 4 & 191,226 & 216 & 0,885307 & 11 & 2342,09 & 0,494329 & 1 & 4 \\
3 & 5 & 191,856 & 216 & 0,88822 & 11 & 2435,14 & 0,50069 & 1 & 4 \\
3 & 6 & 191,856 & 216 & 0,88822 & 11 & 2527,88 & 0,505238 & 1 & 3 \\
3 & 7 & 199,53 & 216 & 0,923749 & 11 & 2620,98 & 0,447345 & 1 & 4 \\
\hline
\end{tabular}

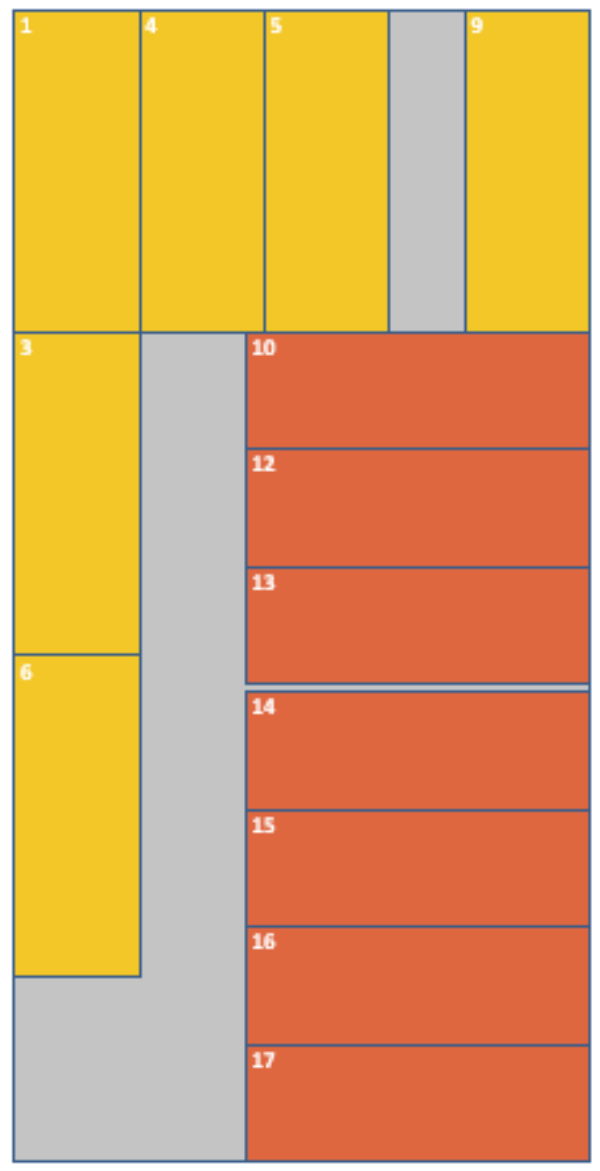

Figura 11 - Exemplo de plano de estivagem resultante do MIS

\subsubsection{Avaliação da qualidade da solução gerada}

Com base nos resultados obtidos, o algoritmo do MIS avalia se a solução encontrada para a iteração atual é melhor ou não do que a melhor solução disponível até o momento, resultante de alguma iteração anterior. Caso a solução seja a melhor encontrada até o 
momento, o controle do MIS é atualizado com essa nova solução.

Por outro lado, caso a solução encontrada na iteração atual não apresente melhoria em relação a melhor solução encontrada em iterações anteriores, o MIS aciona o chamado controle de exaustão. O controle de exaustão é atualizado, quando aplicável, de maneira a registrar a quantidade de iterações consecutivas que não apresentaram melhoria na solução encontrada. Com isso, o algoritmo do MIS garante que o processo não seja executado indefinidamente sem que uma solução de melhor qualidade seja encontrada.

No presente trabalho, em todos os experimentos computacionais realizados, foi utilizado um controle de exaustão com limite de 5 iterações. Isso significa que, para cada instância avaliada, caso não se verifique melhoria na solução durante 5 iterações consecutivas, o processo é encerrado. Sempre que uma melhor solução é encontrada durante a execução de uma iteração o controle de exaustão é reiniciado.

\subsubsection{Avaliação da continuidade ou encerramento do processo iterativo}

Por fim, com base na análise do bloco anterior sobre a qualidade da solução, o algoritmo do MIS determina se o problema pode ser encerrado ou se outra iteração deve ser executada.

O MIS encerra o processo iterativo em quatro diferentes situações:

- Caso a solução encontrada seja ótima ( $G A P$ igual a zero); e

- Caso não sejam encontradas soluções de melhor qualidade durante cinco iterações consecutivas (controle de exaustão).

Caso nenhuma das condições seja satisfeita, o MIS reinicia o processo, retornando ao primeiro bloco do algoritmo e executando a próxima iteração.

\subsubsection{Fluxograma Conceitual do MIS}

A seguir é apresentado, na Figura 12, o fluxograma conceitual de execução do MIS, conforme detalhamento discutido no item 4.2.2, apresentando os blocos determinantes do algoritmo. 


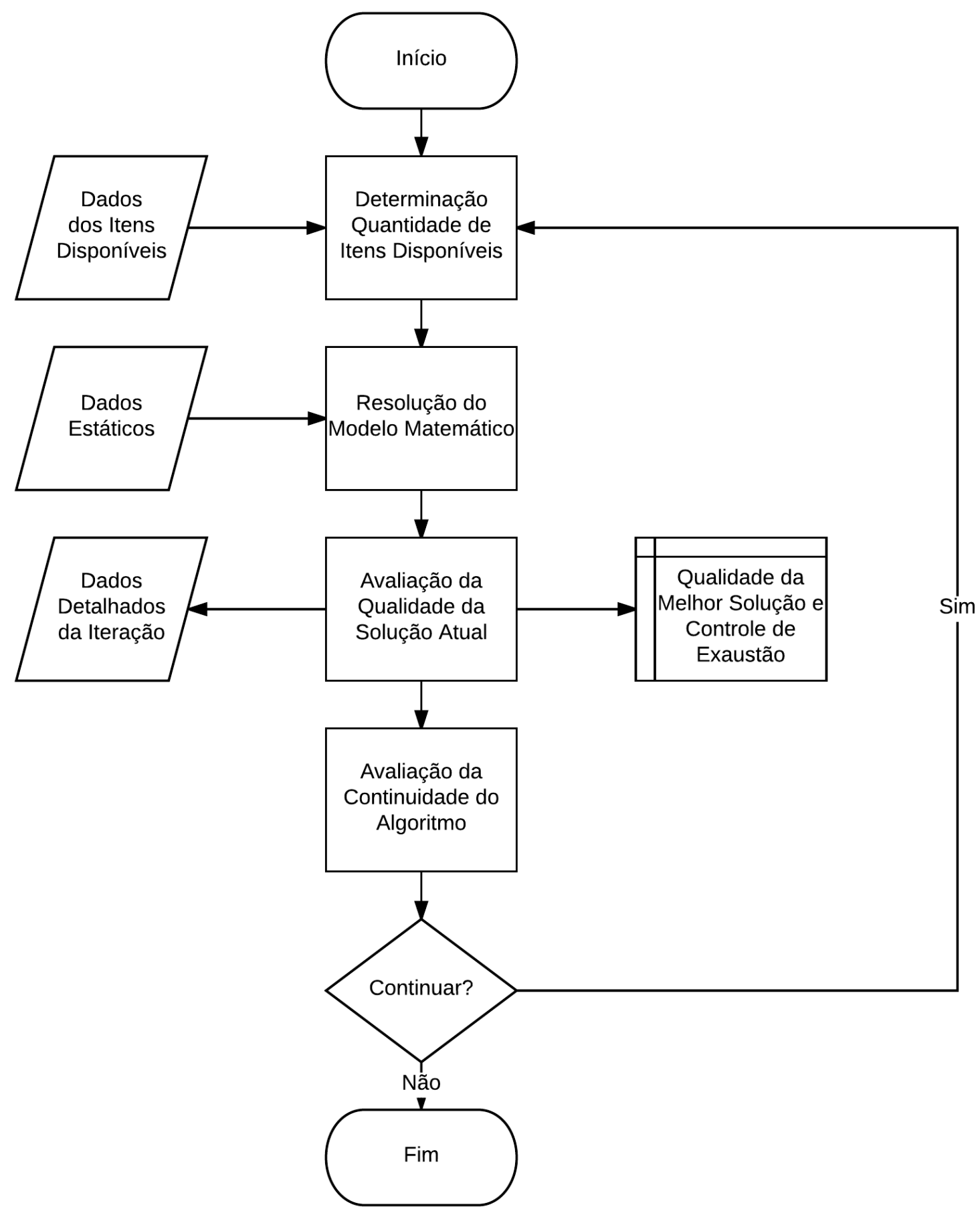

Figura 12 - Fluxograma conceitual do MIS

\subsubsection{Exemplo de Aplicação do MIS}

A seguir é apresentado em detalhes o comportamento do Método Iterativo de Solução, exemplificado através da aplicação em uma das instâncias experimentais apresentadas no Capítulo 5. 
A Tabela 3, a seguir, apresenta as características do objeto e itens dessa instância. Trata-se da instância 4, do grupo 1. Os detalhes sobre a construção dessa instância experimental, bem como outros detalhes, são apresentados ao longo do Capítulo 5.

Tabela 3 - Detalhamento das instâncias experimentais construídas

\begin{tabular}{|c|c|c|c|c|c|c|c|c|c|c|c|c|c|c|}
\hline \multirow{2}{*}{ Inst. } & \multicolumn{2}{|c|}{ Objeto } & \multicolumn{2}{|c|}{ Item 1} & \multicolumn{2}{|c|}{ Item 2} & \multicolumn{2}{|c|}{ Item 3} & \multicolumn{2}{|c|}{ Item 4} & \multicolumn{2}{|c|}{ Item 5} & \multicolumn{2}{|c|}{ Item 6} \\
\hline & $L$ & $W$ & $l_{i}$ & $w_{i}$ & $l_{i}$ & $w_{i}$ & $l_{i}$ & $w_{i}$ & $l_{i}$ & $w_{i}$ & $l_{i}$ & $w_{i}$ & $l_{i}$ & $w_{i}$ \\
\hline 4 & 12,00 & 18,00 & 3,03 & 2,81 & 2,81 & 3,03 & 2,82 & 2,79 & 2,79 & 2,82 & 2,70 & 2,70 & 2,70 & 2,70 \\
\hline
\end{tabular}

\subsubsection{Iteração 1}

O primeiro passo da iteração é a geração da matriz de itens disponíveis para resolução do Modelo Matemático Modificado, com base nos dados da instância. A Tabela 4, a seguir, apresenta os itens gerados para a primeira iteração. Nesse caso, dos 38 possíveis itens, foram gerados 36, distribuídos entre as 6 diferentes famílias. 
Tabela 4 - Matriz de itens disponíveis para a iteração

\begin{tabular}{cccc}
\hline Item $(i)$ & $l_{i}$ & $w_{i}$ & Família \\
\hline 1 & 3,03 & 2,81 & 1 \\
2 & 3,03 & 2,81 & 1 \\
3 & 3,03 & 2,81 & 1 \\
4 & 3,03 & 2,81 & 1 \\
5 & 3,03 & 2,81 & 1 \\
6 & 3,03 & 2,81 & 1 \\
7 & 2,81 & 3,03 & 2 \\
8 & 2,81 & 3,03 & 2 \\
9 & 2,81 & 3,03 & 2 \\
10 & 2,81 & 3,03 & 2 \\
11 & 2,81 & 3,03 & 2 \\
12 & 2,81 & 3,03 & 2 \\
13 & 2,82 & 2,79 & 3 \\
14 & 2,82 & 2,79 & 3 \\
15 & 2,82 & 2,79 & 3 \\
16 & 2,82 & 2,79 & 3 \\
17 & 2,82 & 2,79 & 3 \\
18 & 2,82 & 2,79 & 3 \\
19 & 2,79 & 2,82 & 4 \\
20 & 2,79 & 2,82 & 4 \\
21 & 2,79 & 2,82 & 4 \\
22 & 2,79 & 2,82 & 4 \\
23 & 2,79 & 2,82 & 4 \\
24 & 2,79 & 2,82 & 4 \\
25 & 2,70 & 2,70 & 5 \\
26 & 2,70 & 2,70 & 5 \\
27 & 2,70 & 2,70 & 5 \\
28 & 2,70 & 2,70 & 5 \\
29 & 2,70 & 2,70 & 5 \\
30 & 2,70 & 2,70 & 5 \\
31 & 2,70 & 2,70 & 6 \\
32 & 2,70 & 2,70 & 6 \\
33 & 2,70 & 2,70 & 6 \\
34 & 2,70 & 2,70 & 6 \\
35 & 2,70 & 2,70 & 6 \\
36 & 2,70 & 2,70 & 6 \\
37 & 0,00 & 0,00 & \\
38 & 0,00 & 0,00 & \\
\hline & & &
\end{tabular}

Após a resolução do modelo matemático, é gerada a matriz de soluções, contendo a alocação e posicionamento dos itens no interior do objeto. A matriz com os resultados é apresentada na Tabela 5 .

A variável binária $A l o c_{i}$ indica se o item $i$ foi $\left(A l o c_{i}=1\right)$ ou não $\left(A l o c_{i}=0\right)$ alocado ao objeto. As variáveis $x_{i}$ e $y_{i}$ indicam o posicionamento do item, com relação ao canto inferior esquerdo do objeto. 
Tabela 5 - Matriz de com os resultados da iteração

\begin{tabular}{|c|c|c|c|c|c|c|}
\hline Item $(i)$ & $l_{i}$ & $w_{i}$ & Família & Aloc $_{i}$ & $x_{i}$ & $y_{i}$ \\
\hline 1 & 3,03 & 2,81 & 1 & 1 & 0,00 & 0,00 \\
\hline 2 & 3,03 & 2,81 & 1 & 1 & 0,00 & 2,81 \\
\hline 3 & 3,03 & 2,81 & 1 & 1 & 0,00 & 5,63 \\
\hline 4 & 3,03 & 2,81 & 1 & 1 & 3,03 & 0,00 \\
\hline 5 & 3,03 & 2,81 & 1 & 1 & 3,03 & 2,81 \\
\hline 6 & 3,03 & 2,81 & 1 & 1 & 6,05 & 0,21 \\
\hline 7 & 2,81 & 3,03 & 2 & 1 & 0,00 & 8,44 \\
\hline 8 & 2,81 & 3,03 & 2 & 1 & 3,03 & 5,63 \\
\hline 9 & 2,81 & 3,03 & 2 & 1 & 6,05 & 3,03 \\
\hline 10 & 2,81 & 3,03 & 2 & 1 & 9,19 & 0,00 \\
\hline 11 & 2,81 & 3,03 & 2 & 1 & 9,08 & 3,03 \\
\hline 12 & 2,81 & 3,03 & 2 & 1 & 0,00 & 11,47 \\
\hline 13 & 2,82 & 2,79 & 3 & 1 & 6,36 & 6,05 \\
\hline 14 & 2,82 & 2,79 & 3 & 1 & 3,03 & 8,84 \\
\hline 15 & 2,82 & 2,79 & 3 & 1 & 0,00 & 15,21 \\
\hline 16 & 2,82 & 2,79 & 3 & 1 & 2,82 & 11,63 \\
\hline 17 & 2,82 & 2,79 & 3 & 1 & 9,18 & 6,05 \\
\hline 18 & 2,82 & 2,79 & 3 & 1 & 6,39 & 9,57 \\
\hline 19 & 2,79 & 2,82 & 4 & 1 & 9,21 & 8,84 \\
\hline 20 & 2,79 & 2,82 & 4 & 1 & 6,42 & 12,36 \\
\hline 21 & 2,79 & 2,82 & 4 & 1 & 3,03 & 15,18 \\
\hline 22 & 2,79 & 2,82 & 4 & 1 & 6,42 & 15,18 \\
\hline 23 & 2,79 & 2,82 & 4 & 1 & 9,21 & 12,36 \\
\hline 24 & 2,79 & 2,82 & 4 & 1 & 9,21 & 15,18 \\
\hline 25 & 2,70 & 2,70 & 5 & 0 & 9,30 & 15,30 \\
\hline 26 & 2,70 & 2,70 & 5 & 0 & 9,30 & 15,30 \\
\hline 27 & 2,70 & 2,70 & 5 & 0 & 0,00 & 15,30 \\
\hline 28 & 2,70 & 2,70 & 5 & 0 & 9,30 & 15,30 \\
\hline 29 & 2,70 & 2,70 & 5 & 0 & 9,30 & 15,30 \\
\hline 30 & 2,70 & 2,70 & 5 & 0 & 9,30 & 15,30 \\
\hline 31 & 2,70 & 2,70 & 6 & 0 & 9,30 & 15,30 \\
\hline 32 & 2,70 & 2,70 & 6 & 0 & 9,30 & 15,30 \\
\hline 33 & 2,70 & 2,70 & 6 & 0 & 6,59 & 15,30 \\
\hline 34 & 2,70 & 2,70 & 6 & 0 & 9,30 & 15,30 \\
\hline 35 & 2,70 & 2,70 & 6 & 0 & 9,30 & 15,30 \\
\hline 36 & 2,70 & 2,70 & 6 & 0 & 9,30 & 15,30 \\
\hline 37 & 0,00 & 0,00 & & 0 & 0,00 & 0,00 \\
\hline 38 & 0,00 & 0,00 & & 0 & 0,00 & 0,00 \\
\hline
\end{tabular}

Com base nesses resultados, é gerada a representação gráfica do plano de estivagem. A Figura 13 mostra essa representação.

Os resultados finais da iteração mostram que a solução gerada gerou a ocupação de 90,98\% da área do objeto, com 'folga' em apenas duas famílias (famílias 5 e 6). 


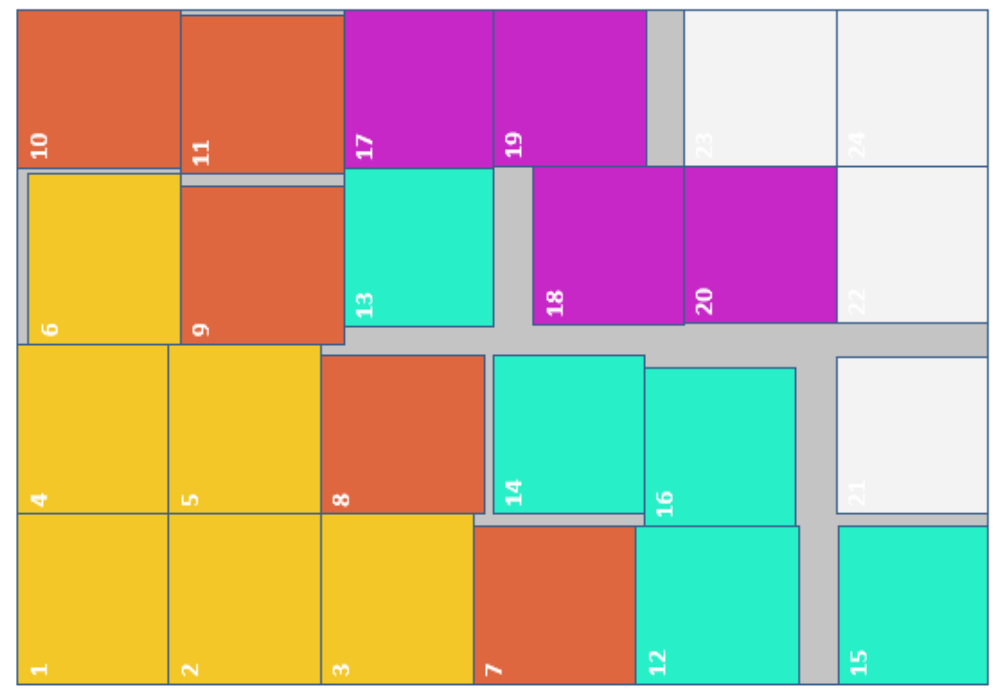

Figura 13 - Representação gráfica do plano de estivagem, iteração 1

Com base nesses resultados, passa-se a próxima iteração.

\subsubsection{Iteração 2}

A segunda iteração é iniciada com a geração de uma nova matriz de itens disponíveis para alocação. Essa geração leva em conta a quantidade de itens de cada família alocados na última iteração e o conceito de 'folga'.

Com isso, após a execução do modelo matemático, chegou-se a um novo plano de estivagem. A representação gráfica desse plano é mostrada da Figura 14.

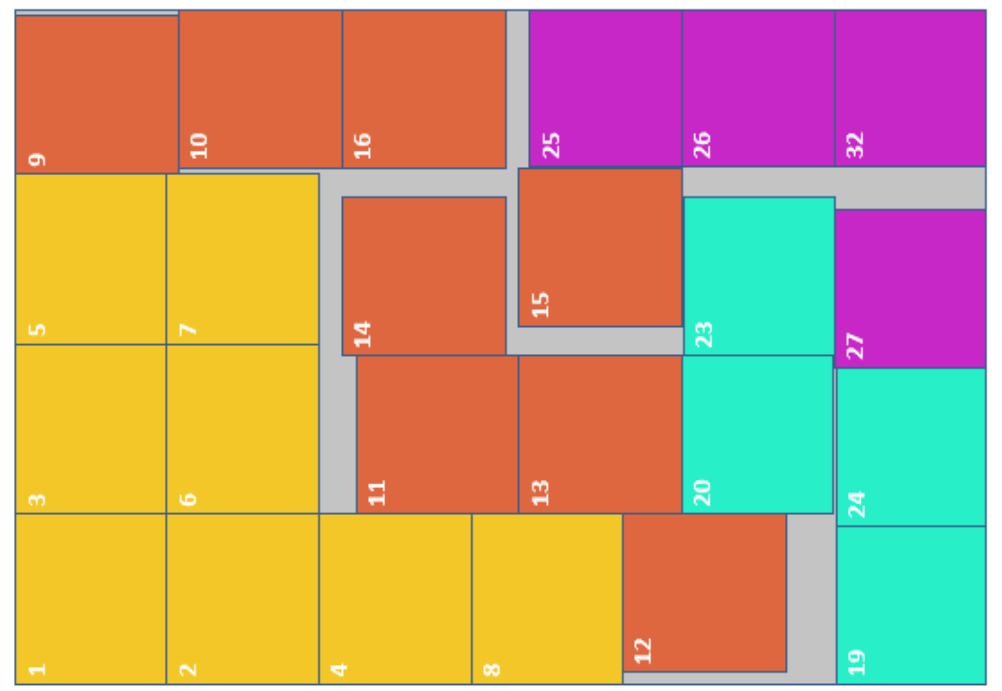

Figura 14 - Representação gráfica do plano de estivagem, iteração 2

Os resultados finais da iteração mostram que a solução gerada gerou a ocupação de 92,19\% da área do objeto, com 'folga' nas famílias 3, 4 e 5 de itens. Como houve melhoria 
na solução encontrada, esse novo valor passar a ser a referência de comparação para as próximas instâncias.

\subsubsection{Iteração 3}

A terceira iteração repete o mesmo procedimento já verificado nas iterações anteriores.

Após a execução do modelo matemático, chegou-se a um novo plano de estivagem. A representação gráfica desse plano é mostrada da Figura 15.

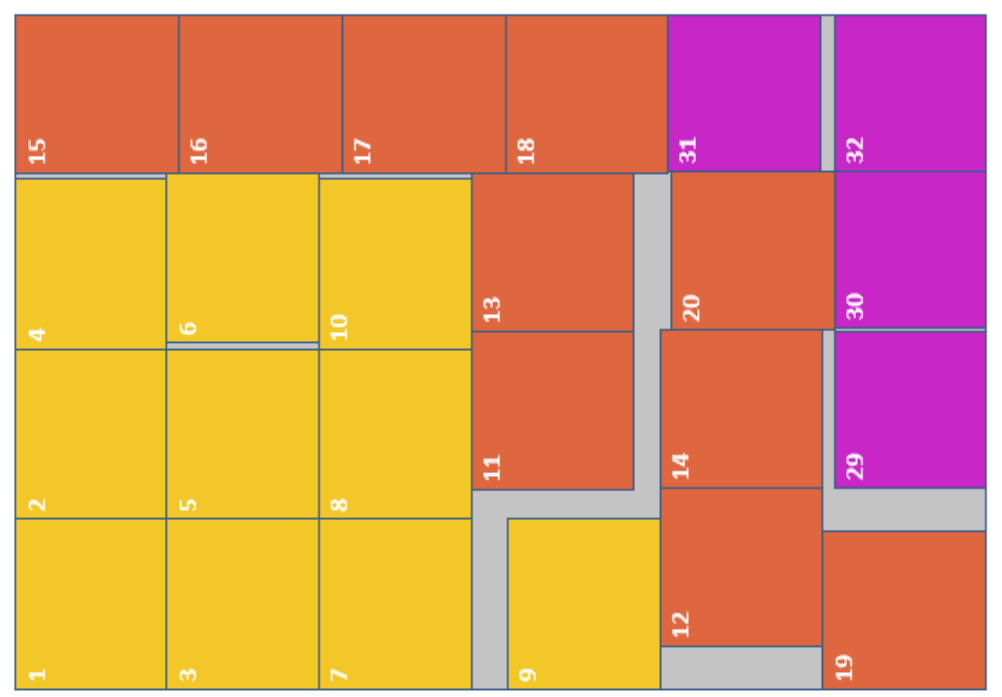

Figura 15 - Representação gráfica do plano de estivagem, iteração 3

Os resultados finais da iteração mostram que a solução gerada gerou a ocupação de 93,41\% da área do objeto, com 'folga' nas famílias 3, 4 e 5 de itens. Como houve melhoria na solução encontrada, esse novo valor passar a ser a referência de comparação para as próximas instâncias.

\subsubsection{Iteração 4}

A quarta iteração repete o mesmo procedimento já verificado nas iterações anteriores.

Após a execução do modelo matemático, chegou-se a um novo plano de estivagem. A representação gráfica desse plano é mostrada da Figura 16. 


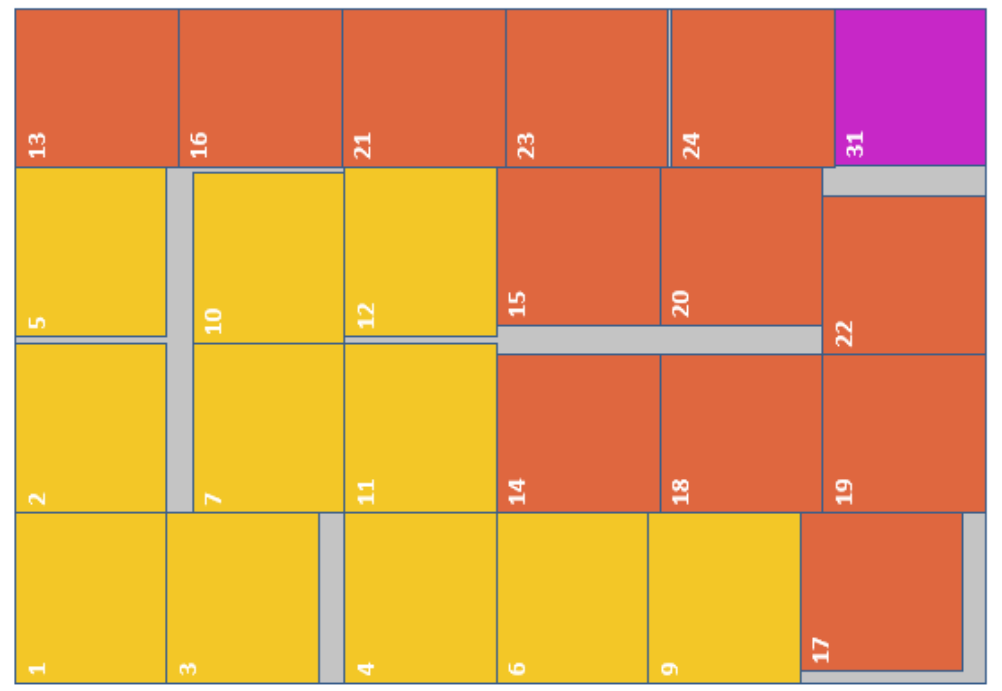

Figura 16 - Representação gráfica do plano de estivagem, iteração 4

Os resultados finais da iteração mostram que a solução gerada gerou a ocupação de 94,32\% da área do objeto, com 'folga' nas famílias 3, 4 e 5 de itens. Como houve melhoria na solução encontrada, esse novo valor passar a ser a referência de comparação para as próximas instâncias.

\subsubsection{Iterações 5 a 9}

As próxima iterações, executadas exatamente da mesma forma que as iterações descritas anteriormente, não apresentam melhorias na solução encontrada. Desta forma, as iterações são repetidas até que seja satisfeito o critério de parada do algoritmo por exaustão (cinco iterações consecutivas sem qualquer melhoria na solução).

A instância é então encerrada, com resultado de 94,32\% de ocupação do objeto, encontrado na quarta iteração. O tempo total transcorrido para resolução das instância, incluindo as 9 iterações, foi de 273 segundos. 


\section{Procedimento Experimental}

Com base nos modelos matemáticos apresentados anteriormente, bem como no método de solução proposto, foram realizados experimentos computacionais com diferentes instâncias do PEUC. A seguir são apresentadas as instâncias utilizadas e os experimentos realizados.

\subsection{Instâncias Experimentais}

Para que os experimentos pudessem ser realizados, diferentes instâncias de itens e objetos foram construídas através de um procedimento baseado em distribuições de probabilidade uniformes. Esse algoritmo de construção de instâncias foi implementado em VBA (Visual Basic for Applications) para MS Excel. O procedimento considerou valores mínimos e máximos para comprimento e largura dos itens, de acordo com limites pré-estabelecidos. Um único par de dimensões (comprimento e largura) de objeto foi utilizado para todas as instâncias, permitindo a comparação dos resultados para as diferentes configurações dos itens de cada instância.

As instâncias foram construídas de acordo com duas diferentes características para os itens: tamanho e forma.

Em relação ao tamanho, foram construídas 10 instâncias com itens considerados "pequenos"e outras 10 instâncias com itens considerados "grandes". Itens considerados pequenos são aqueles nos quais a área do item não ultrapassa $5 \%$ da área total do objeto. Além disso, no caso dos itens considerados pequenos, foi determinado um limite para que a área total de cada item não fosse inferior a 3\% da área total do objeto. Para o caso dos itens grandes, a área total de cada item gerado deve ser superior a $8 \%$ da área total do objeto e inferior a $10 \%$ da área total do objeto.

No caso da forma dos itens, foram considerados itens "homogêneos"e "heterogêneos". Os itens gerados pelo algoritmo de construção das instâncias são considerados homogêneos quando os limites inferior e superior para geração aleatória de suas dimensões $l_{i}$ e $w_{i}$ são idênticos. Por outro lado, no caso dos itens heterogêneos, o procedimento de construção das instâncias utiliza limites inferior e superior com diferença significativa entre as dimensões $l_{i}$ e $w_{i}$.

Essa diferença entre a forma dos itens faz com os itens considerados homogêneos apresentem formato mais próximo a quadrados, com comprimento e largura em dimensões próximas. Já os itens considerados heterogêneos apresentam formatos mais próximos a retângulos alongados, com uma de suas dimensões consideravelmente superior a outra. 
O algoritmo desenvolvido para a construção de instâncias experimentais foi utilizado na geração de 4 diferentes grupos, cada um com 5 diferentes instâncias. Cada uma das instâncias apresenta 6 diferentes itens, incluindo itens rotacionados. Cada um dos grupos de instâncias utilizou as variações nas dimensões dos itens (forma e tamanho) descritas anteriormente:

Grupo 1 - Itens pequenos e homogêneos;

Grupo 2 - Itens pequenos e heterogêneos;

Grupo 3 - Itens grandes e homogêneos;

Grupo 4 - Itens grandes e heterogêneos.

Além das características de tamanho e forma já mencionadas, as instâncias experimentais foram construídas levando em conta a possibilidade de rotação dos itens. Com isso, cada um dos itens gerados aparece em sua orientação original e também rotacionado $90^{\circ}$.

Considerando as dimensões de comprimento e largura pré-determinadas do objeto, utilizando como referência um porão de navio real, $L=12,00$ e $W=18,00$, as dimensões máximas e mínimas $\left(l_{i}\right.$ e $\left.w_{i}\right)$ para os itens de cada um dos grupos de instâncias experimentais foram definidas de acordo com o apresentado na Tabela 6, a seguir:

Tabela 6 - Dimensões máximas e mínimas dos itens para construção das instâncias

\begin{tabular}{ccccc}
\hline Grupo & $l_{i}$ Mínimo & $l_{i}$ Máximo & $w_{i}$ Mínimo & $w_{i}$ Máximo \\
\hline 1 & 2,55 & 3,29 & 2,55 & 3,29 \\
2 & 1,27 & 1,64 & 5,09 & 6,57 \\
3 & 4,16 & 4,65 & 4,16 & 4,65 \\
4 & 2,08 & 2,32 & 8,31 & 9,30 \\
\hline
\end{tabular}

A Tabela 7 apresenta o detalhamento de cada uma das 20 instâncias geradas, incluindo as respectivas dimensões de objetos e itens. As instâncias 1-5 referem-se ao Grupo 1, instâncias 6-10 ao Grupo 2, instâncias 11-15 ao Grupo 3 e instâncias 16-20 ao Grupo 4, de acordo com as características apresentadas anteriormente na Tabela 6.

As instâncias foram geradas com 6 diferentes famílias de itens. Esse número foi definido com base na análise de instâncias reais, que usualmente possuem entre 2 e 6 diferentes tipos de lingadas carregadas em cada porão. Além disso, as versão rotacionada de cada lingada foi considerada como uma família própria. 
Tabela 7 - Detalhamento das instâncias experimentais construídas

\begin{tabular}{ccccccccccccccc}
\hline \multirow{2}{*}{ Inst. } & \multicolumn{2}{c}{ Objeto } & \multicolumn{1}{c}{ Item 1} & \multicolumn{1}{c}{ Item 2} & \multicolumn{1}{c}{ Item 3} & \multicolumn{2}{c}{ Item 4} & \multicolumn{2}{c}{ Item 5} & \multicolumn{2}{c}{ Item 6} \\
\hline 1 & 12,00 & 18,00 & 2,85 & 3,10 & 3,10 & 2,85 & 2,87 & 3,08 & 3,08 & 2,87 & 2,92 & 2,67 & 2,67 & 2,92 \\
2 & 12,00 & 18,00 & 3,27 & 2,76 & 2,76 & 3,27 & 3,00 & 2,77 & 2,77 & 3,00 & 2,77 & 2,60 & 2,60 & 2,77 \\
3 & 12,00 & 18,00 & 2,99 & 2,57 & 2,57 & 2,99 & 2,78 & 2,65 & 2,65 & 2,78 & 2,59 & 2,75 & 2,75 & 2,59 \\
4 & 12,00 & 18,00 & 3,03 & 2,81 & 2,81 & 3,03 & 2,82 & 2,79 & 2,79 & 2,82 & 2,70 & 2,70 & 2,70 & 2,70 \\
5 & 12,00 & 18,00 & 2,72 & 3,05 & 3,05 & 2,72 & 2,60 & 2,58 & 2,58 & 2,60 & 2,58 & 2,57 & 2,57 & 2,58 \\
\hline 6 & 12,00 & 18,00 & 1,41 & 6,03 & 6,03 & 1,41 & 1,34 & 5,73 & 5,73 & 1,34 & 1,37 & 5,18 & 5,18 & 1,37 \\
7 & 12,00 & 18,00 & 1,37 & 6,26 & 6,26 & 1,37 & 1,37 & 5,78 & 5,78 & 1,37 & 1,60 & 5,32 & 5,32 & 1,60 \\
8 & 12,00 & 18,00 & 1,61 & 6,33 & 6,33 & 1,61 & 1,56 & 6,24 & 6,24 & 1,56 & 1,45 & 6,18 & 6,18 & 1,45 \\
9 & 12,00 & 18,00 & 1,39 & 5,78 & 5,78 & 1,39 & 1,39 & 5,21 & 5,21 & 1,39 & 1,36 & 5,17 & 5,17 & 1,36 \\
10 & 12,00 & 18,00 & 1,32 & 6,08 & 6,08 & 1,32 & 1,35 & 5,43 & 5,43 & 1,35 & 1,50 & 5,24 & 5,24 & 1,50 \\
\hline 11 & 12,00 & 18,00 & 4,33 & 4,18 & 4,18 & 4,33 & 4,24 & 4,24 & 4,24 & 4,24 & 4,27 & 4,19 & 4,19 & 4,27 \\
12 & 12,00 & 18,00 & 4,32 & 4,36 & 4,36 & 4,32 & 4,32 & 4,23 & 4,23 & 4,32 & 4,19 & 4,16 & 4,16 & 4,19 \\
13 & 12,00 & 18,00 & 4,60 & 4,38 & 4,38 & 4,60 & 4,24 & 4,30 & 4,30 & 4,24 & 4,28 & 4,17 & 4,17 & 4,28 \\
14 & 12,00 & 18,00 & 4,34 & 4,47 & 4,47 & 4,34 & 4,25 & 4,19 & 4,19 & 4,25 & 4,19 & 4,21 & 4,21 & 4,19 \\
15 & 12,00 & 18,00 & 4,34 & 4,53 & 4,53 & 4,34 & 4,26 & 4,32 & 4,32 & 4,26 & 4,22 & 4,16 & 4,16 & 4,22 \\
\hline 16 & 12,00 & 18,00 & 2,16 & 8,98 & 8,98 & 2,16 & 2,21 & 8,60 & 8,60 & 2,21 & 2,15 & 8,57 & 8,57 & 2,15 \\
17 & 12,00 & 18,00 & 2,21 & 9,23 & 9,23 & 2,21 & 2,19 & 8,89 & 8,89 & 2,19 & 2,16 & 8,49 & 8,49 & 2,16 \\
18 & 12,00 & 18,00 & 2,19 & 8,76 & 8,76 & 2,19 & 2,16 & 8,36 & 8,36 & 2,16 & 2,21 & 8,32 & 8,32 & 2,21 \\
19 & 12,00 & 18,00 & 2,16 & 8,76 & 8,76 & 2,16 & 2,19 & 8,50 & 8,50 & 2,19 & 2,14 & 8,43 & 8,43 & 2,14 \\
20 & 12,00 & 18,00 & 2,22 & 8,56 & 8,56 & 2,22 & 2,16 & 8,53 & 8,53 & 2,16 & 2,31 & 8,35 & 8,35 & 2,31 \\
\hline
\end{tabular}

Para exemplificar as instâncias construídas e as diferenças existentes entre os diferentes grupos de instâncias, apresentados na Tabela 6, a seguir são apresentadas a representações gráficas (Figuras 17, 18, 19 e 20) dos itens gerados para quatro diferentes instâncias $(1,5,11$ e 16).
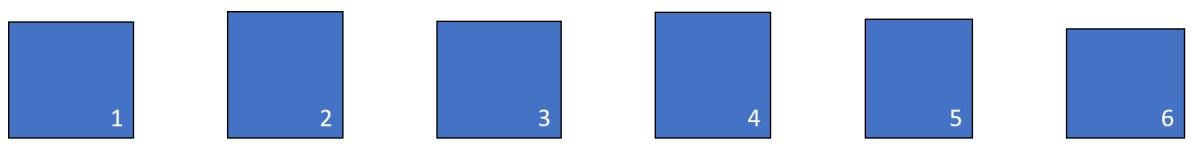

Figura 17 - Instância 1, Grupo 1

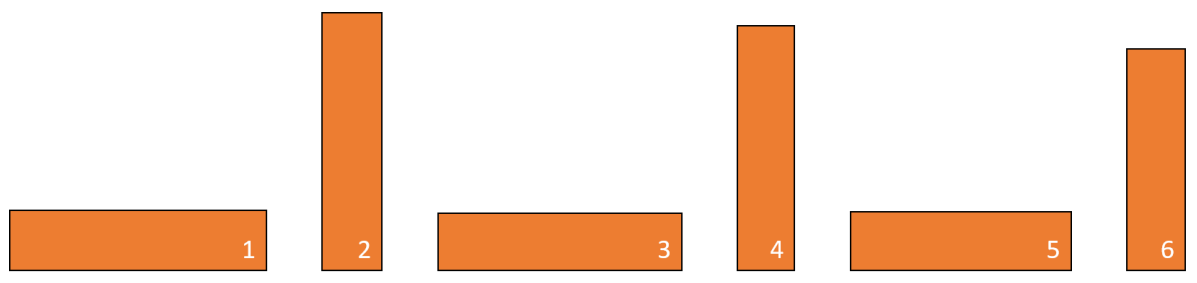

Figura 18 - Instância 6, Grupo 2
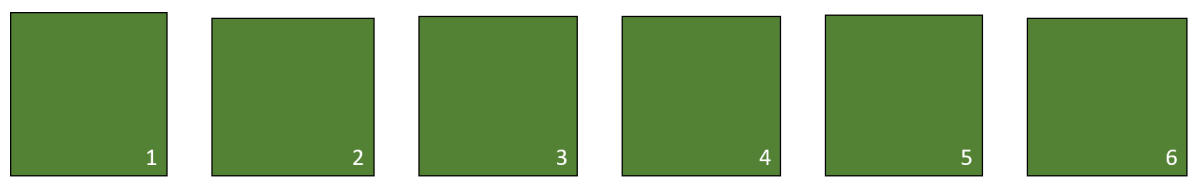

Figura 19 - Instância 11, Grupo 3 


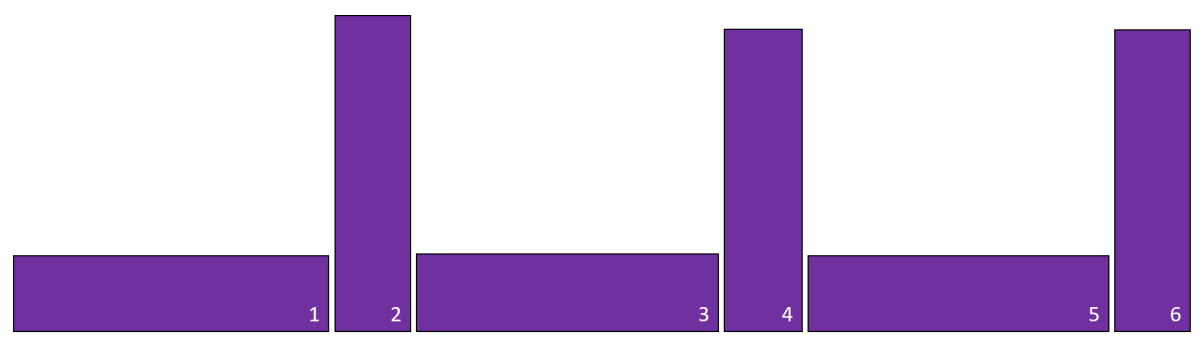

Figura 20 - Instância 16, Grupo 4

O código fonte da implementação do Gerador de Instâncias é apresentado detalhadamente no Apêndice A.

\subsection{Experimentos}

Com base nos modelos matemáticos e método de solução apresentados no Capítulo 4, bem como nas instâncias construídas com base nos conceitos apresentados anteriormente, são propostos quatro diferentes experimentos computacionais.

Tais experimentos envolvem uma combinação dos diferentes modelos matemáticos desenvolvidos (Modelo Matemático Base, onde não é aplicado o conceito de famílias de itens/lingadas, e Modelo Matemático Modificado, onde é aplicado o conceito de famílias de itens/lingadas) com e sem a aplicação do Método de Solução Iterativo (MIS), de acordo com a descrição a seguir:

a) Modelo Matemático Base, sem aplicação do MIS;

b) Modelo Matemático Modificado, sem aplicação do MIS;

c) Modelo Matemático Base, com aplicação do MIS;

d) Modelo Matemático Modificado, com aplicação do MIS.

Os experimentos computacionais propostos tem dois objetivos principais:

i) Determinar a efetividade do Modelo Matemático Modificado, avaliando se a redução teórica do espaço de soluções (variáveis binárias de decisão) se traduz em menor tempo computacional e/ou melhores soluções; e

ii) Determinar a efetividade do Método Iterativo de Solução, avaliando se a resolução de iterações com menor número de itens (e consequentemente menor número de variáveis) também se traduz em menor tempo computacional e/ou melhores soluções. 
Além disso, os experimentos buscam avaliar se, para cada um dos grupos de instâncias construídos, há uma combinação de modelo e método que seja mais favorável a obtenção de melhores soluções ou soluções equivalentes em menor tempo computacional.

Os experimentos apresentados foram executados com diferentes configurações de tempo computacional disponível para cada rodada ou iteração (no caso de experimentos com aplicação do MIS). No Capítulo 6, onde são apresentados os resultados, são detalhados os limites de tempos computacionais utilizados em casa um dos casos.

\subsection{Experimentos com Dados Reais}

Além dos experimentos conduzidos com as instâncias geradas (item 5.2), foram conduzidos 4 experimentos adicionais com dados reais.

Os dados dos porões dos navios de cada um dos experimentos são apresentados na Tabela 8 .

Tabela 8 - Dimensões, em metros, dos porões dos navios

\begin{tabular}{ccccccc}
\hline Instância Real & Navio & Porão & Camadas & $\mathrm{L}(\mathrm{m})$ & $\mathrm{W}(\mathrm{m})$ & Área $\left(\mathrm{m}_{2}\right)$ \\
\hline 1 & Corella Arrow & 1 & $4-8$ & 15,20 & 15,50 & 235,60 \\
2 & Delicata & 2 & $3-8$ & 18,40 & 28,20 & 518,88 \\
3 & Star Louisiana & 3 & $1-5$ & 26,40 & 16,94 & 739,20 \\
4 & Star Louisiana & 4 & $6-10$ & 12,80 & 19,44 & 358,40 \\
\hline
\end{tabular}

Para as instâncias reais 1, 3 e 4 foi considerada uma unidade de celulose com dimensões $l_{i}=0,82$ metros e $w_{i}=1,40$ metros. Para a instância 2 foi considerada unidade de celulose com dimensões $l_{i}=0,96$ metros e $w_{i}=1,38$ metros. À partir dessas unidades, a exemplo do apresentado no Capítulo 2, foram formadas as lingadas de celulose para carregamento de cada um dos porões.

As instâncias apresentadas foram resolvidas com aplicação simultânea do Modelo Matemático Modificado e Método Iterativo de Solução. No Capítulo 6 são apresentados os resultados obtidos para cada uma das instâncias reais descritas acima e a comparação com o plano de estivagem real. 


\section{Resultados}

Os experimentos apresentados no Capítulo 5 foram realizados em um computador com processador Intel Core i7-6500U @ $2.50 \mathrm{GHz}, 8 \mathrm{~Gb}$ de memória $R A M$ e sistema operacional Windows 10 (64 bits). Os modelos matemáticos e o Método Iterativo de Solução foram implementados no software ILOG CPLEX Optimization Studio 12.6, através da linguagem de programação OPL ( Optimization Programming Language). O CPLEX Solver foi utilizado na resolução dos modelos matemáticos.

A avaliação dos resultados dos experimentos é realizada com base em dois indicadores principais, a Ocupação do Objeto e o Tempo Computacional. A Ocupação do Objeto indica, percentualmente, a área total ocupada pelos itens alocados ao objeto, sempre em relação a área total do próprio objeto. Já o Tempo Computacional indica o tempo total, em segundos, necessário para obtenção do resultado apresentado.

A seguir são apresentados os resultados detalhados para cada um dos quatro experimentos realizados.

\subsection{Detalhamento dos Resultados}

\subsubsection{Experimento 1 - Modelo Matemático Base, sem MIS}

A Tabela 9 apresenta o detalhamento dos resultados do experimento 1, realizado com tempo computacional limite de 600 segundos para cada uma das instâncias. 
Tabela 9 - Detalhamento dos resultados do experimento 1

\begin{tabular}{cccccccc}
\hline Grupo & Instância & Iteração & Objetivo & Ocupação & Tempo & Controle Exaustão & Controle Folga \\
\hline 1 & 1 & 1 & 208,95 & $96,74 \%$ & 600 & 1 & 4 \\
1 & 2 & 1 & 206,96 & $95,81 \%$ & 600 & 1 & 3 \\
1 & 3 & 1 & 180,41 & $83,52 \%$ & 600 & 1 & 2 \\
1 & 4 & 1 & 196,51 & $90,98 \%$ & 600 & 1 & 2 \\
1 & 5 & 1 & 180,34 & $83,49 \%$ & 600 & 1 & 3 \\
\hline 2 & 6 & 1 & 198,62 & $91,95 \%$ & 600 & 1 & 5 \\
2 & 7 & 1 & 195,30 & $90,42 \%$ & 600 & 1 & 4 \\
2 & 8 & 1 & 180,77 & $83,69 \%$ & 600 & 1 & 5 \\
2 & 9 & 1 & 195,57 & $90,54 \%$ & 600 & 1 & 5 \\
2 & 10 & 1 & 196,00 & $90,74 \%$ & 600 & 1 & 5 \\
3 & 11 & 1 & 144,58 & $66,94 \%$ & 600 & 1 & 6 \\
3 & 12 & 1 & 150,79 & $69,81 \%$ & 600 & 1 & 6 \\
3 & 13 & 1 & 160,85 & $74,47 \%$ & 600 & 1 & 5 \\
3 & 14 & 1 & 155,37 & $71,93 \%$ & 600 & 1 & 5 \\
3 & 15 & 1 & 157,32 & $72,83 \%$ & 600 & 1 & 5 \\
\hline 4 & 16 & 1 & 194,32 & $89,96 \%$ & 600 & 1 & 5 \\
4 & 17 & 1 & 200,01 & $92,60 \%$ & 600 & 1 & \\
4 & 18 & 1 & 191,18 & $88,51 \%$ & 600 & 1 & 5 \\
4 & 19 & 1 & 189,25 & $87,61 \%$ & 600 & 1 & \\
4 & 20 & 1 & 192,81 & $89,27 \%$ & 600 & 1 & \\
\hline
\end{tabular}

\subsubsection{Experimento 2 - Modelo Matemático Modificado, sem MIS}

A Tabela 10 apresenta o detalhamento dos resultados do experimento 2, realizado com tempo computacional limite de 600 segundos para cada uma das instâncias.

Tabela 10 - Detalhamento dos resultados do experimento 2

\begin{tabular}{cccccccc}
\hline Grupo & Instância & Iteração & Objetivo & Ocupação & Tempo & Controle Exaustão & Controle Folga \\
\hline 1 & 1 & 1 & 209,98 & $97,21 \%$ & 600 & 1 & 4 \\
1 & 2 & 1 & 203,56 & $94,24 \%$ & 600 & 1 & 4 \\
1 & 3 & 1 & 180,41 & $83,52 \%$ & 600 & 1 & 2 \\
1 & 4 & 1 & 196,51 & $90,98 \%$ & 600 & 1 & 2 \\
1 & 5 & 1 & 180,42 & $83,53 \%$ & 600 & 1 & 2 \\
\hline 2 & 6 & 1 & 205,42 & $95,10 \%$ & 600 & 1 & 3 \\
2 & 7 & 1 & 203,86 & $94,38 \%$ & 600 & 1 & 4 \\
2 & 8 & 1 & 189,15 & $87,57 \%$ & 600 & 1 & 4 \\
2 & 9 & 1 & 201,99 & $93,51 \%$ & 600 & 1 & 5 \\
2 & 10 & 1 & 198,07 & $91,70 \%$ & 600 & 1 & 5 \\
3 & 11 & 1 & 144,58 & $66,94 \%$ & 600 & 1 & 5 \\
3 & 12 & 1 & 150,79 & $69,81 \%$ & 600 & 1 & 6 \\
3 & 13 & 1 & 160,85 & $74,47 \%$ & 600 & 1 & 5 \\
3 & 14 & 1 & 155,37 & $71,93 \%$ & 600 & 1 & 5 \\
3 & 15 & 1 & 157,32 & $72,83 \%$ & 600 & 1 & 6 \\
\hline 4 & 16 & 1 & 194,32 & $89,96 \%$ & 600 & 1 & 5 \\
4 & 17 & 1 & 198,86 & $92,07 \%$ & 600 & 1 & \\
4 & 18 & 1 & 192,03 & $88,90 \%$ & 600 & 1 & 1 \\
4 & 19 & 1 & 188,95 & $87,48 \%$ & 600 & 1 & 5 \\
4 & 20 & 1 & 192,81 & $89,27 \%$ & 600 & 1 & \\
\hline
\end{tabular}




\subsubsection{Experimento 3 - Modelo Matemático Base, com MIS}

A Tabela 11 apresenta o detalhamento dos resultados do experimento 3, executados com tempo computacional limite de 30 segundos para iterações normais e 90 segundos para iterações com folga em todas famílias de itens.

Tabela 11 - Detalhamento dos resultados do experimento 3

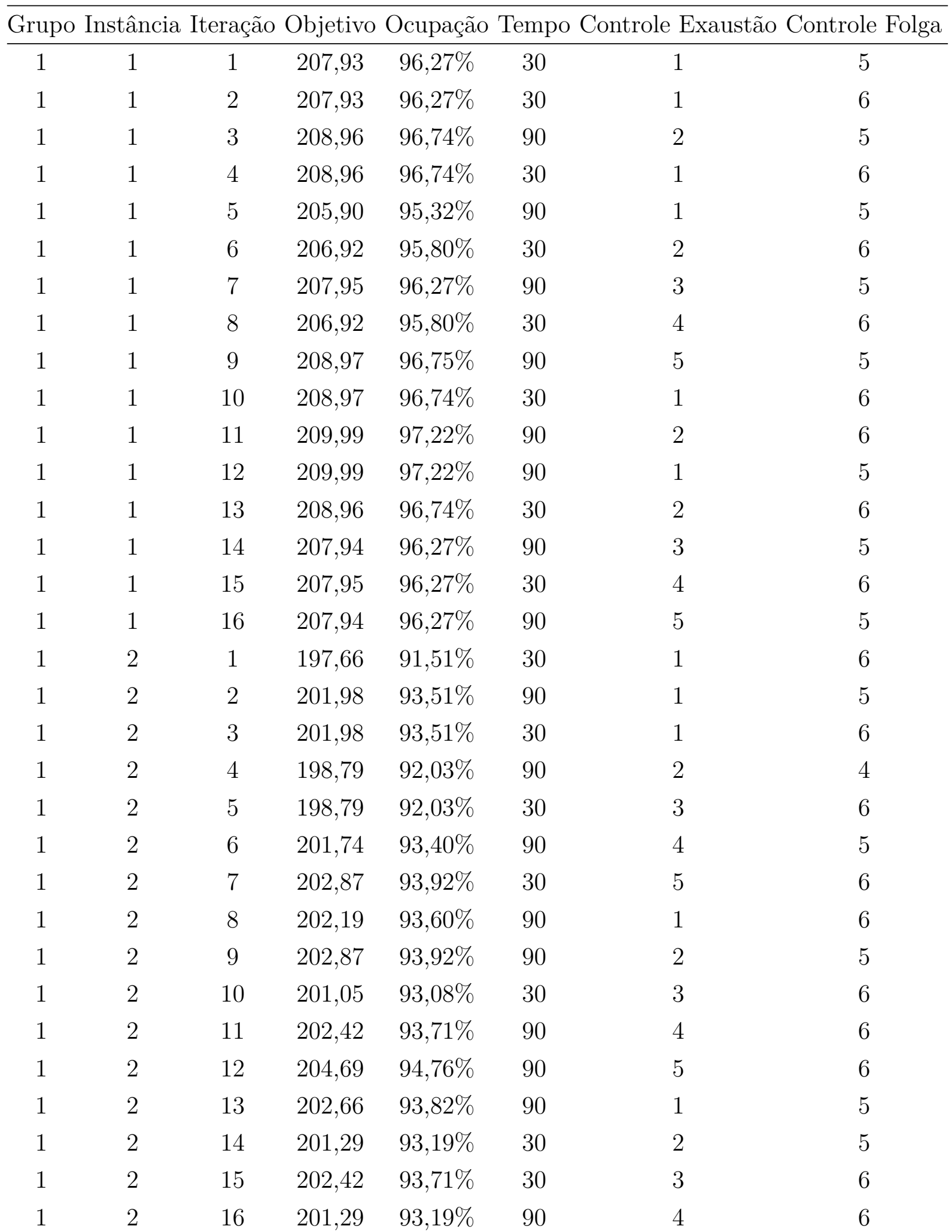


Tabela 11 - Detalhamento dos resultados do experimento 3

\begin{tabular}{|c|c|c|c|c|c|c|c|}
\hline Grupo & Instância & Iteração & Objetivo & Ocupação & Tempo & Controle Exaustão & Controle Folga \\
\hline 1 & 2 & 17 & 202,42 & $93,71 \%$ & 90 & 5 & 6 \\
\hline 1 & 3 & 1 & 179,92 & $83,30 \%$ & 30 & 1 & 3 \\
\hline 1 & 3 & 2 & 181,42 & $83,99 \%$ & 30 & 1 & 4 \\
\hline 1 & 3 & 3 & 182,61 & $84,54 \%$ & 30 & 1 & 5 \\
\hline 1 & 3 & 4 & 182,99 & $84,72 \%$ & 30 & 1 & 5 \\
\hline 1 & 3 & 5 & 183,87 & $85,12 \%$ & 30 & 1 & 5 \\
\hline 1 & 3 & 6 & 183,87 & $85,12 \%$ & 30 & 1 & 5 \\
\hline 1 & 3 & 7 & 183,31 & $84,87 \%$ & 30 & 2 & 5 \\
\hline 1 & 3 & 8 & 183,24 & $84,83 \%$ & 30 & 3 & 5 \\
\hline 1 & 3 & 9 & 183,24 & $84,83 \%$ & 30 & 4 & 5 \\
\hline 1 & 3 & 10 & 183,31 & $84,87 \%$ & 30 & 5 & 5 \\
\hline 1 & 4 & 1 & 195,41 & $90,47 \%$ & 30 & 1 & 3 \\
\hline 1 & 4 & 2 & 197,38 & $91,38 \%$ & 30 & 1 & 5 \\
\hline 1 & 4 & 3 & 198,59 & $91,94 \%$ & 30 & 1 & 5 \\
\hline 1 & 4 & 4 & 199,24 & $92,24 \%$ & 30 & 1 & 6 \\
\hline 1 & 4 & 5 & 202,41 & $93,71 \%$ & 90 & 1 & 4 \\
\hline 1 & 4 & 6 & 203,07 & $94,01 \%$ & 30 & 1 & 5 \\
\hline 1 & 4 & 7 & 203,07 & $94,01 \%$ & 30 & 1 & 5 \\
\hline 1 & 4 & 8 & 203,07 & $94,01 \%$ & 30 & 2 & 5 \\
\hline 1 & 4 & 9 & 203,73 & $94,32 \%$ & 30 & 3 & 5 \\
\hline 1 & 4 & 10 & 203,73 & $94,32 \%$ & 30 & 1 & 5 \\
\hline 1 & 4 & 11 & 202,52 & $93,76 \%$ & 30 & 2 & 5 \\
\hline 1 & 4 & 12 & 204,38 & $94,62 \%$ & 30 & 3 & 5 \\
\hline 1 & 4 & 13 & 203,73 & $94,32 \%$ & 30 & 1 & 4 \\
\hline 1 & 4 & 14 & 203,07 & $94,01 \%$ & 30 & 2 & 4 \\
\hline 1 & 4 & 15 & 202,41 & $93,71 \%$ & 30 & 3 & 5 \\
\hline 1 & 4 & 16 & 202,52 & $93,76 \%$ & 30 & 4 & 5 \\
\hline 1 & 4 & 17 & 202,52 & $93,76 \%$ & 30 & 5 & 5 \\
\hline 1 & 5 & 1 & 180,27 & $83,46 \%$ & 30 & 1 & 3 \\
\hline 1 & 5 & 2 & 186,69 & $86,43 \%$ & 30 & 1 & 4 \\
\hline 1 & 5 & 3 & 189,90 & $87,92 \%$ & 30 & 1 & 6 \\
\hline 1 & 5 & 4 & 194,79 & $90,18 \%$ & 90 & 1 & 5 \\
\hline 1 & 5 & 5 & 196,40 & $90,92 \%$ & 30 & 1 & 6 \\
\hline 1 & 5 & 6 & 198,08 & $91,70 \%$ & 90 & 1 & 4 \\
\hline 1 & 5 & 7 & 199,68 & $92,44 \%$ & 30 & 1 & 4 \\
\hline 1 & 5 & 8 & 198,08 & $91,70 \%$ & 30 & 1 & 4 \\
\hline 1 & 5 & 9 & 199,68 & $92,44 \%$ & 30 & 2 & 4 \\
\hline
\end{tabular}


Tabela 11 - Detalhamento dos resultados do experimento 3

\begin{tabular}{|c|c|c|c|c|c|c|c|}
\hline Grupo & Instância & Iteração & Objetivo & Ocupação & Tempo C & Controle Exaustão & Controle Folga \\
\hline 1 & 5 & 10 & 196,47 & $90,96 \%$ & 30 & 3 & 4 \\
\hline 1 & 5 & 11 & 198,08 & $91,70 \%$ & 30 & 4 & 5 \\
\hline 1 & 5 & 12 & 196,40 & $90,92 \%$ & 30 & 5 & 5 \\
\hline 2 & 6 & 1 & 187,64 & $86,87 \%$ & 30 & 1 & 6 \\
\hline 2 & 6 & 2 & 198,62 & $91,95 \%$ & 90 & 1 & 5 \\
\hline 2 & 6 & 3 & 202,72 & $93,85 \%$ & 30 & 1 & 5 \\
\hline 2 & 6 & 4 & 187,36 & $86,74 \%$ & 30 & 1 & 4 \\
\hline 2 & 6 & 5 & 195,85 & $90,67 \%$ & 30 & 2 & 5 \\
\hline 2 & 6 & 6 & 189,25 & $87,62 \%$ & 30 & 3 & 4 \\
\hline 2 & 6 & 7 & 198,54 & $91,92 \%$ & 30 & 4 & 4 \\
\hline 2 & 6 & 8 & 193,92 & $89,78 \%$ & 30 & 5 & 6 \\
\hline 2 & 7 & 1 & 192,86 & $89,29 \%$ & 30 & 1 & 6 \\
\hline 2 & 7 & 2 & 192,82 & $89,27 \%$ & 90 & 1 & 5 \\
\hline 2 & 7 & 3 & 192,86 & $89,29 \%$ & 30 & 2 & 6 \\
\hline 2 & 7 & 4 & 185,57 & $85,91 \%$ & 90 & 1 & 6 \\
\hline 2 & 7 & 5 & 195,37 & $90,45 \%$ & 90 & 2 & 5 \\
\hline 2 & 7 & 6 & 194,77 & $90,17 \%$ & 30 & 1 & 5 \\
\hline 2 & 7 & 7 & 195,41 & $90,47 \%$ & 30 & 2 & 5 \\
\hline 2 & 7 & 8 & 186,25 & $86,23 \%$ & 30 & 1 & 6 \\
\hline 2 & 7 & 9 & 204,54 & $94,70 \%$ & 90 & 2 & 4 \\
\hline 2 & 7 & 10 & 185,01 & $85,65 \%$ & 30 & 1 & 6 \\
\hline 2 & 7 & 11 & 194,19 & $89,90 \%$ & 90 & 2 & 6 \\
\hline 2 & 7 & 12 & 187,46 & $86,78 \%$ & 90 & 3 & 4 \\
\hline 2 & 7 & 13 & 186,88 & $86,52 \%$ & 30 & 4 & 6 \\
\hline 2 & 7 & 14 & 196,65 & $91,04 \%$ & 90 & 5 & 4 \\
\hline 2 & 8 & 1 & 170,12 & $78,76 \%$ & 30 & 1 & 5 \\
\hline 2 & 8 & 2 & 177,96 & $82,39 \%$ & 30 & 1 & 6 \\
\hline 2 & 8 & 3 & 190,63 & $88,25 \%$ & 90 & 1 & 5 \\
\hline 2 & 8 & 4 & 172,38 & $79,81 \%$ & 30 & 1 & 6 \\
\hline 2 & 8 & 5 & 179,65 & $83,17 \%$ & 90 & 2 & 6 \\
\hline 2 & 8 & 6 & 192,32 & $89,04 \%$ & 90 & 3 & 5 \\
\hline 2 & 8 & 7 & 171,60 & $79,44 \%$ & 30 & 1 & 6 \\
\hline 2 & 8 & 8 & 190,18 & $88,04 \%$ & 90 & 2 & 6 \\
\hline 2 & 8 & 9 & 179,65 & $83,17 \%$ & 90 & 3 & 6 \\
\hline 2 & 8 & 10 & 191,08 & $88,46 \%$ & 90 & 4 & 6 \\
\hline 2 & 8 & 11 & 193,22 & $89,45 \%$ & 90 & 5 & 5 \\
\hline 2 & 8 & 12 & 179,20 & $82,96 \%$ & 30 & 1 & 5 \\
\hline
\end{tabular}


Tabela 11 - Detalhamento dos resultados do experimento 3

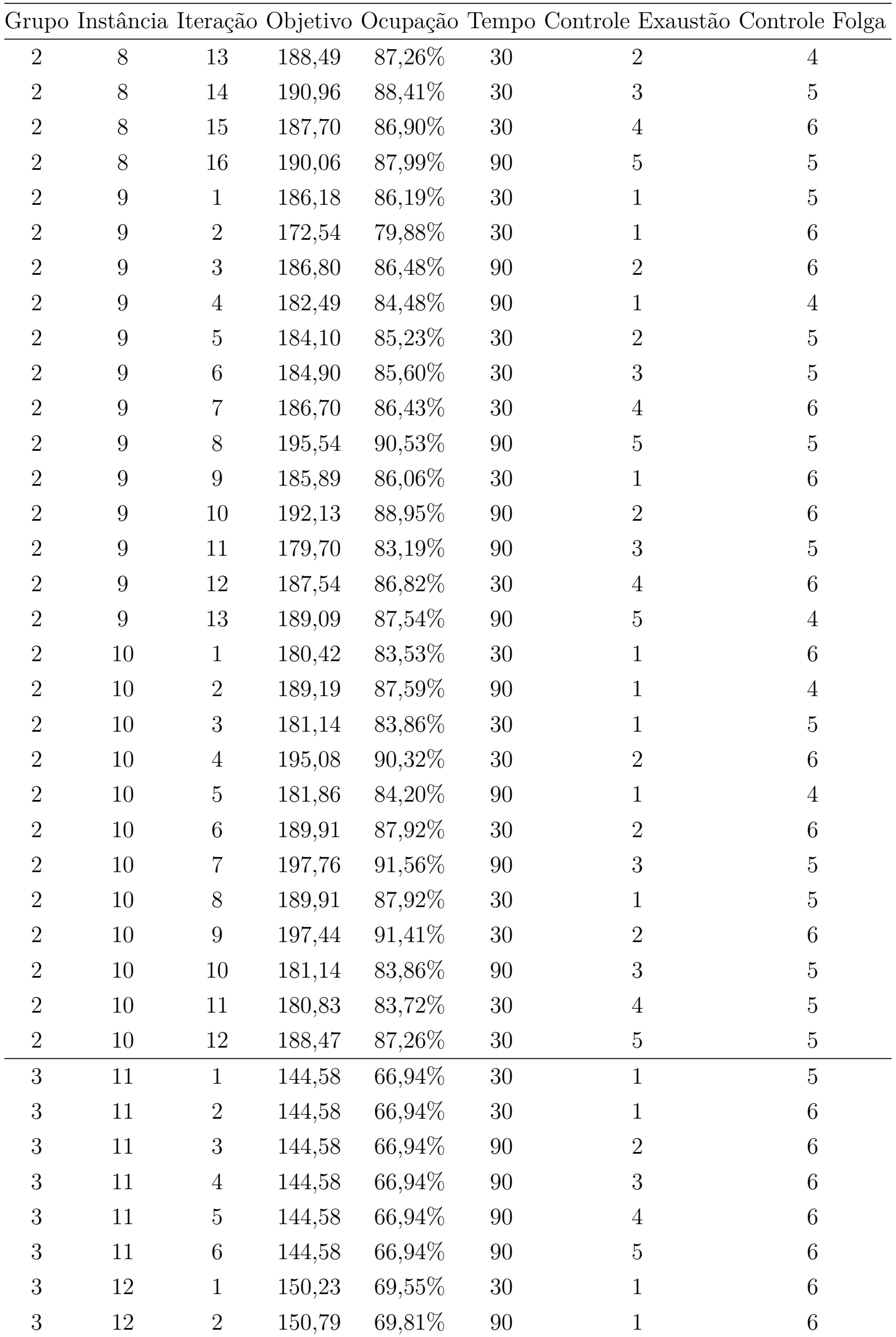


Tabela 11 - Detalhamento dos resultados do experimento 3

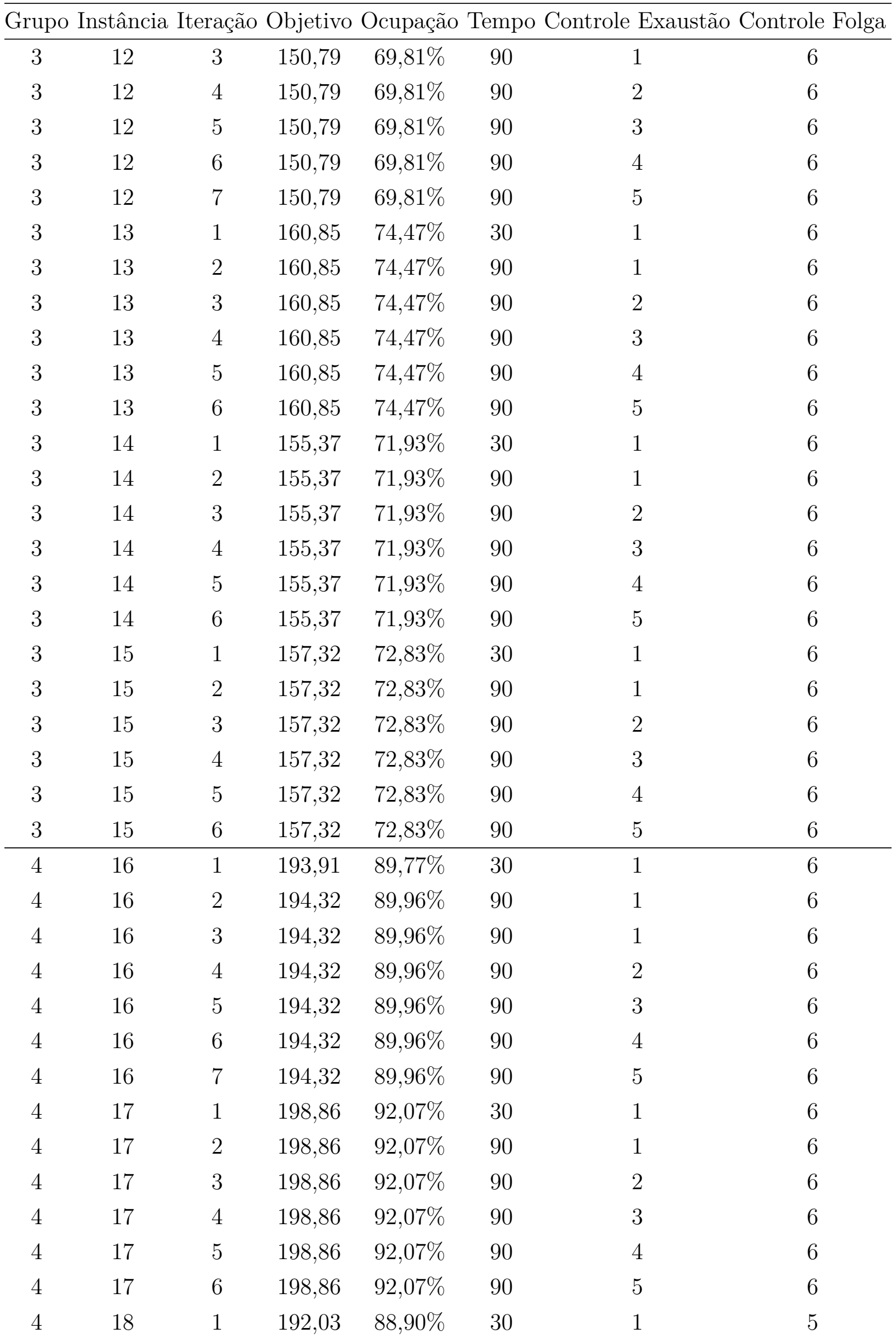


Tabela 11 - Detalhamento dos resultados do experimento 3

\begin{tabular}{|c|c|c|c|c|c|c|c|}
\hline Grupo & Instância & Iteração & Objetivo & Ocupação & Tempo & Controle Exaustão & Controle Folga \\
\hline 4 & 18 & 2 & 191,18 & $88,51 \%$ & 30 & 1 & 6 \\
\hline 4 & 18 & 3 & 192,03 & $88,90 \%$ & 90 & 2 & 6 \\
\hline 4 & 18 & 4 & 192,03 & $88,90 \%$ & 90 & 3 & 6 \\
\hline 4 & 18 & 5 & 192,03 & $88,90 \%$ & 90 & 4 & 6 \\
\hline 4 & 18 & 6 & 192,03 & $88,90 \%$ & 90 & 5 & 6 \\
\hline 4 & 19 & 1 & 188,95 & $87,48 \%$ & 30 & 1 & 5 \\
\hline 4 & 19 & 2 & 188,95 & $87,48 \%$ & 30 & 1 & 6 \\
\hline 4 & 19 & 3 & 189,25 & $87,61 \%$ & 90 & 2 & 6 \\
\hline 4 & 19 & 4 & 189,25 & $87,61 \%$ & 90 & 1 & 6 \\
\hline 4 & 19 & 5 & 189,25 & $87,61 \%$ & 90 & 2 & 6 \\
\hline 4 & 19 & 6 & 189,25 & $87,61 \%$ & 90 & 3 & 6 \\
\hline 4 & 19 & 7 & 189,25 & $87,61 \%$ & 90 & 4 & 6 \\
\hline 4 & 19 & 8 & 189,25 & $87,61 \%$ & 90 & 5 & 6 \\
\hline 4 & 20 & 1 & 192,28 & $89,02 \%$ & 30 & 1 & 6 \\
\hline 4 & 20 & 2 & 192,81 & $89,27 \%$ & 90 & 1 & 6 \\
\hline 4 & 20 & 3 & 192,81 & $89,27 \%$ & 90 & 1 & 6 \\
\hline 4 & 20 & 4 & 192,81 & $89,27 \%$ & 90 & 2 & 6 \\
\hline 4 & 20 & 5 & 192,81 & $89,27 \%$ & 90 & 3 & 6 \\
\hline 4 & 20 & 6 & 192,81 & $89,27 \%$ & 90 & 4 & 6 \\
\hline 4 & 20 & 7 & 192,81 & $89,27 \%$ & 90 & 5 & 6 \\
\hline
\end{tabular}

\subsubsection{Experimento 4 - Modelo Matemático Modificado, com MIS}

A Tabela 12 apresenta o detalhamento dos resultados do experimento 4, executados com tempo computacional limite de 30 segundos para iterações normais e 90 segundos para iterações com folga em todas famílias de itens.

Tabela 12 - Detalhamento dos resultados do experimento 4

\begin{tabular}{|c|c|c|c|c|c|c|c|}
\hline Grupo & Instância & Iteração & Objetivo & Ocupação & Tempo & Controle Exaustão & Controle Folga \\
\hline 1 & 1 & 1 & 209,98 & $97,21 \%$ & 30 & 1 & 4 \\
\hline 1 & 1 & 2 & 207,94 & $96,27 \%$ & 30 & 1 & 6 \\
\hline 1 & 1 & 3 & 208,96 & $96,74 \%$ & 90 & 2 & 5 \\
\hline 1 & 1 & 4 & 208,97 & $96,75 \%$ & 30 & 3 & 5 \\
\hline 1 & 1 & 5 & 206,92 & $95,79 \%$ & 30 & 4 & 4 \\
\hline 1 & 1 & 6 & 208,96 & $96,74 \%$ & 30 & 5 & 6 \\
\hline 1 & 2 & 1 & 203,56 & $94,24 \%$ & 30 & 1 & 4 \\
\hline 1 & 2 & 2 & 197,73 & $91,54 \%$ & 30 & 1 & 5 \\
\hline
\end{tabular}


Tabela 12 - Detalhamento dos resultados do experimento 4

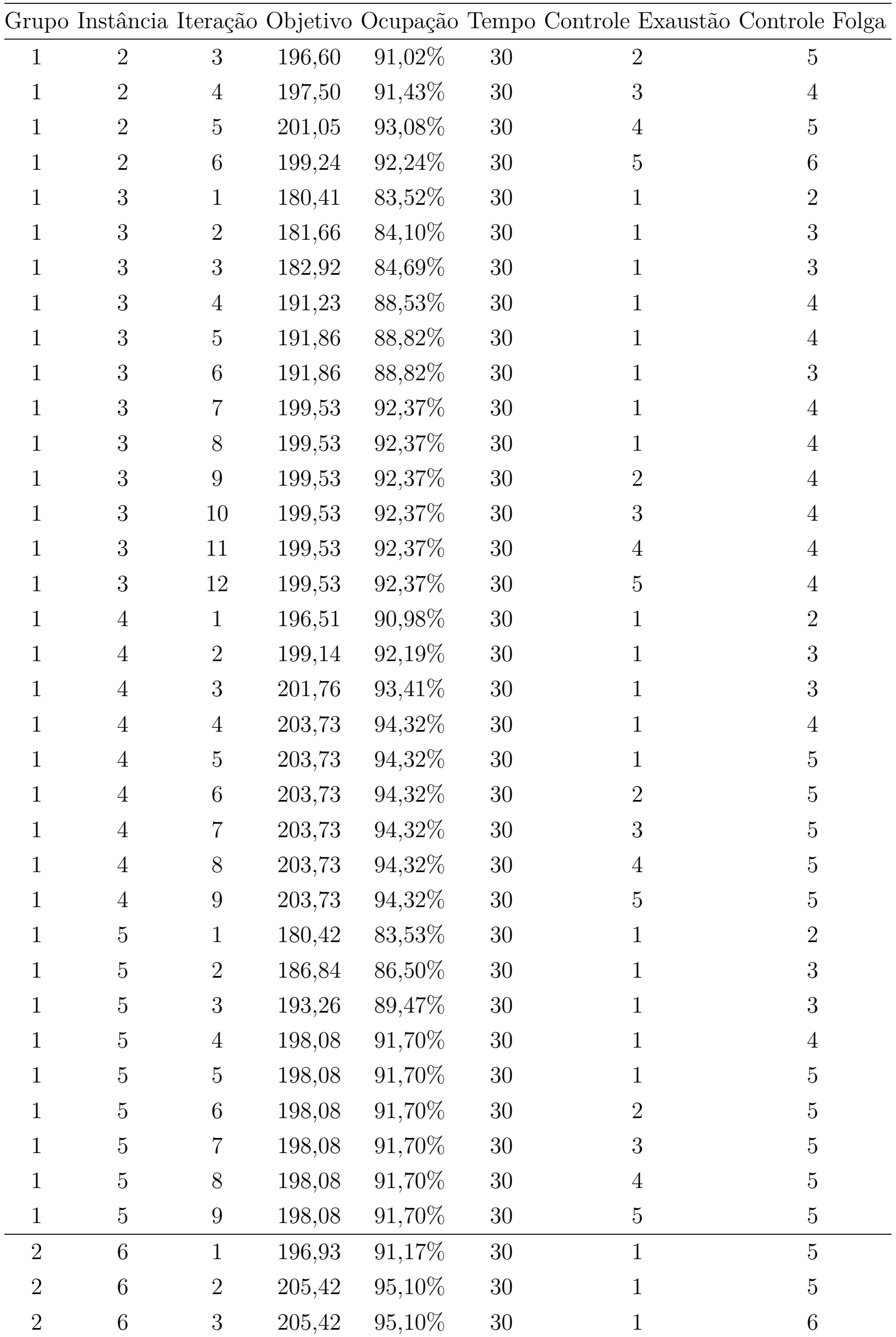


Tabela 12 - Detalhamento dos resultados do experimento 4

\begin{tabular}{|c|c|c|c|c|c|c|c|}
\hline Grupo & Instância & Iteração & Objetivo & Ocupação & Tempo Cont & le Exaustão & Controle Folga \\
\hline 2 & 6 & 4 & 205,42 & $95,10 \%$ & 90 & 2 & 6 \\
\hline 2 & 6 & 5 & 205,42 & $95,10 \%$ & 90 & 3 & 6 \\
\hline 2 & 6 & 6 & 205,42 & $95,10 \%$ & 90 & 4 & 6 \\
\hline 2 & 6 & 7 & 205,42 & $95,10 \%$ & 90 & 5 & 6 \\
\hline 2 & 7 & 1 & 203,86 & $94,38 \%$ & 30 & 1 & 3 \\
\hline 2 & 7 & 2 & 202,64 & $93,81 \%$ & 30 & 1 & 5 \\
\hline 2 & 7 & 3 & 202,64 & $93,81 \%$ & 30 & 2 & 6 \\
\hline 2 & 7 & 4 & 204,50 & $94,68 \%$ & 90 & 3 & 5 \\
\hline 2 & 7 & 5 & 203,90 & $94,40 \%$ & 30 & 1 & 4 \\
\hline 2 & 7 & 6 & 205,14 & $94,97 \%$ & 30 & 2 & 4 \\
\hline 2 & 7 & 7 & 202,14 & $93,58 \%$ & 30 & 1 & 5 \\
\hline 2 & 7 & 8 & 203,90 & $94,40 \%$ & 30 & 2 & 5 \\
\hline 2 & 7 & 9 & 205,14 & $94,97 \%$ & 30 & 3 & 4 \\
\hline 2 & 7 & 10 & 202,14 & $93,58 \%$ & 30 & 4 & 5 \\
\hline 2 & 7 & 11 & 203,90 & $94,40 \%$ & 30 & 5 & 5 \\
\hline 2 & 8 & 1 & 186,01 & $86,12 \%$ & 30 & 1 & 5 \\
\hline 2 & 8 & 2 & 179,86 & $83,27 \%$ & 30 & 1 & 5 \\
\hline 2 & 8 & 3 & 188,15 & $87,11 \%$ & 30 & 2 & 5 \\
\hline 2 & 8 & 4 & 188,15 & $87,11 \%$ & 30 & 1 & 6 \\
\hline 2 & 8 & 5 & 188,61 & $87,32 \%$ & 90 & 2 & 6 \\
\hline 2 & 8 & 6 & 180,32 & $83,48 \%$ & 90 & 1 & 6 \\
\hline 2 & 8 & 7 & 189,15 & $87,57 \%$ & 90 & 2 & 5 \\
\hline 2 & 8 & 8 & 179,95 & $83,31 \%$ & 30 & 1 & 5 \\
\hline 2 & 8 & 9 & 176,94 & $81,92 \%$ & 30 & 2 & 6 \\
\hline 2 & 8 & 10 & 188,37 & $87,21 \%$ & 90 & 3 & 5 \\
\hline 2 & 8 & 11 & 188,82 & $87,42 \%$ & 30 & 4 & 6 \\
\hline 2 & 8 & 12 & 189,15 & $87,57 \%$ & 90 & 5 & 5 \\
\hline 2 & 9 & 1 & 195,57 & $90,54 \%$ & 30 & 1 & 4 \\
\hline 2 & 9 & 2 & 199,91 & $92,55 \%$ & 30 & 1 & 3 \\
\hline 2 & 9 & 3 & 193,49 & $89,58 \%$ & 30 & 1 & 5 \\
\hline 2 & 9 & 4 & 201,52 & $93,30 \%$ & 30 & 2 & 5 \\
\hline 2 & 9 & 5 & 195,91 & $90,70 \%$ & 30 & 1 & 4 \\
\hline 2 & 9 & 6 & 200,78 & $92,95 \%$ & 30 & 2 & 4 \\
\hline 2 & 9 & 7 & 201,95 & $93,50 \%$ & 30 & 3 & 5 \\
\hline 2 & 9 & 8 & 201,77 & $93,41 \%$ & 30 & 1 & 5 \\
\hline 2 & 9 & 9 & 196,71 & $91,07 \%$ & 30 & 2 & 4 \\
\hline 2 & 9 & 10 & 201,95 & $93,50 \%$ & 30 & 3 & 4 \\
\hline
\end{tabular}


Tabela 12 - Detalhamento dos resultados do experimento 4

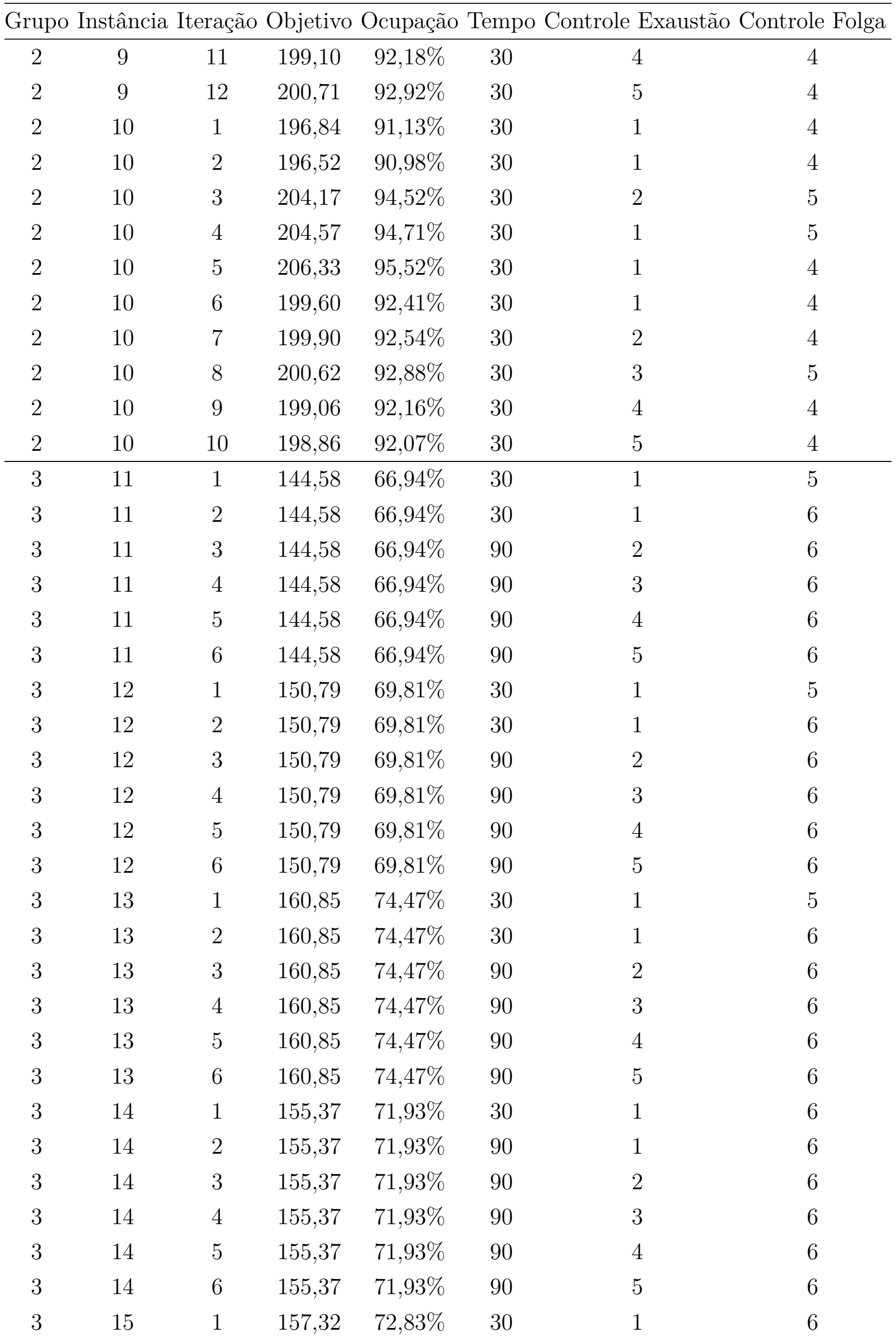


Tabela 12 - Detalhamento dos resultados do experimento 4

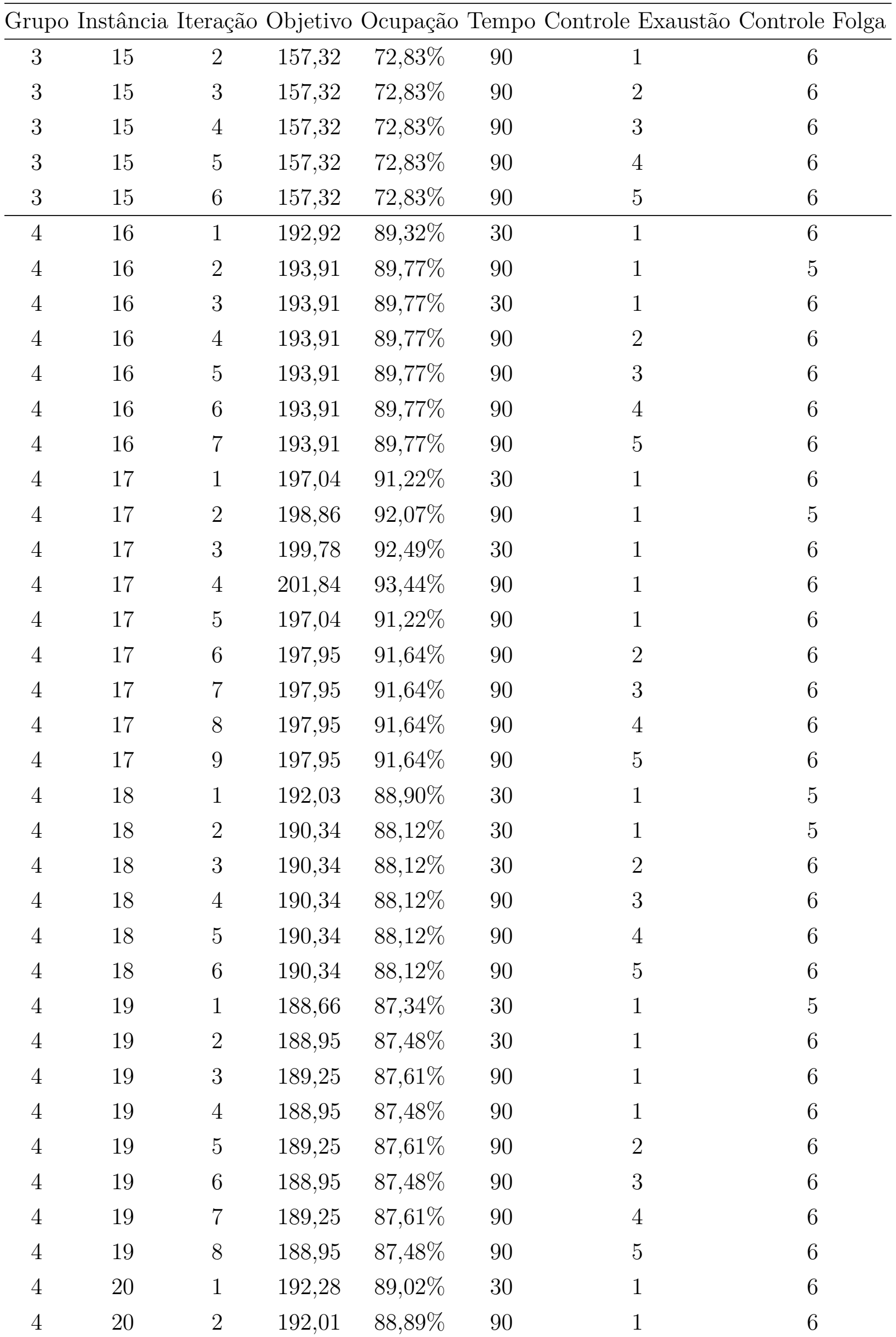


Tabela 12 - Detalhamento dos resultados do experimento 4

\begin{tabular}{cccccccc}
\hline \multicolumn{7}{c}{ Grupo Instância Iteração Objetivo } & Ocupação Tempo Controle Exaustão Controle Folga \\
\hline 4 & 20 & 3 & 192,55 & $89,14 \%$ & 90 & 2 & 6 \\
4 & 20 & 4 & 192,81 & $89,27 \%$ & 90 & 1 & 6 \\
4 & 20 & 5 & 192,28 & $89,02 \%$ & 90 & 1 & 6 \\
4 & 20 & 6 & 192,01 & $88,89 \%$ & 90 & 2 & 6 \\
4 & 20 & 7 & 192,55 & $89,14 \%$ & 90 & 3 & 6 \\
4 & 20 & 8 & 192,81 & $89,27 \%$ & 90 & 4 & 6 \\
4 & 20 & 9 & 192,28 & $89,02 \%$ & 90 & 5 & 6 \\
\hline
\end{tabular}

\subsection{Sumário dos Resultados}

A Tabela 13 apresenta o sumário dos resultados obtidos para os quatro experimentos realizados para cada uma das 20 instâncias experimentais, em termos de Ocupação do Objeto. A Ocupação do Objeto é apresentada percentualmente, sendo a área do objeto a mesma para todas as instâncias e iterações $\left(216 \mathrm{~m}^{2}\right)$.

Na Tabela 13 os resultados obtidos à partir da aplicação do Modelo Matemático Base são identificados pela sigla MMB. Já os resultados obtidos pela aplicação do Modelo Matemático Modificado são identificados pela sigla MMM. Como já descrito, ambos os modelos foram testados com e sem a aplicação do Método Iterativo de Solução (MIS).

Tabela 13 - Sumário dos resultados experimentais - Ocupação do Objeto

\begin{tabular}{cccccc}
\hline \multirow{2}{*}{ Grupo } & \multirow{2}{*}{ Instância } & \multicolumn{2}{c}{ Sem MIS } & \multicolumn{2}{c}{ Com MIS } \\
\cline { 2 - 5 } & & MMB & MMM & MMB & MMM \\
\hline 1 & 1 & $96,74 \%$ & $97,21 \%$ & $\mathbf{9 7 , 2 2} \%$ & $97,21 \%$ \\
1 & 2 & $\mathbf{9 5 , 8 1} \%$ & $94,24 \%$ & $94,76 \%$ & $94,24 \%$ \\
1 & 3 & $83,52 \%$ & $83,52 \%$ & $85,12 \%$ & $\mathbf{9 2 , 3 7} \%$ \\
1 & 4 & $90,98 \%$ & $90,98 \%$ & $\mathbf{9 4 , 6 2} \%$ & $94,32 \%$ \\
1 & 5 & $83,49 \%$ & $83,53 \%$ & $\mathbf{9 2 , 4 4} \%$ & $91,70 \%$ \\
\hline 2 & 6 & $91,95 \%$ & $\mathbf{9 5 , 1 0} \%$ & $93,85 \%$ & $\mathbf{9 5 , 1 0} \%$ \\
2 & 7 & $90,42 \%$ & $94,38 \%$ & $94,70 \%$ & $\mathbf{9 4 , 9 7} \%$ \\
2 & 8 & $83,69 \%$ & $87,57 \%$ & $\mathbf{8 9 , 4 5} \%$ & $87,57 \%$ \\
2 & 9 & $90,54 \%$ & $\mathbf{9 3 , 5 1} \%$ & $90,53 \%$ & $93,50 \%$ \\
2 & 10 & $90,74 \%$ & $91,70 \%$ & $91,56 \%$ & $\mathbf{9 5 , 5 2} \%$ \\
\hline 3 & 11 & $\mathbf{6 6 , 9 4} \%$ & $\mathbf{6 6 , 9 4} \%$ & $\mathbf{6 6 , 9 4} \%$ & $\mathbf{6 6 , 9 4} \%$ \\
3 & 12 & $\mathbf{6 9 , 8 1} \%$ & $\mathbf{6 9 , 8 1} \%$ & $\mathbf{6 9 , 8 1} \%$ & $\mathbf{6 9 , 8 1} \%$ \\
3 & 13 & $\mathbf{7 4 , 4 7} \%$ & $\mathbf{7 4 , 4 7} \%$ & $\mathbf{7 4 , 4 7} \%$ & $\mathbf{7 4 , 4 7} \%$ \\
3 & 14 & $\mathbf{7 1 , 9 3} \%$ & $\mathbf{7 1 , 9 3} \%$ & $\mathbf{7 1 , 9 3} \%$ & $\mathbf{7 1 , 9 3} \%$ \\
3 & 15 & $\mathbf{7 2 , 8 3} \%$ & $\mathbf{7 2 , 8 3} \%$ & $\mathbf{7 2 , 8 3} \%$ & $\mathbf{7 2 , 8 3} \%$ \\
\hline 4 & 16 & $\mathbf{8 9 , 9 6} \%$ & $\mathbf{8 9 , 9 6} \%$ & $\mathbf{8 9 , 9 6} \%$ & $\mathbf{8 9 , 7 7} \%$ \\
4 & 17 & $92,60 \%$ & $92,07 \%$ & $92,07 \%$ & $\mathbf{9 3 , 4 4} \%$ \\
4 & 18 & $88,51 \%$ & $\mathbf{8 8 , 9 0} \%$ & $\mathbf{8 8 , 9 0} \%$ & $\mathbf{8 8 , 9 0} \%$ \\
4 & 19 & $\mathbf{8 7 , 6 1} \%$ & $87,48 \%$ & $\mathbf{8 7 , 6 1} \%$ & $\mathbf{8 7 , 6 1} \%$ \\
4 & 20 & $\mathbf{8 9 , 2 7} \%$ & $\mathbf{8 9 , 2 7} \%$ & $\mathbf{8 9 , 2 7} \%$ & $\mathbf{8 9 , 2 7} \%$ \\
\hline
\end{tabular}


A Tabela 14 apresenta o sumário dos resultados experimentais em termos de Tempo Computacional. Os resultados são apresentados em segundos. No caso dos resultados obtidos com aplicação do Método Iterativo de Solução (MIS) é indicado o Tempo Computacional total, ou seja, incluindo os tempos de todas as iterações processadas. O melhor resultado obtido para cada instância (menor Tempo Computacional) é apresentado em destaque.

Na Tabela 14 os resultados obtidos à partir da aplicação do Modelo Matemático Base são identificados pela sigla MMB. Já os resultados obtidos pela aplicação do Modelo Matemático Modificado são identificados pela sigla MMM. Como já descrito, ambos os modelos foram testados com e sem a aplicação do Método Iterativo de Solução (MIS).

Tabela 14 - Sumário dos resultados experimentais - Tempo Computacional

\begin{tabular}{cccccc}
\hline \multirow{2}{*}{ Grupo } & \multirow{2}{*}{ Instância } & \multicolumn{2}{c}{ Sem MIS } & \multicolumn{2}{c}{ Com MIS } \\
\cline { 2 - 5 } & & MMB & MMM & MMB & MMM \\
\hline 1 & 1 & 600 & 600 & 961 & $\mathbf{2 4 2}$ \\
1 & 2 & 600 & 600 & 1.111 & $\mathbf{1 8 2}$ \\
1 & 3 & 600 & 600 & $\mathbf{3 0 1}$ & 364 \\
1 & 4 & 600 & 600 & 571 & $\mathbf{2 7 3}$ \\
1 & 5 & 600 & 600 & 481 & $\mathbf{2 7 3}$ \\
\hline 2 & 6 & 600 & 600 & $\mathbf{3 0 1}$ & 452 \\
2 & 7 & 600 & 600 & 841 & $\mathbf{3 9 4}$ \\
2 & 8 & 600 & 600 & 961 & $\mathbf{6 6 4}$ \\
2 & 9 & 600 & 600 & 751 & $\mathbf{3 6 4}$ \\
2 & 10 & 600 & 600 & 601 & $\mathbf{3 0 3}$ \\
\hline 3 & 11 & 600 & 600 & $\mathbf{4 2 0}$ & 422 \\
3 & 12 & 600 & 600 & 570 & $\mathbf{4 2 2}$ \\
3 & 13 & 600 & 600 & 480 & $\mathbf{4 2 2}$ \\
3 & 14 & 600 & 600 & 480 & $\mathbf{4 8 2}$ \\
3 & 15 & 600 & 600 & 480 & $\mathbf{4 8 2}$ \\
\hline 4 & 16 & 600 & 600 & 571 & $\mathbf{5 1 2}$ \\
4 & 17 & 600 & 600 & $\mathbf{4 8 0}$ & 693 \\
4 & 18 & 600 & 600 & 420 & $\mathbf{3 6 2}$ \\
4 & 19 & $\mathbf{6 0 0}$ & $\mathbf{6 0 0}$ & 601 & 603 \\
4 & 20 & 600 & 600 & $\mathbf{5 7 1}$ & 753 \\
\hline
\end{tabular}

\subsection{Discussão dos Resultados}

\subsubsection{Análise dos resultados dos modelos matemáticos}

De maneira geral, levando-se em conta os resultados das 20 instâncias experimentais, é possível verificar que o Modelo Matemático Modificado apresenta resultados de Ocupação do Objeto, em média, 0,68 ponto percentual melhores que o Modelo Matemático Base. Ou seja, os resultados mostram que, para o mesmo tempo computacional (600 segundos, no caso dos experimentos apresentados), o Modelo Matemático Modificado apresenta melhores resultados do que o Modelo Matemático Base.

A análise dos resultados segregada por grupo de instâncias, entretanto, apresenta 
algumas particularidades. Essa análise mostra que o Modelo Matemático Modificado apresentou resultados acima da média para as instâncias do Grupo 2 (itens pequenos e heterogêneos), com uma melhoria média das soluções em 2,98 pontos percentuais.

Por outro lado, a análise das instâncias do Grupo 1 (itens pequenos e homogêneos), indica que as soluções do Modelo Matemático Base são, em média, 0,21 ponto percentual melhores. Esse resultado é especialmente impactado pela solução encontrada pelos dois modelos matemáticos para a instância 2, onde o Modelo Matemático Base apresentou uma solução 1,57 ponto percentual melhor, em termos de Ocupação do Objeto.

Por fim, a análise dos Grupos 3 e 4 (respectivamente, itens grandes e homogêneos e itens grandes e heterogêneos) não mostrou diferença significativa entre os resultados apresentados pelos dois modelos matemáticos.

Os resultados encontrados estão em linha com o esperado, já que se esperava que o Modelo Matemático Modificado fosse capaz de apresentar soluções de melhor qualidade. Como já discutido anteriormente ao longo deste trabalho, esse resultado é esperado em função da redução no número de variáveis de decisão proporcionada pelo Modelo Matemático Modificado.

Além disso, com exceção da instância 2, os melhores resultados do Modelo Matemático Modificado foram obtidos nas instâncias dos Grupos 1 e 2. Isso indica uma efetividade mais acentuada do Modelo Matemático Modificado em instâncias com maior número de itens (instâncias com itens pequenos apresentam maior número total de itens para alocação). Se forem consideradas apenas as instâncias dos Grupos 1 e 2, o Modelo Matemático Modificado apresentou uma melhoria média de 1,39 ponto percentual nas soluções geradas. Excluindo a instância 2 desse resultado, a melhora média das soluções ficou na casa de 1,71 ponto percentual em relação ao Modelo Matemático Base.

\subsubsection{Experimentos adicionais}

Além dos experimentos apresentados no Capítulo 5, foram realizados dois experimentos adicionais para avaliar a efetividade da aplicação do Modelo Matemático Modificado. Os dois modelos matemáticos foram aplicados às mesmas 20 instâncias experimentais, porém com tempo computacional máximo de apenas 30 segundos.

Os experimentos adicionais foram realizados para avaliar dois aspectos dos modelos matemáticos:

1. Verificar se há diferença significativa na qualidade das soluções em função do tempo computacional máximo; e

2. Verificar se a melhoria nas soluções proporcionadas pelo Modelo Matemático Modificado também é válida para um tempo computacional reduzido. 
Os resultados da Ocupação do Objeto, apresentados na Tabela 15, mostram aspectos importantes, relacionados as hipóteses mencionadas anteriormente. A melhor solução para cada instância é apresentada em destaque.

Na Tabela 15 os resultados obtidos à partir da aplicação do Modelo Matemático Base são identificados pela sigla MMB. Já os resultados obtidos pela aplicação do Modelo Matemático Modificado são identificados pela sigla MMM. Nesse caso os modelos foram avaliados apenas sem a aplicação do Método Iterativo de Solução (MIS).

Tabela 15 - Experimentos adicionais - Tempo Computacional máximo 30 segundos

\begin{tabular}{cccc}
\hline \multirow{2}{*}{ Grupo } & \multirow{2}{*}{ Instância } & \multicolumn{2}{c}{ Sem MIS } \\
\cline { 3 - 4 } & & MMB & MMM \\
\hline 1 & 1 & $96,27 \%$ & $\mathbf{9 7 , 2 1} \%$ \\
1 & 2 & $92,03 \%$ & $\mathbf{9 4 , 2 4} \%$ \\
1 & 3 & $83,30 \%$ & $\mathbf{8 3 , 5 2} \%$ \\
1 & 4 & $90,21 \%$ & $\mathbf{9 0 , 9 8} \%$ \\
1 & 5 & $83,46 \%$ & $\mathbf{8 3 , 5 3} \%$ \\
\hline 2 & 6 & $86,87 \%$ & $\mathbf{9 1 , 1 7} \%$ \\
2 & 7 & $89,56 \%$ & $\mathbf{9 4 , 3 8} \%$ \\
2 & 8 & $78,76 \%$ & $\mathbf{8 3 , 2 7} \%$ \\
2 & 9 & $83,48 \%$ & $\mathbf{9 0 , 5 4} \%$ \\
2 & 10 & $83,53 \%$ & $\mathbf{9 1 , 1 3} \%$ \\
\hline 3 & 11 & $\mathbf{6 6 , 9 4} \%$ & $\mathbf{6 6 , 9 4} \%$ \\
3 & 12 & $\mathbf{6 9 , 8 1} \%$ & $\mathbf{6 9 , 8 1} \%$ \\
3 & 13 & $\mathbf{7 4 , 4 7} \%$ & $\mathbf{7 4 , 4 7} \%$ \\
3 & 14 & $\mathbf{7 1 , 9 3} \%$ & $\mathbf{7 1 , 9 3} \%$ \\
3 & 15 & $\mathbf{7 2 , 8 3} \%$ & $\mathbf{7 2 , 8 3} \%$ \\
\hline 4 & 16 & $\mathbf{8 9 , 7 7} \%$ & $89,32 \%$ \\
4 & 17 & $\mathbf{9 2 , 0 7} \%$ & $91,22 \%$ \\
4 & 18 & $88,51 \%$ & $\mathbf{8 8 , 9 0} \%$ \\
4 & 19 & $\mathbf{8 7 , 3 4} \%$ & $\mathbf{8 7 , 3 4} \%$ \\
4 & 20 & $\mathbf{8 9 , 0 2} \%$ & $\mathbf{8 9 , 0 2} \%$ \\
\hline
\end{tabular}

Primeiramente, é possível verificar que os resultados das soluções com uma limitação de 30 segundos no tempo computacional apresentam diferenças importantes em relação aos resultados encontrados na resolução dos modelos matemáticos com limite de 600 segundos no tempo computacional (Tabela 13).

No caso do Modelo Matemático Base, a melhoria verificada entre os experimentos mostrou que o limite de 600 segundos no tempo computacional de resolução do modelo apresentou soluções, em média, 1,58 ponto percentual melhores. Por outro lado, no caso do Modelo Matemático Modificado, a melhoria média das soluções foi de 0,68 ponto percentual. O Modelo Matemático Base mostrou melhorias em 14 das 20 instâncias experimentais. Já o Modelo Matemático Modificado, por sua vez, apresentou soluções melhores em 8 das 20 instâncias.

Esses resultados indicam que o limite de tempo computacional tem maior impacto na qualidade das soluções do Modelo Matemático Base. Tais resultados reforçam a efetividade do Modelo Matemático Modificado, já que, como este modelo reduz o número de 
variáveis de decisão, boas soluções podem ser obtidas mesmo com tempo computacional reduzido.

Além disso, a comparação dos resultados dos dois modelos com tempo computacional limitado a 30 segundos, mostra que as soluções do Modelo Matemático Modificado são, em média, 1,58 ponto percentual melhores que as soluções do Modelo Matemático Base. Isso indica que em situações de tempo computacional máximo reduzido a efetividade do Modelo Matemático Modificado é ainda maior.

\subsubsection{Análise dos resultados dos MIS}

Além da avaliação dos resultados da aplicação do Modelo Matemático Modificado, o presente trabalho avalia também a efetividade da aplicação do Método Iterativo de Solução (MIS) proposto.

Os dados apresentados anteriormente (Tabelas 13 e 14) permitem verificar que, para o caso do Modelo Matemático Base, a aplicação do MIS resulta em soluções 1,31 ponto percentual melhores em relação as soluções verificadas sem aplicação do MIS e com limite de tempo computacional de 600 segundos.

Já no caso do Modelo Matemático Modificado, as soluções são em média 1,30 ponto percentual melhores quando comparadas as soluções obtidas sem aplicação do MIS e com tempo computacional de 600 segundos.

Os dados apresentados anteriormente permitem concluir que a aplicação do MIS, de fato, melhora as soluções obtidas quando comparadas as soluções encontradas sem a aplicação do Método Iterativo de Solução. Esse comportamento é válido tanto para o Modelo Matemático Base, como para o Modelo Matemático Modificado.

Além disso, a análise do Tempo Computacional resultante para cada uma das instâncias resolvidas com o Modelo Matemático Modificado e com a aplicação do Método Iterativo de Solução mostrou que as soluções, além de serem em média 1,30 pontos percentuais melhores em termos de Ocupação do Objeto, são obtidas em um Tempo Computacional médio 27,8\% menor do que as soluções obtidas sem aplicação do MIS.

No caso do Modelo Matemático Base, as soluções são, em média, 1,31 ponto percentual melhores com a aplicação do MIS e encontradas em um Tempo Computacional médio 0,4\% menor quando comparadas às soluções obtidas pelo mesmo modelo sem a aplicação do Método Iterativo de Solução (MIS).

Por fim, vale destacar que os resultados obtidos pelas combinação da aplicação do Modelo Matemático Modificado e do Método Iterativo de Solução, quando comparados ao Modelo Matemático Base sem a aplicação do Método Iterativo de Solução, apresentaram soluções de Ocupação do Objeto 1,98 ponto percentual melhores em um Tempo 
Computacional 27,8\% menor. Ou seja, a combinação do Modelo Matemático Modificado e do MIS apresentam resultados melhores e em menor do tempo do que a aplicação pura e simples do Modelo Matemático Base.

Os resultados encontrados para a aplicação do Método Iterativo de Solução corroboram a hipótese apresentada no Capítulo 4, quando da descrição dos conceitos do MIS. Novamente, assim como no caso do Modelo Matemático Modificado, os melhores resultados eram esperados em função da redução do número de variáveis de decisão do problema.

\subsubsection{Experimentos adicionais}

Além dos experimentos já apresentados, e descritos no Capítulo 5, foi realizado um experimento adicional para avaliar o impacto do Tempo Computacional na qualidade das soluções obtidas com a aplicação do Método Iterativo de Solução (MIS).

Esse novo experimento, realizado com as mesmas 20 instâncias experimentais utilizadas nos demais experimentos, consistiu na resolução do problema com aplicação do Modelo Matemático Modificado e do MIS.

Diferentemente do algoritmo padrão do MIS as iterações desse experimento foram executadas continuamente, sem aplicação do critério de parada por exaustão. Desta forma, foi possível comparar as soluções obtidas pelo Modelo Matemático Base e pelo Modelo Matemático Modificado para um mesmo Tempo Computacional total, ou seja, considerando o número total de iterações para resolução de cada instância.

A Tabela 16, a seguir, mostra os resultados obtidos por esse novo experimento, em termos de Ocupação do Objeto e Tempo Computacional total. Em destaque na tabela a melhor solução encontrada para cada instância. 
Tabela 16 - Experimento adicional - Tempo Computacional similar

\begin{tabular}{cccccc}
\hline \multirow{2}{*}{ Grupo } & Instância & \multicolumn{3}{c}{ MMB } & \multicolumn{2}{c}{ MMM } \\
\cline { 2 - 6 } & & Ocupação & $\begin{array}{c}\text { Tempo } \\
\text { Computacional }\end{array}$ & Ocupação & $\begin{array}{c}\text { Tempo } \\
\text { Computacional }\end{array}$ \\
\hline 1 & 1 & $\mathbf{9 7 , 2 2} \%$ & 961 & $\mathbf{9 7 , 2 2} \%$ & 967 \\
1 & 2 & $\mathbf{9 4 , 7 6} \%$ & 1.111 & $94,45 \%$ & 1.147 \\
1 & 3 & $85,12 \%$ & 301 & $\mathbf{9 2 , 3 7 \%}$ & 303 \\
1 & 4 & $\mathbf{9 4 , 6 2} \%$ & 571 & $94,32 \%$ & 577 \\
1 & 5 & $\mathbf{9 2 , 4 4} \%$ & 481 & $91,70 \%$ & 487 \\
\hline 2 & 6 & $93,85 \%$ & 301 & $\mathbf{9 5 , 1 0} \%$ & 362 \\
2 & 7 & $94,70 \%$ & 841 & $\mathbf{9 5 , 0 2} \%$ & 848 \\
2 & 8 & $\mathbf{8 9 , 4 5} \%$ & 961 & $87,57 \%$ & 967 \\
2 & 9 & $90,53 \%$ & 751 & $\mathbf{9 4 , 7 5} \%$ & 758 \\
2 & 10 & $91,56 \%$ & 601 & $\mathbf{9 5 , 3 2} \%$ & 606 \\
\hline 3 & 11 & $\mathbf{6 6 , 9 4} \%$ & 420 & $\mathbf{6 6 , 9 4} \%$ & 422 \\
3 & 12 & $\mathbf{6 9 , 8 1} \%$ & 570 & $\mathbf{6 9 , 8 1} \%$ & 604 \\
3 & 13 & $\mathbf{7 4 , 4 7} \%$ & 480 & $\mathbf{7 4 , 4 7} \%$ & 545 \\
3 & 14 & $\mathbf{7 1 , 9 3} \%$ & 480 & $\mathbf{7 1 , 9 3} \%$ & 482 \\
3 & 15 & $\mathbf{7 2 , 8 3} \%$ & 480 & $\mathbf{7 2 , 8 3} \%$ & 482 \\
\hline 4 & 16 & $\mathbf{8 9 , 9 6} \%$ & 571 & $\mathbf{8 9 , 9 6} \%$ & 544 \\
4 & 17 & $92,07 \%$ & 480 & $\mathbf{9 3 , 4 4} \%$ & 512 \\
4 & 18 & $\mathbf{8 8 , 9 0} \%$ & 420 & $88,51 \%$ & 423 \\
4 & 19 & $87,61 \%$ & 601 & $\mathbf{8 7 , 6 1} \%$ & 603 \\
4 & 20 & $89,27 \%$ & 571 & $\mathbf{8 9 , 2 7} \%$ & 572 \\
\hline
\end{tabular}

\subsection{Resultados de Instâncias Reais}

Além dos resultados verificados para as instâncias experimentais, apresentados anteriormente, foram realizados experimentos adicionais com instâncias reais. As quatro instâncias reais utilizados nos experimentos são apresentadas com maiores detalhes no Capítulo 5.

A Tabela 17, a seguir, apresenta um sumário dos resultados encontrados para cada uma das quatro instâncias reais. Nela são apresentados os resultados de Ocupação do Objeto obtidos pelo modelo matemático, bem como a Ocupação do Objeto no plano de estivagem real e a diferença, em pontos percentuais, entre as duas soluções. Por fim, é apresentado o Tempo Computacional total para resolução do modelo, em segundos.

Entre os resultados apresentados na Tabela 17, a melhor solução para cada instância é destacada.

Os resultados obtidos pela aplicação do Modelo Matemático Modificado e do Método Iterativo de Solução às instâncias reais podem ser considerados positivos. Em três das instâncias houve melhora na solução e em apenas uma das instâncias os resultados ficaram abaixo do plano de estivagem real. As instâncias 3 e 4 apresentaram incremento na qualidade da solução acima de 3 pontos percentuais. 
Tabela 17 - Resultados das instâncias reais

\begin{tabular}{ccccc}
\hline Instância Real & Modelo & Real & Diferença & Tempo Computacional \\
\hline 1 & $\mathbf{9 4 , 2 0} \%$ & $93,56 \%$ & $0,64 \mathrm{pp}$ & 363 \\
2 & $95,49 \%$ & $\mathbf{9 6 , 5 1} \%$ & $-1,02 \mathrm{pp}$ & 665 \\
3 & $\mathbf{9 5 , 6 7} \%$ & $92,25 \%$ & $3,42 \mathrm{pp}$ & 375 \\
4 & $\mathbf{9 6 , 7 3} \%$ & $91,93 \%$ & $4,80 \mathrm{pp}$ & 605 \\
\hline
\end{tabular}

Além de bons resultados em termos de Ocupação do Objeto, as soluções foram obtidas em um Tempo Computacional relativamente pequeno para essa classe de problemas. Vale ressaltar que os planos reais são elaborados manualmente, com certeza em maior tempo total do que as soluções encontradas pelo modelo matemático.

A seguir são apresentados e discutidos os resultados detalhados para cada uma das quatro instâncias reais avaliadas.

\subsubsection{Instância real 1}

Os resultados obtidos para a primeira instância real avaliada, do navio Corella Arrow, são apresentados na Tabela 18 abaixo:

Tabela 18 - Detalhamento dos resultados da instância real 1

\begin{tabular}{cccccc}
\hline Iteração & Objetivo & Ocupação & Tempo & Controle Exaustão & Controle Folga \\
\hline 1 & 236,49 & $92,40 \%$ & 30 & 1 & 5 \\
2 & 234,19 & $91,50 \%$ & 30 & 1 & 5 \\
3 & 236,49 & $92,40 \%$ & 30 & 2 & 6 \\
4 & 241,08 & $94,20 \%$ & 90 & 1 & 5 \\
5 & 241,08 & $94,20 \%$ & 30 & 1 & 5 \\
6 & 236,49 & $92,40 \%$ & 30 & 1 & 5 \\
7 & 238,78 & $93,30 \%$ & 30 & 2 & 5 \\
8 & 236,49 & $92,40 \%$ & 30 & 3 & 4 \\
9 & 241,08 & $94,20 \%$ & 30 & 4 & 5 \\
10 & 241,08 & $94,20 \%$ & 30 & 5 & 5 \\
\hline
\end{tabular}

Em comparação com plano de estivagem real (Figura 21) a aplicação do Modelo Matemático Modificado, em conjunto com o Método Iterativo de Solução, apresentou uma Ocupação do Objeto 0,64 ponto percentual melhor. A Figura 22 apresenta graficamente o plano de estivagem resultante da aplicação do modelo matemático.

É importante que ressaltar que a Figura 21 não necessariamente levou em conta as dimensões e proporções exatas dos itens e objeto. Desta forma, a comparação visual entre os planos de estivagem real e o gerado pelo modelo pode levar a erros. 


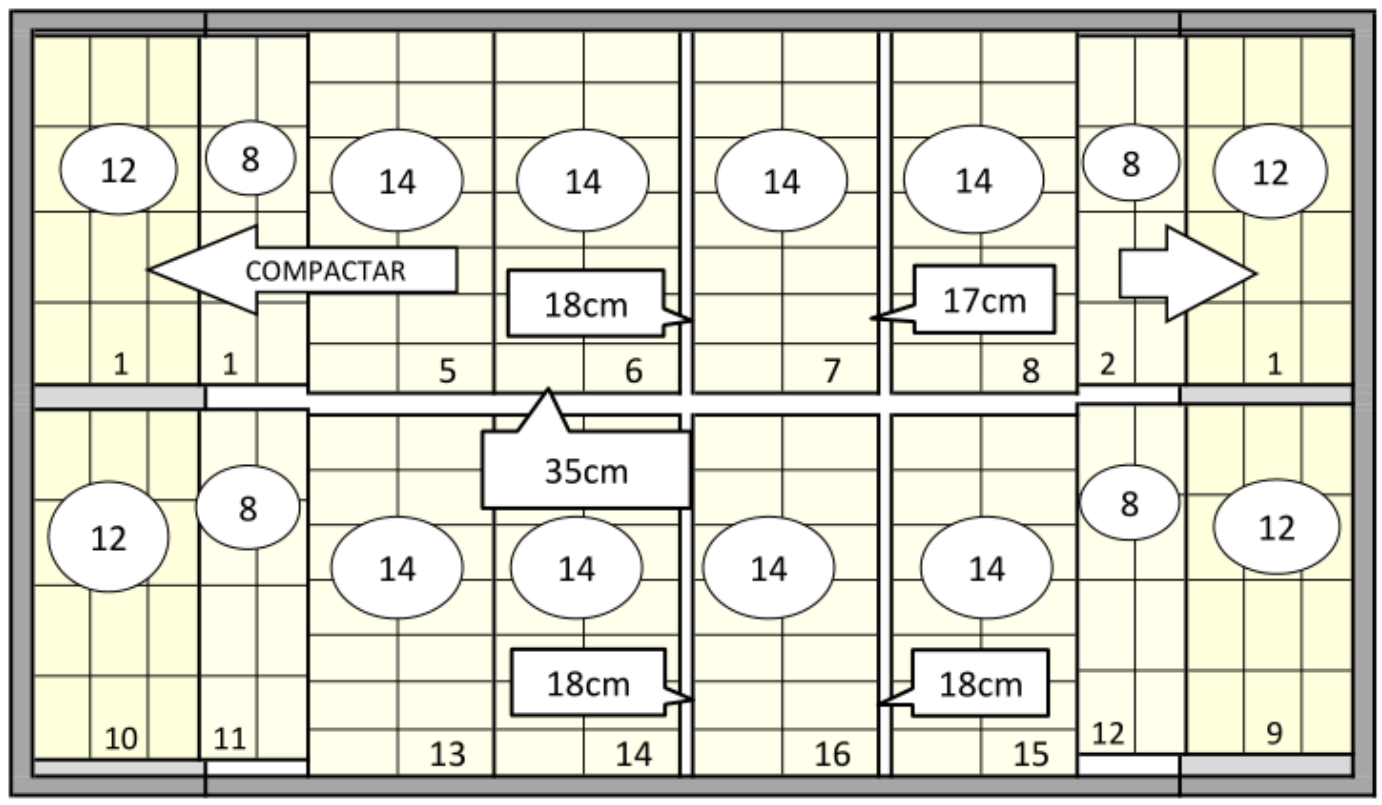

Figura 21 - Representação gráfica do plano de estivagem real da instância 1

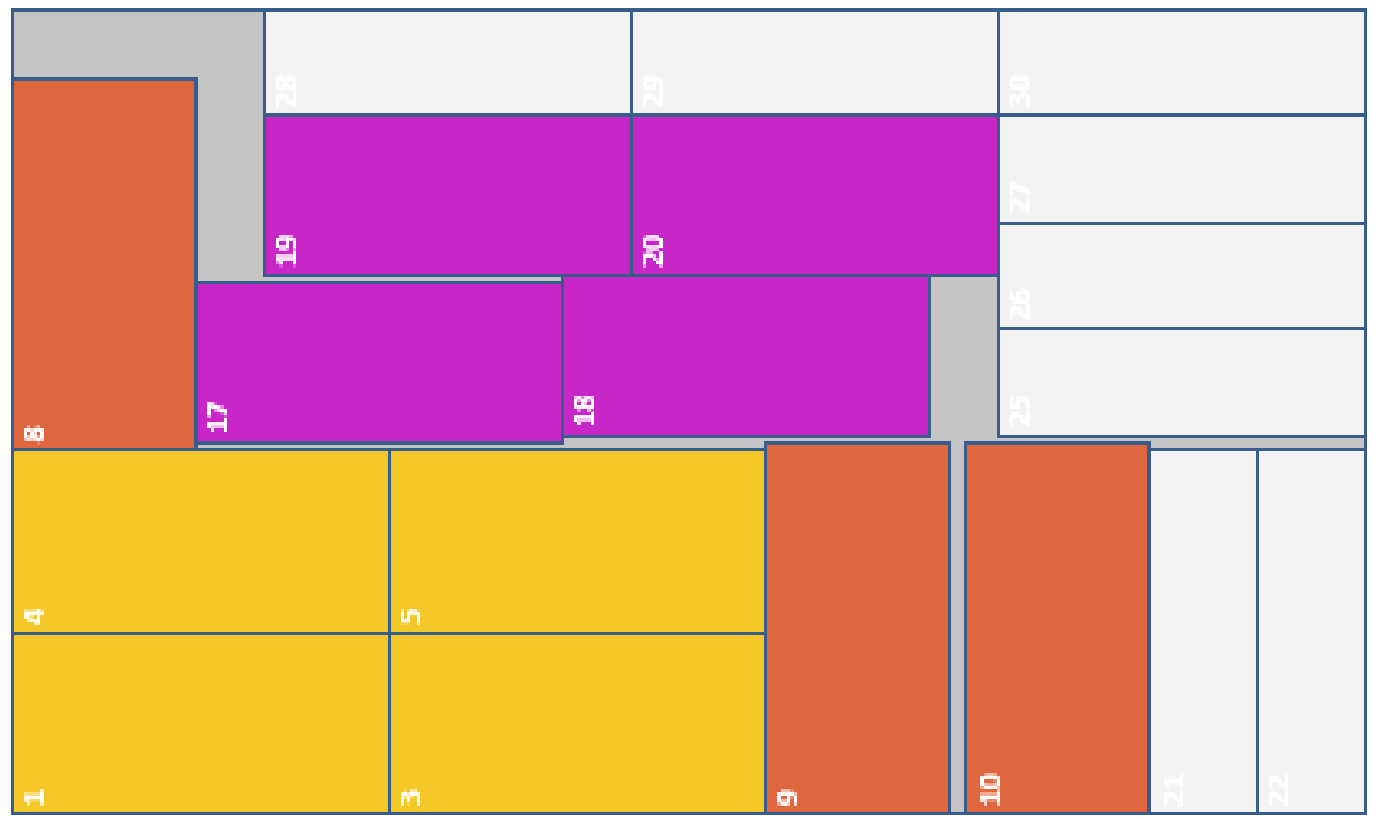

Figura 22 - Representação gráfica do plano de estivagem gerado pelo modelo para a instância real 1

\subsubsection{Instância real 2}

Os resultados obtidos para a segunda instância real avaliada, referente a um porão do navio Delicata, são apresentados na Tabela 19, a seguir: 
Tabela 19 - Detalhamento dos resultados da instância real 2

\begin{tabular}{cccccc}
\hline Iteração & Objetivo & Ocupação & Tempo & Controle Exaustão & Controle Folga \\
\hline 1 & 487,53 & $93,96 \%$ & 31 & 1 & 2 \\
2 & 492,83 & $94,98 \%$ & 30 & 1 & 5 \\
3 & 492,83 & $94,98 \%$ & 30 & 1 & 5 \\
4 & 495,48 & $95,49 \%$ & 30 & 1 & 6 \\
5 & 495,48 & $95,49 \%$ & 91 & 1 & 6 \\
6 & 495,48 & $95,49 \%$ & 90 & 1 & 6 \\
7 & 495,48 & $95,49 \%$ & 90 & 2 & 6 \\
8 & 495,48 & $95,49 \%$ & 90 & 3 & 6 \\
9 & 495,48 & $95,49 \%$ & 90 & 4 & 6 \\
10 & 495,48 & $95,49 \%$ & 90 & 5 & 6 \\
\hline
\end{tabular}

Em comparação com plano de estivagem real (Figura 23) a aplicação do Modelo Matemático Modificado, em conjunto com o Método Iterativo de Solução, apresentou resultado de Ocupação do Objeto 1,02 ponto percentual pior. A Figura 24 apresenta graficamente o plano de estivagem resultante da aplicação do modelo matemático.

É importante que ressaltar que a Figura 23 não necessariamente levou em conta as dimensões e proporções exatas dos itens e objeto. Desta forma, a comparação visual entre os planos de estivagem real e o gerado pelo modelo pode levar a erros.

O fato do resultado do modelo matemático ser pior do que o plano de estivagem real pode ser, em parte, explicado pelo grande número de itens pequenos utilizados no plano real. Como foi imposto um limite ao número total de itens avaliados em cada iteração, o modelo priorizou a alocação de itens maiores, buscando maximizar a ocupação do porão do navio. Ainda assim, essa alocação não foi suficiente para igualar ou superar o plano de estivagem real, que fez uso de 29 lingadas pequenas, com apenas 2 unidades de celulose em cada.

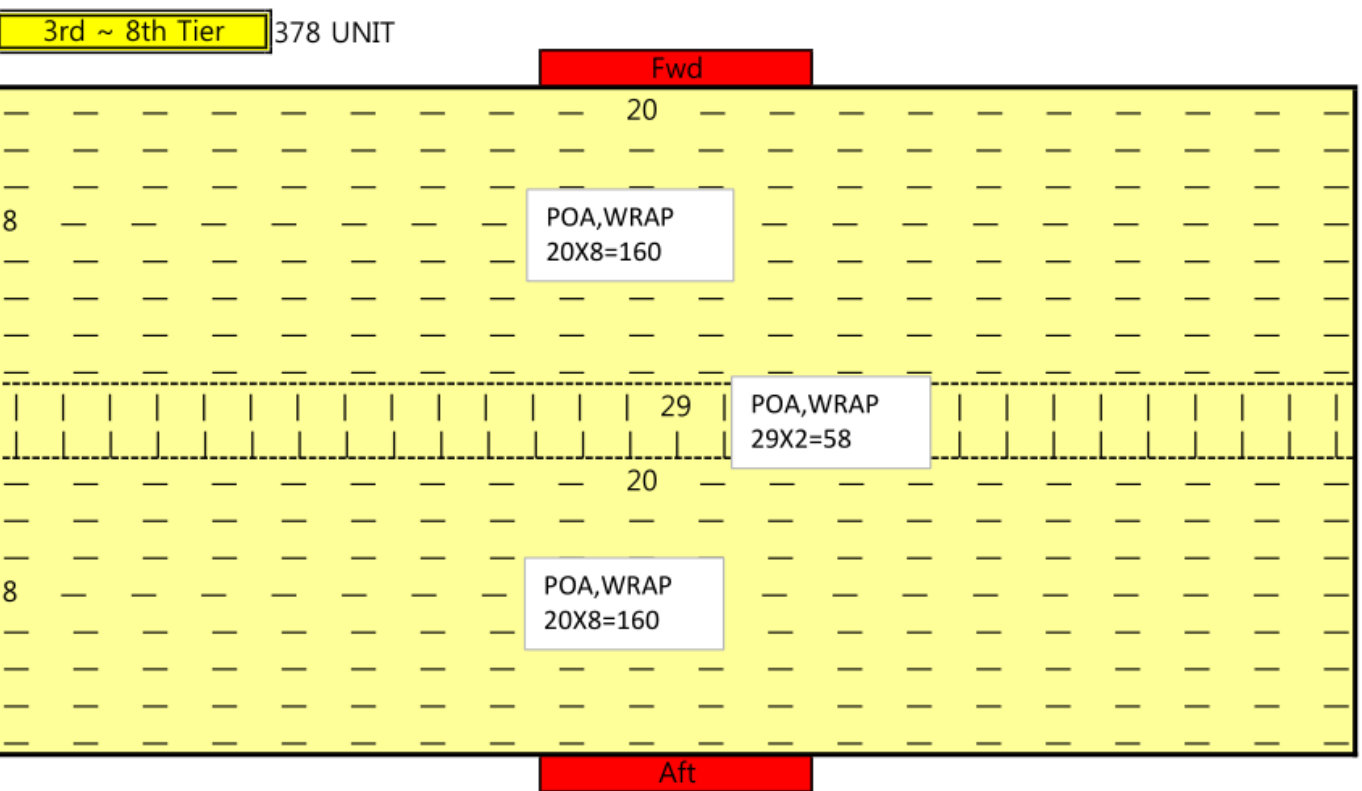

Figura 23 - Representação gráfica do plano de estivagem real da instância 2 


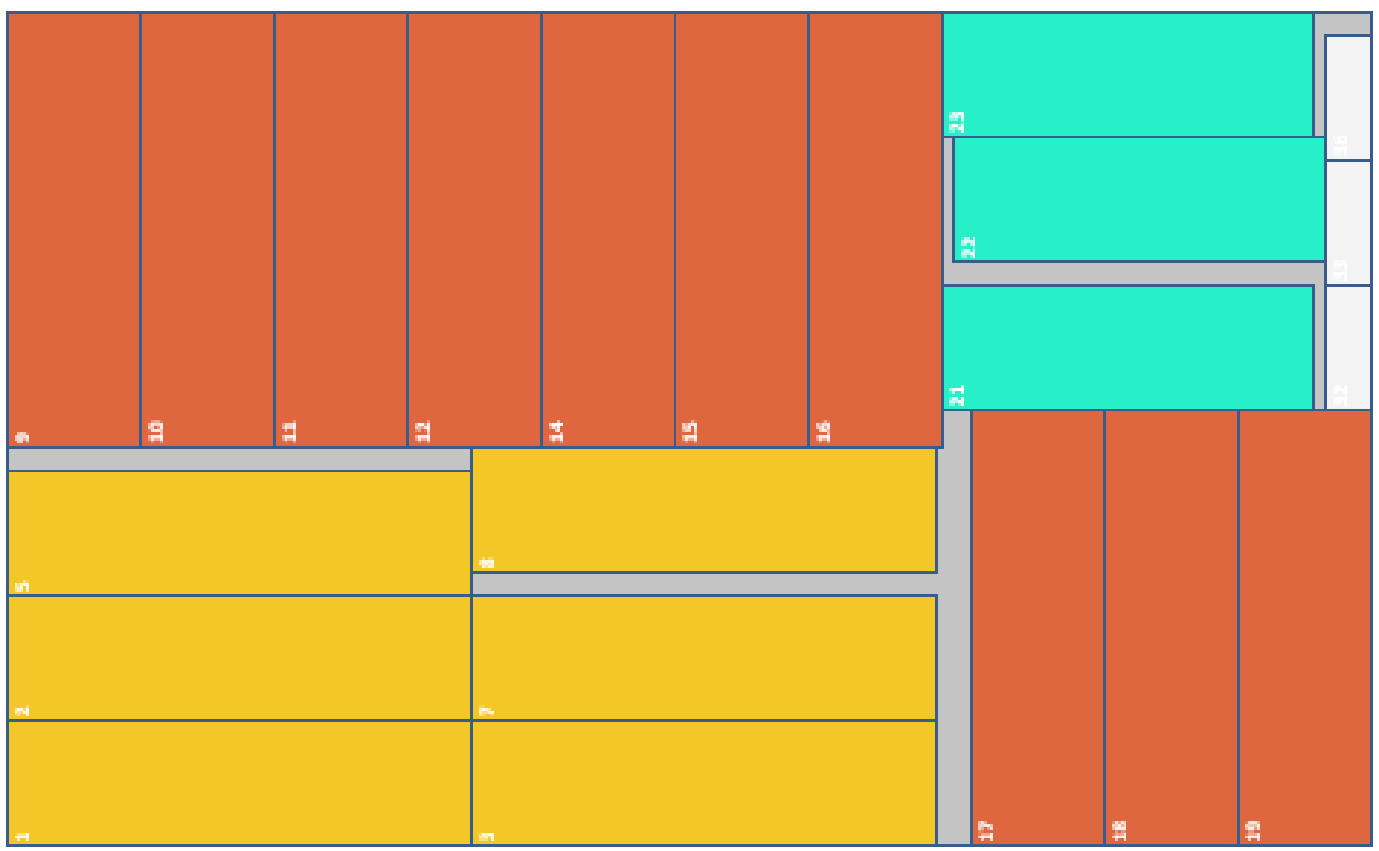

Figura 24 - Representação gráfica do plano de estivagem gerado pelo modelo para a instância real 2

\subsubsection{Instância real 3}

Os resultados obtidos para a terceira instância real avaliada, do porão \#3 do navio Star Louisiana, são apresentados na Tabela 20, abaixo:

Tabela 20 - Detalhamento dos resultados da instância real 3

\begin{tabular}{cccccc}
\hline Iteração & Objetivo & Ocupação & Tempo & Controle Exaustão & Controle Folga \\
\hline 1 & 487,53 & $93,96 \%$ & 31 & 1 & 2 \\
2 & 492,83 & $94,98 \%$ & 30 & 1 & 5 \\
3 & 492,83 & $94,98 \%$ & 30 & 1 & 5 \\
4 & 495,48 & $95,49 \%$ & 30 & 1 & 6 \\
5 & 495,48 & $95,49 \%$ & 91 & 1 & 6 \\
6 & 495,48 & $95,49 \%$ & 90 & 1 & 6 \\
7 & 495,48 & $95,49 \%$ & 90 & 2 & 6 \\
8 & 495,48 & $95,49 \%$ & 90 & 3 & 6 \\
9 & 495,48 & $95,49 \%$ & 90 & 4 & 6 \\
10 & 495,48 & $95,49 \%$ & 90 & 5 & 6 \\
\hline
\end{tabular}

Em comparação com plano de estivagem real (Figura 25) a aplicação do Modelo Matemático Modificado, em conjunto com o Método Iterativo de Solução, apresentou resultado de Ocupação do Objeto 3,42 pontos percentuais melhor. A Figura 26 apresenta graficamente o plano de estivagem resultante da aplicação do modelo matemático.

É importante que ressaltar que a Figura 25 não necessariamente levou em conta as dimensões e proporções exatas dos itens e objeto. Desta forma, a comparação visual entre os planos de estivagem real e o gerado pelo modelo pode levar a erros. 


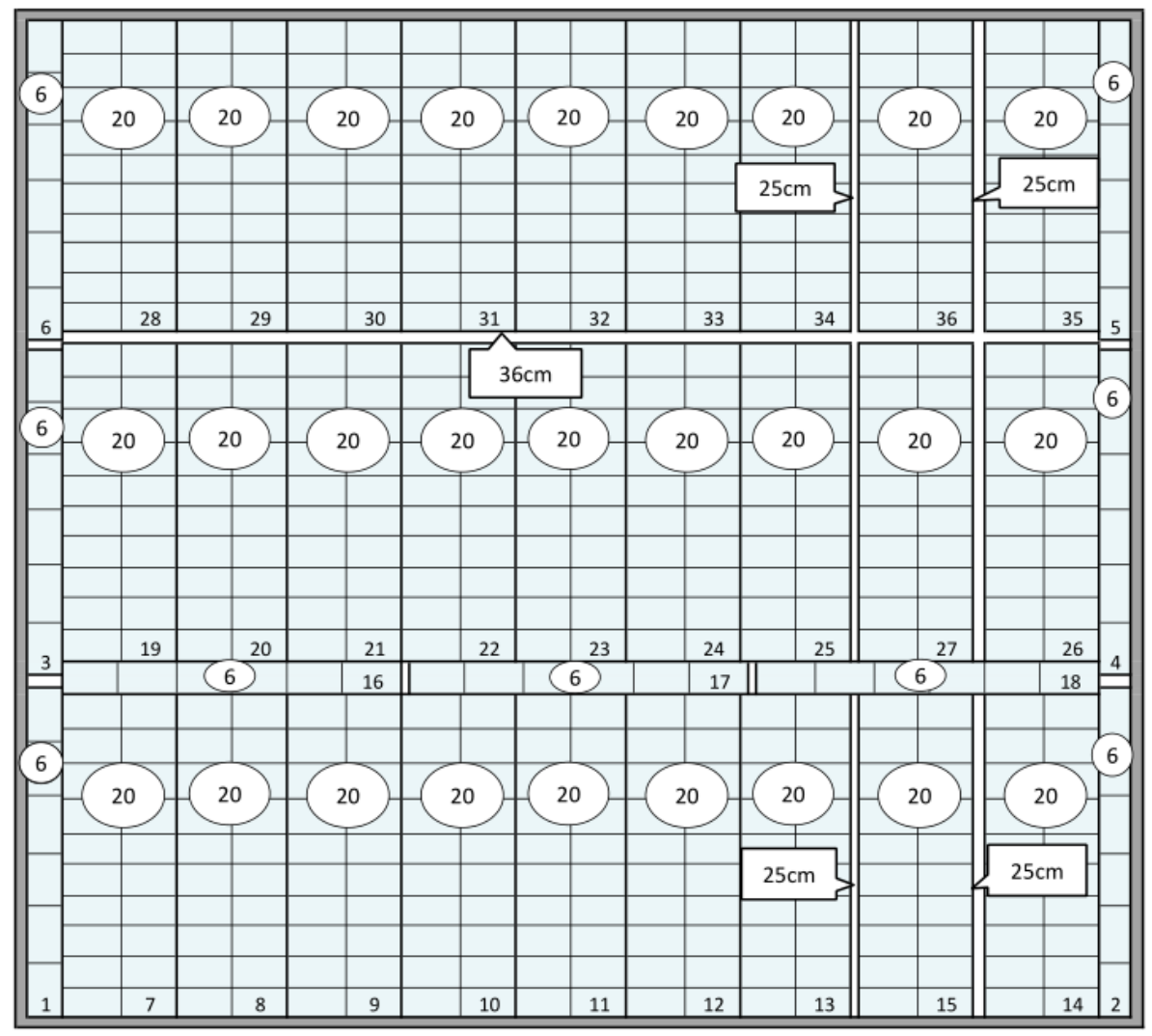

Figura 25 - Representação gráfica do plano de estivagem real da instância real 3

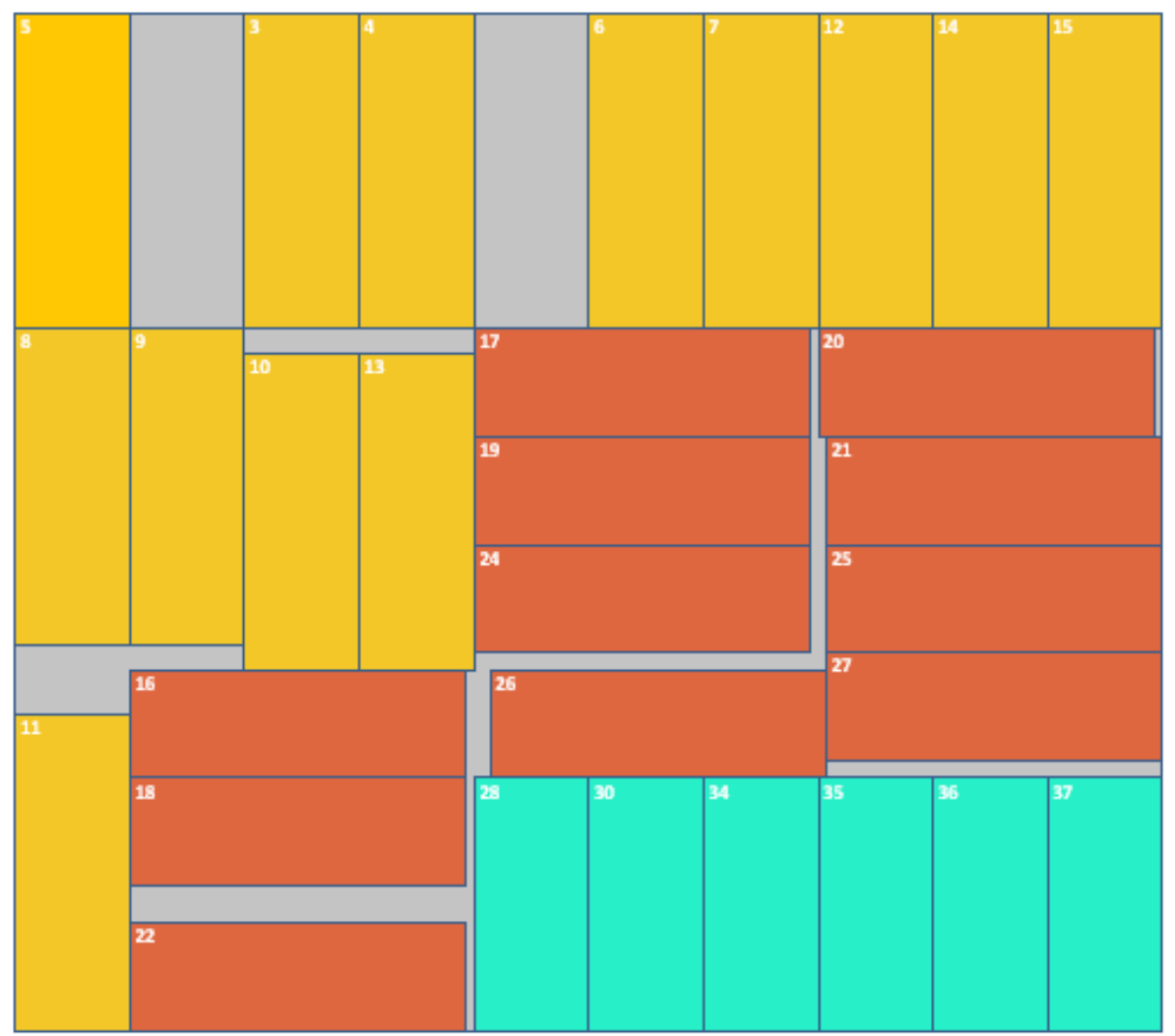

Figura 26 - Representação gráfica do plano de estivagem gerado pelo modelo para a instância real 3 


\subsubsection{Instância real 4}

Os resultados obtidos para a primeira instância real avaliada, do porão \#4 do navio Star Louisiana, são apresentados na Tabela 21 abaixo:

Tabela 21 - Detalhamento dos resultados da instância real 4

\begin{tabular}{cccccc}
\hline Iteração & Objetivo & Ocupação & Tempo & Controle Exaustão & Controle Folga \\
\hline 1 & 321,44 & $89,69 \%$ & 31 & 1 & 5 \\
2 & 339,81 & $94,81 \%$ & 31 & 1 & 5 \\
3 & 344,40 & $96,09 \%$ & 30 & 1 & 5 \\
4 & 342,10 & $95,45 \%$ & 31 & 1 & 6 \\
5 & 346,70 & $96,73 \%$ & 90 & 2 & 5 \\
6 & 342,10 & $95,45 \%$ & 31 & 1 & 6 \\
7 & 344,40 & $96,09 \%$ & 91 & 2 & 6 \\
8 & 342,10 & $95,45 \%$ & 91 & 3 & 6 \\
9 & 342,10 & $95,45 \%$ & 91 & 4 & 6 \\
10 & 342,10 & $95,45 \%$ & 91 & 5 & 6 \\
\hline
\end{tabular}

Em comparação com plano de estivagem real (Figura 27) a aplicação do Modelo Matemático Modificado, em conjunto com o Método Iterativo de Solução, apresentou resultado de Ocupação do Objeto 4,80 pontos percentuais melhor. A Figura 28 apresenta graficamente o plano de estivagem resultante da aplicação do modelo matemático.

É importante que ressaltar que a Figura 27 não necessariamente foi elaborada levando em consideração as dimensões e proporções exatas dos itens e objeto. Desta forma, a comparação visual entre os planos de estivagem real e o gerado pelo modelo pode levar a erros.

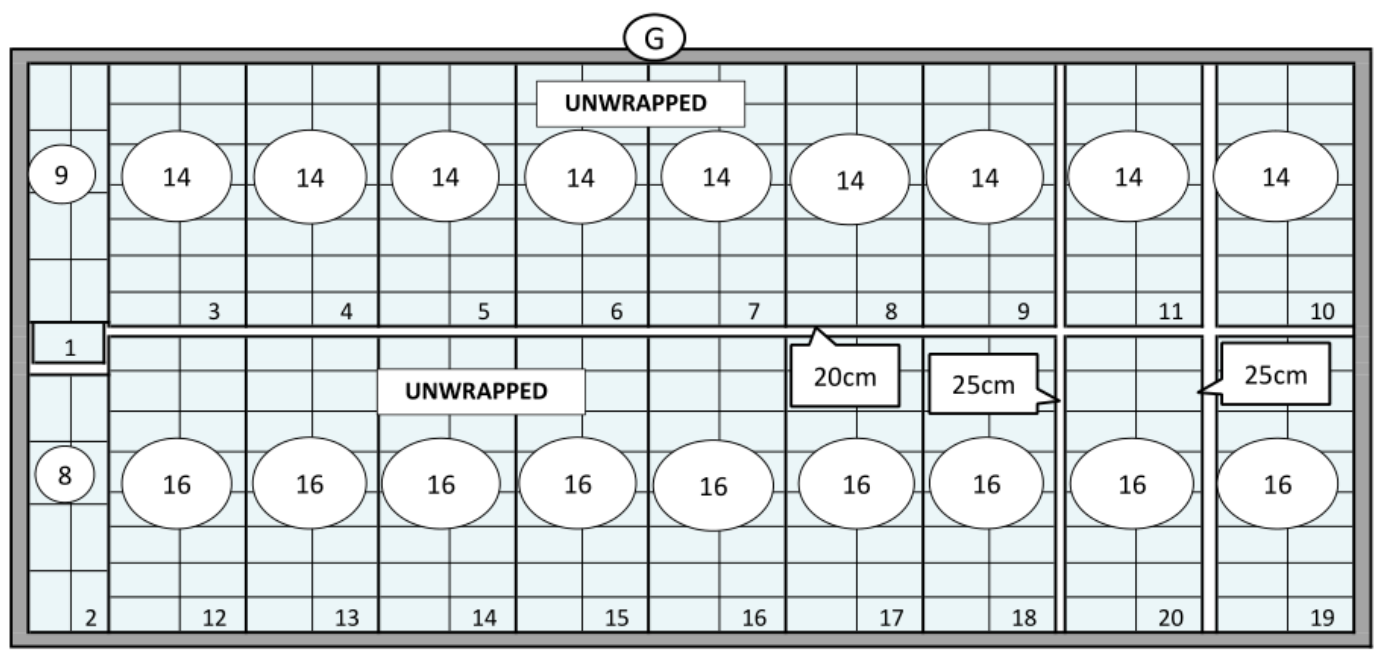

Figura 27 - Representação gráfica do plano de estivagem real da instância real 4 


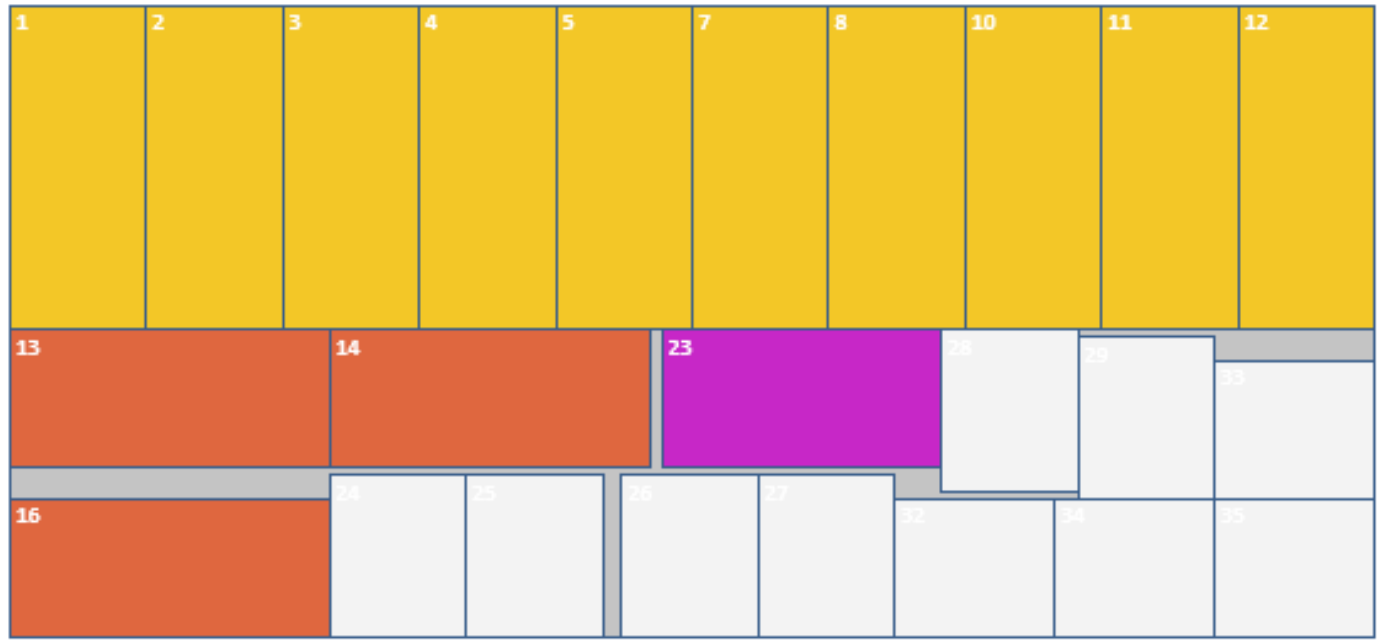

Figura 28 - Representação gráfica do plano de estivagem gerado pelo modelo para a instância real 4 


\section{Conclusões}

O presente trabalho fez uso da aplicação de modelos de Corte e Empacotamento na resolução do Problema de Estivagem de Unidades de Celulose (PEUC).

O problema consiste na alocação de itens (unidades de celulose) a um determinado objeto (porão do navio). Esse tipo de problema é classificado, de acordo com a literatura mais recente sobre tipologia de problemas de Corte e Empacotamento, como um Single Larga Object Placement Problem (SLOPP).

Em função da complexidade computacional do problema, considerado NP-Completo, foram apresentadas duas abordagens alternativas à Formulação Disjuntiva base para o Problema de Estivagem de Unidades de Celulose (PEUC).

A primeira abordagem, o Modelo Matemático Modificado, fez uso da aplicação do conceito de famílias de itens para reduzir o número total de variáveis de decisão envolvidas na resolução do modelo.

Na primeira abordagem, com aplicação do Modelo Matemático Modificado, foram obtidos resultados, em média, 0,68 ponto percentual melhores em relação ao Modelo Matemático Base. Em algumas instâncias a solução encontrada superou 3 pontos percentuais de melhoria.

Já a segunda abordagem, o Método Iterativo de Solução (MIS), aplicou o conceito de iterações com ajustes sucessivos no número de itens disponíveis para alocação ao objeto. O objetivo dessa abordagem também foi o de reduzir a quantidade total de variáveis de decisão envolvidas na resolução do problema.

Nessa segunda abordagem a aplicação do Método Iterativo de Solução apresentou uma melhoria média de até 1,31 ponto percentual em relação aos modelos matemáticos resolvidos sem aplicação do MIS. As soluções foram melhores até mesmo no caso do Modelo Matemático Base.

Já a aplicação conjunta das duas abordagens (Método Iterativo de Solução e Modelo Matemático Modificado) apresentou, em relação ao Modelo Matemático Base, melhora média nas soluções de 1,98 ponto percentual. Em algumas instâncias a melhoria na solução obtida passou de 8 pontos percentuais.

Os resultados apresentados ao longo deste trabalho, e sumarizados acima, mostram que as duas hipóteses formuladas e testadas sobre a resolução do Problema de Estivagem de Celulose (PEUC) foram confirmadas.

Além disso, resultados obtidos através da resolução de instâncias reais se mostra- 
ram promissores, com melhorias significativas em 3 das 4 instâncias. Entretanto, dada a pequena quantidade de dados reais disponíveis, a análise de uma maior massa de instâncias reais se faz necessária para que seja possível avaliar de forma conclusiva a efetividade da aplicação do Modelo Matemático Modificado e do Método Iterativo de Solução aos problemas reais.

Mesmo com os bons resultados obtidos pela aplicação dos dois métodos desenvolvidos, especialmente nas instâncias experimentais, algumas extensões do trabalho são recomendadas. Entre elas, destacam-se:

- Aprimoramento do Método Iterativo de Solução, com a incorporação de outros conceitos que possam aumentar a qualidade das soluções ou reduzir o tempo computacional necessário para obtenção de bons resultados. Entre esses conceitos, pode-se destacar a potencial aplicação do History Bucket (HUANG; HWANG; LU, 2016), que busca evitar a repetição de configurações de itens nas diferentes iterações;

- Expansão do Modelo Matemático Modificado para que seja possível a construção de planos de estivagem com mais de 6 diferentes configurações de lingadas de celulose;

- Incorporação de restrições operacionais propositadamente desconsideradas no presente trabalho. Entre essas restrições pode-se citar, por exemplo, a posição dos arames de amarração das unidades de celulose (não é recomendado que os arames fiquem diretamente em contato com as paredes do porão do navio); e

- Inclusão de parâmetros adicionais para definição do plano de estivagem ótimo, como por exemplo, o tempo total necessário para carregamento do navio. 


\section{Referências}

AMBROSINO, D.; SIRI, S. Comparison of solution approaches for the train load planning problem in seaport terminals. Transportation Research Part E: Logistics and Transportation Review, v. 79, p. 65-82, 2015.

ARENALES, M. et al. Pesquisa Operacional. 6. ed. [S.l.: s.n.], 2007.

BALAS, E. Disjunctive programming. Annals of Discrete Mathematics, 1979.

BALAS, E. Disjunctive programming: Properties of the convex hull of feasible points. Discrete Applied Mathematics, v. 89, n. 98, p. 3-44, 1998.

BISCHOFF, E.; WÄSCHER, G. Cutting and packing. European Journal of Operational Research, v. 84, p. 503-505, 1995.

CARLSSON, D. et al. Supply Chain Planning Models in the Pulp and Paper Industry. Infor, v. 47, n. 3, p. 167-183, 2009. ISSN 03155986. Disponível em: < http: //search.ebscohost.com/login.aspx?direct $=$ true $\{\&\} \mathrm{db}=\operatorname{buh}\{\&\} \mathrm{AN}=52445099\{\&\}$ site $>$.

CARVALHO, J. M. V. D. LP models for bin packing and cutting stock problems. European Journal of Operational Research, v. 141, p. 253-273, 2002.

CHEN, C.; LEE, S.; SHEN, Q. An analytical model for the container loading problem. European Journal of Operational Research, v. 80, n. 1, p. 68-76, 1995.

CHRISTENSEN, H. I. et al. Approximation and online algorithms for multidimensional bin packing: A survey. Computer Science Review, Elsevier Inc., v. 24, p. 63-79, 2017. ISSN 15740137. Disponível em: <http://dx.doi.org/10.1016/j.cosrev.2016.12.001>.

CHRISTOFIDES, N.; WHITLOCK, C. An Algorithm for Two-Dimensional Cutting Problems. Operations Research, v. 25, n. 1, p. 30-44, 1977. ISSN 0030-364X.

CUI, Y.; CUI, Y.-P.; YANG, L. Heuristic for the two-dimensional arbitrary stock-size cutting stock problem. Computers $\mathcal{E}$ Industrial Engineering, v. 78, p. 195-204, 2014.

DELGADO, A. et al. A Constraint Programming model for fast optimal stowage of container vessel bays. European Journal of Operational Research, v. 220, n. 1, p. 251-261, 2012 .

DOWSLAND, K. a.; DOWSLAND, W. B. Packing problems. European Journal of Operational Research, v. 56, p. 2-14, 1992.

DYCKHOFF, H. A typology of cutting and packing problems. European Journal of Operational Research, v. 44, n. 2, p. 145-159, 1990.

ESICUP. 2012.

FIBRIA. Notice to The Market. 2017. Disponível em: <http://fibria.infoinvest.com.br/ enu/6596/Fibria $\left\{\backslash \_\right\}$NoticetotheMarket $\left\{\searrow_{\ldots}\right\}$ PanOcean $\left\{\backslash \_\right\} \mathrm{v}>$.

Fibria S.A. UBS II Pulp \& Paper Day - SP. [S.l.], 2017. 
HADJICONSTANTINOU, E.; CHRISTOFIDES, N. An exact algorithm for general, orthogonal, two-dimensional knapsack problems. European Journal of Operational Research, v. 83, n. 1980, p. 39-56, 1995.

HAIMS, M.; FREEMAN, H. A Multistage Solution of the Template-Layout Problem. IEEE Transactions on Systems Science and Cybernetics, v. 6, n. 2, p. 145-151, 1970.

HIFI, M. et al. A linear programming approach for the three-dimensional bin-packing problem. Electronic Notes in Discrete Mathematics, v. 36, p. 993-1000, 2010.

HILLIER, F. S.; LIEBERMAN, G. J. Introduction to Operations Research. 7. ed. [S.l.: s.n.], 2000.

HOPPER, E.; TURTON, B. C. H. Empirical investigation of meta-heuristic and heuristic algorithms for a 2D packing problem. European Journal of Operational Research, v. 128, n. 1, p. 34-57, 2001.

HORA, A. B. da; MELO, L. Papel e Celulose. Bndes, p. 47-54, 2016. Disponível em: <https://web.bndes.gov.br/bib/jspui/handle/1408/7201>.

HUANG, Y. H.; HWANG, F. J.; LU, H. C. An effective placement method for the single container loading problem. Computers and Industrial Engineering, v. 97, p. 212-221, 2016. ISSN 03608352. Disponível em: <http://dx.doi.org/10.1016/j.cie.2016.05.008>.

IBÁ. Relatório 2017. 2017.

KALLRATH, J. et al. Solving real-world cutting stock-problems in the paper industry: Mathematical approaches, experience and challenges. European Journal of Operational Research, v. 238, n. 1, p. 374-389, 2014.

LODI, A.; MARTELLO, S.; MONACI, M. Two-dimensional packing problems: A survey. European Journal of Operational Research, v. 141, p. 241-252, 2002.

LÓPEZ-CAMACHO, E. et al. A unified hyper-heuristic framework for solving bin packing problems. Expert Systems with Applications, v. 41, n. 15, p. 6876-6889, 2014.

LU, H.-c.; HUANG, Y.-h. An efficient genetic algorithm with a corner space algorithm for a cutting stock problem in the TFT-LCD industry. European Journal of Operational Research, v. 246, n. 1, p. 51-65, 2015.

MALAGUTI, E.; DURáN, R. M.; TOTH, P. Approaches to real world two-dimensional cutting problems. Omega (United Kingdom), v. 47, p. 99-115, 2013.

MARTELLO, S.; MONACI, M. Models and algorithms for packing rectangles into the smallest square. Computers and Operations Research, Elsevier, v. 63, p. 161-171, 2015. ISSN 03050548. Disponível em: <http://dx.doi.org/10.1016/j.cor.2015.04.024>.

MONACO, M. F.; SAMMARRA, M.; SORRENTINO, G. The terminal-oriented ship stowage planning problem. European Journal of Operational Research, Elsevier B.V., v. 239, n. 1, p. 256-265, 2014. ISSN 03772217. Disponível em: <http://dx.doi.org/10.1016/j.ejor.2014.05.030>.

MORALES, S. R.; MORABITO, R.; WIDMER, J. A. Otimização do carregamento de produtos paletizados em caminhões. Gestão 6 Produção, v. 4, p. 234-252, 1997. 
OLIVEIRA, J. F. et al. A SURVEY ON HEURISTICS FOR THE TWO-DIMENSIONAL RECTANGULAR STRIP PACKING PROBLEM. Pesquisa Operacional, 2016. ISSN 0101-7438.

ØVSTEBØ, B. O.; HVATTUM, L. M.; FAGERHOLT, K. Optimization of stowage plans for RoRo ships. Computers and Operations Research, Elsevier, v. 38, n. 10, p. 1425-1434, 2011. ISSN 03050548. Disponível em: <http://dx.doi.org/10.1016/j.cor.2011.01.004>.

RAMAN, R.; GROSSMANN, I. E. Modelling and computational techniques for logic based integer programming. Computers and Chemical Engineering, v. 18, n. 7, p. 563-578, 1994. ISSN 00981354.

RIBEIRO, G. M.; LORENA, L. a. N. Optimizing the woodpulp stowage using Lagrangean relaxation with clusters. Journal of the Operational Research Society, v. 59, p. 600-606, 2008.

SAWAYA, N. W.; GROSSMANN, I. E. A cutting plane method for solving linear generalized disjunctive programming problems. Computers $\&$ Chemical Engineering, v. 29, n. 9, p. 1891-1913, 2005.

SAWAYA, N. W.; GROSSMANN, I. E. Computational implementation of non-linear convex hull reformulation. Computers and Chemical Engineering, v. 31, n. 7, p. 856-866, 2007. ISSN 00981354.

SCIOMACHEN, A.; TANFANI, E. A 3D-BPP approach for optimising stowage plans and terminal productivity. European Journal of Operational Research, v. 183, n. 3, p. 1433-1446, 2007. ISSN 03772217.

SEATRADE. Cosco Shipping Specialised Carriers orders paper pulp vessels for Brazilian COA. 2017. Disponível em: <http://www.seatrade-maritime.com/news/asia/ cosco-shipping-specialised-carriers-orders-paper-pulp-vessels-for-brazil-s-coa.html $>$.

SPEROTTO, F. Q. Expansion of the Pulp Sector in Brazil: constraints and perspectives. Indicadores Econômicos FEE, v. 41, n. 4, p. 85-100, 2014.

SWEeney, P. E.; PATERnOSTER, E. R. Cutting and Packing Problems: A Categorized, Application-Orientated Research Bibliography. Operations Research1, v. 43, n. 7, p. 691-706, 1992. ISSN 0160-5682.

VIDAL, A. C. F.; HORA, A. B. da. A Indústria de Papel e Celulose. p. 48, 2012.

WÄSCHER, G.; HAUSSNER, H.; SCHUMANN, H. An improved typology of cutting and packing problems. European Journal of Operational Research, v. 183, p. 1109-1130, 2007.

WINSTON, W. L. Operations Research: Applications and Algorithms. 4. ed. [S.l.: s.n.], 2003. 
Apêndices 


\section{APÊNDICE A - Implementação do Gerador de Instâncias}

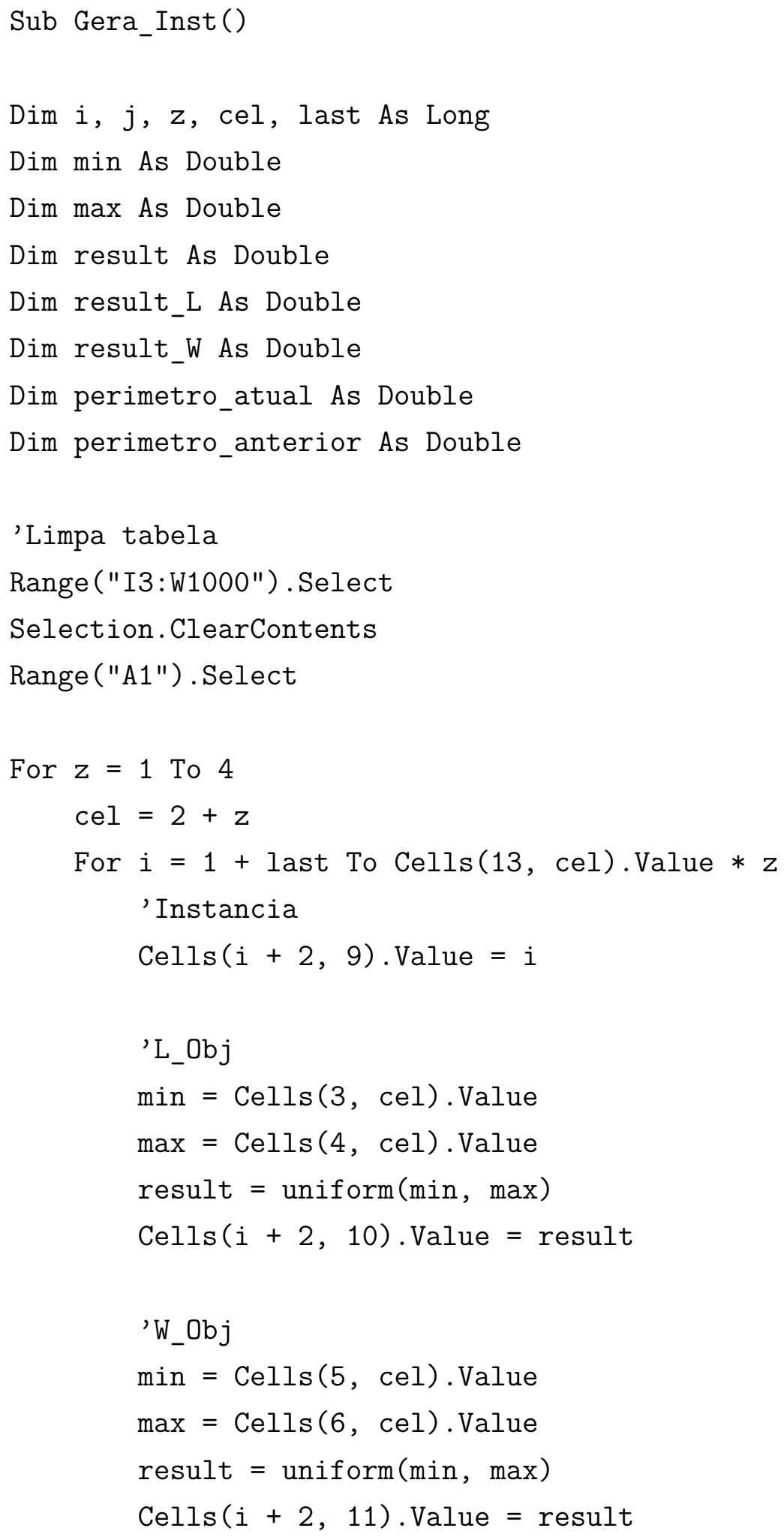




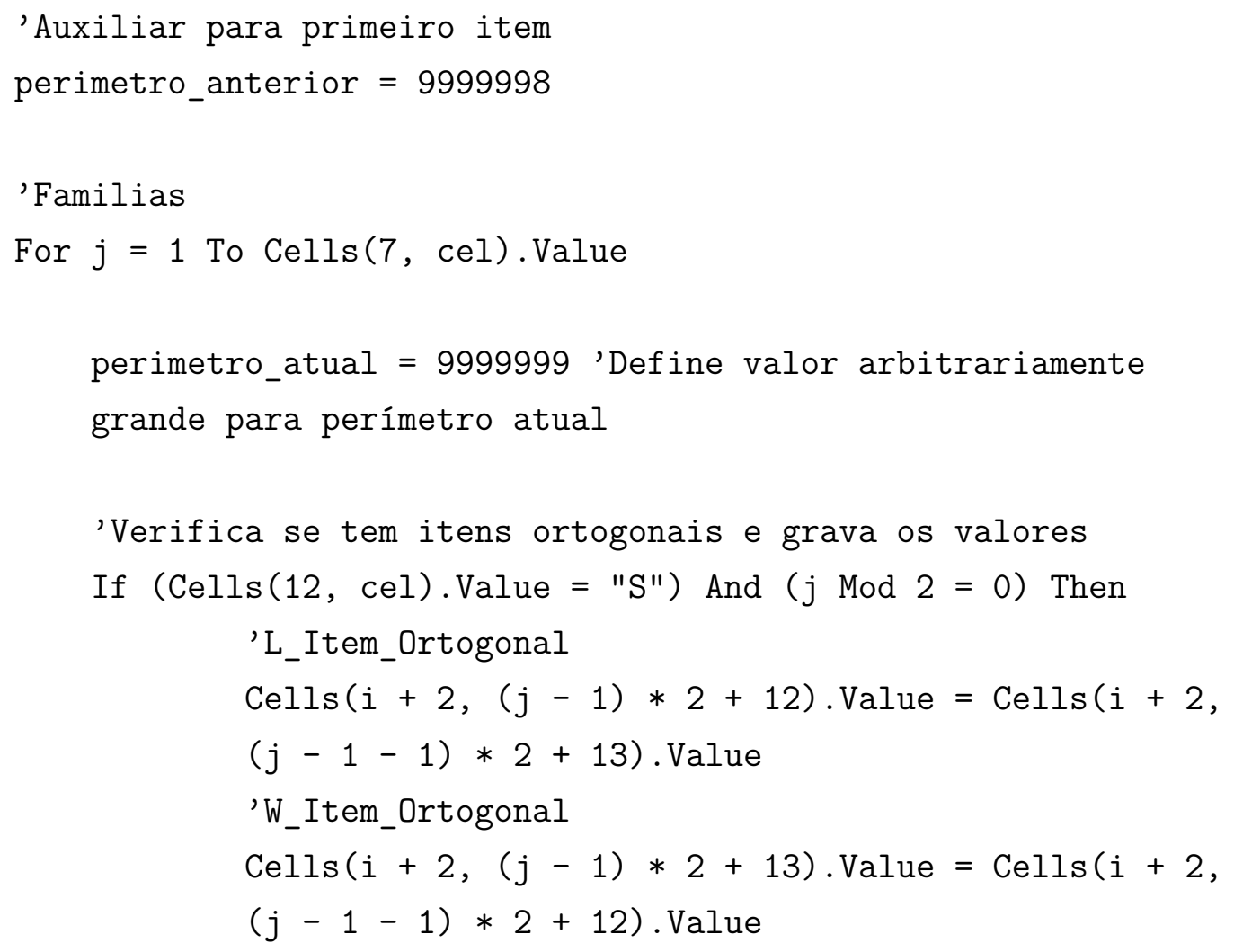

Else

Do While perimetro_atual > perimetro_anterior 'Estrutura para garantir que o perímetro seja cada vez menor
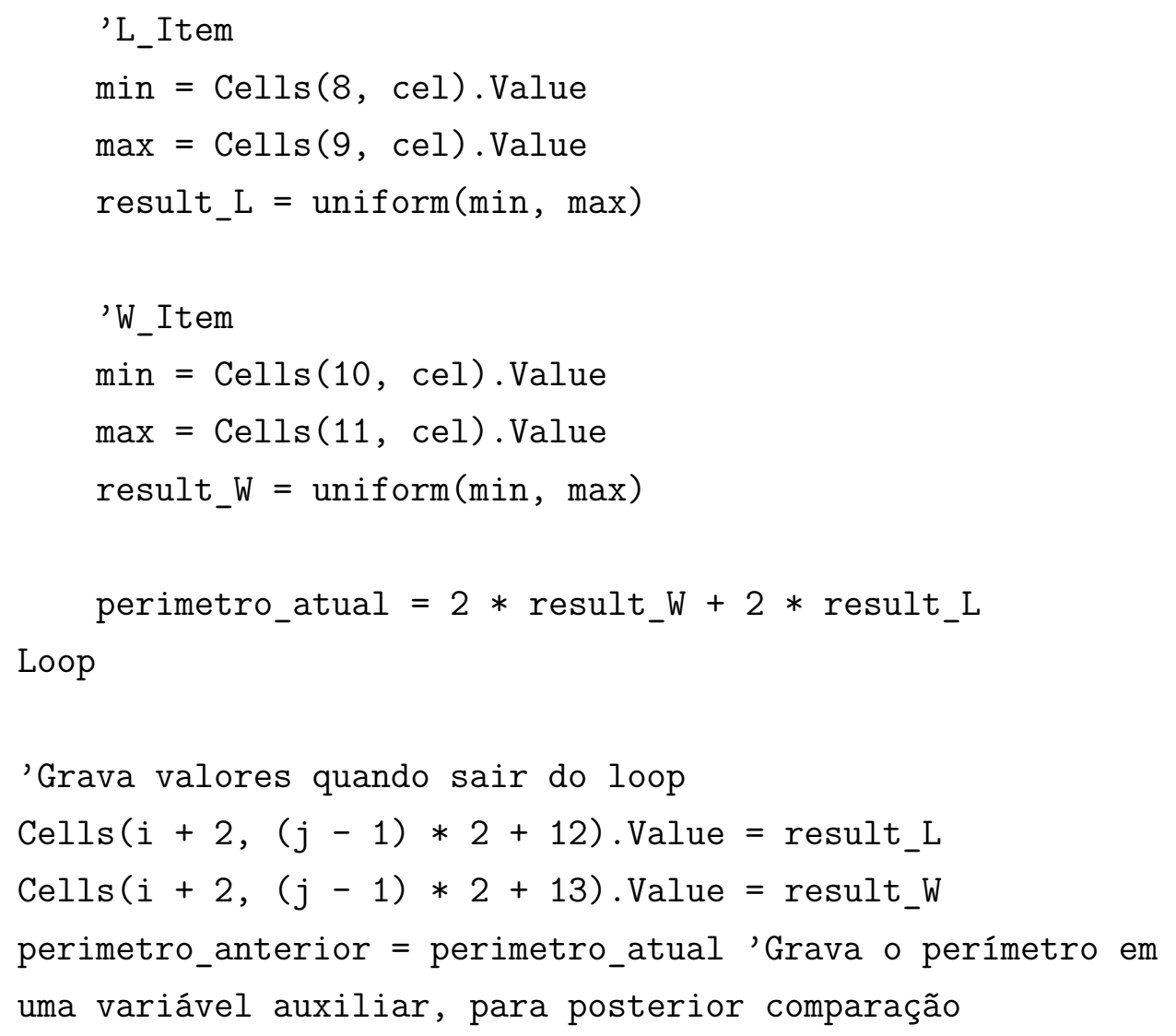
End If

Next $j$

last $=i$

Next $i$

Next $z$

End Sub 


\section{APÊNDICE B - Implementação do Modelo Matemático Base}

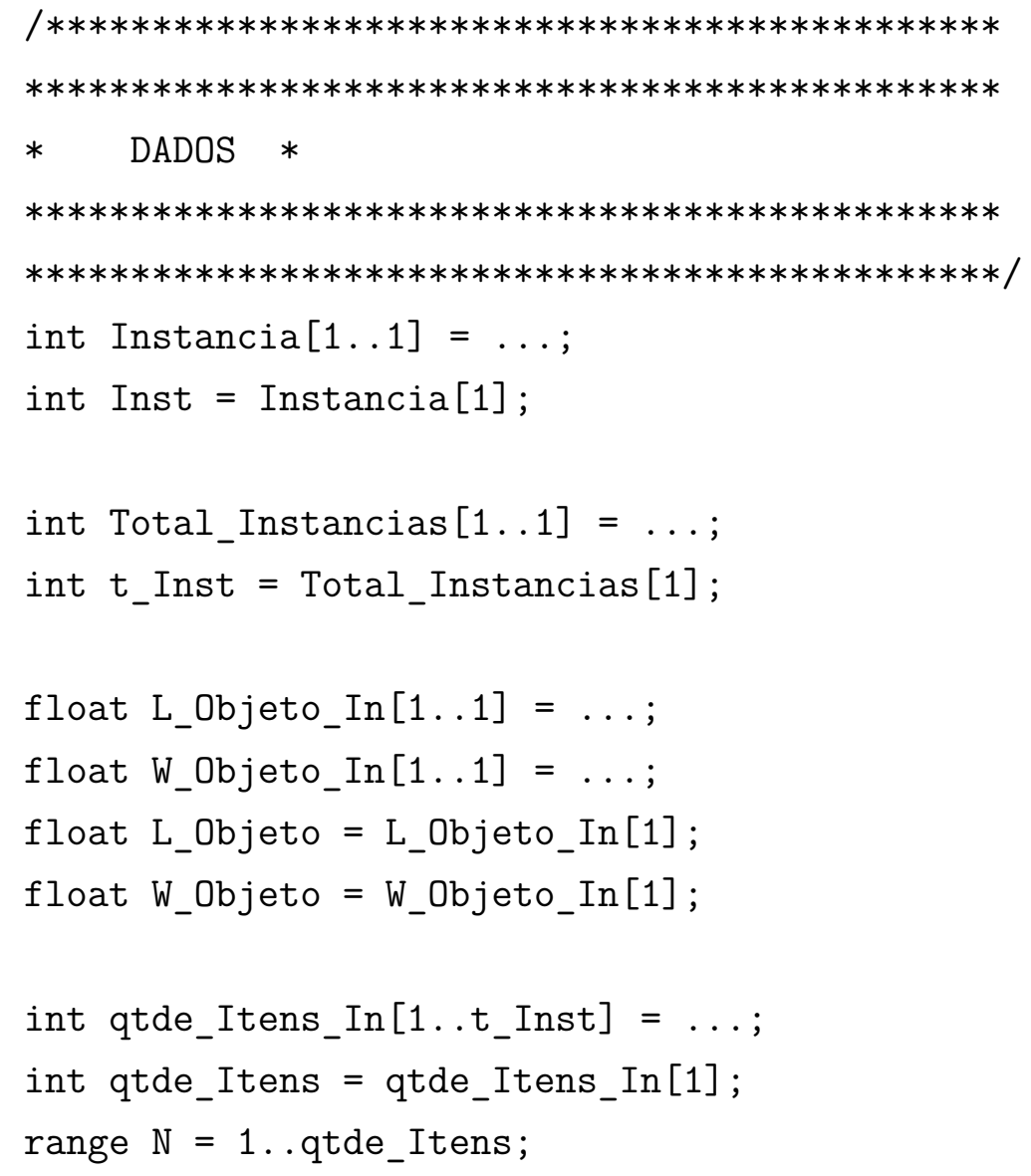




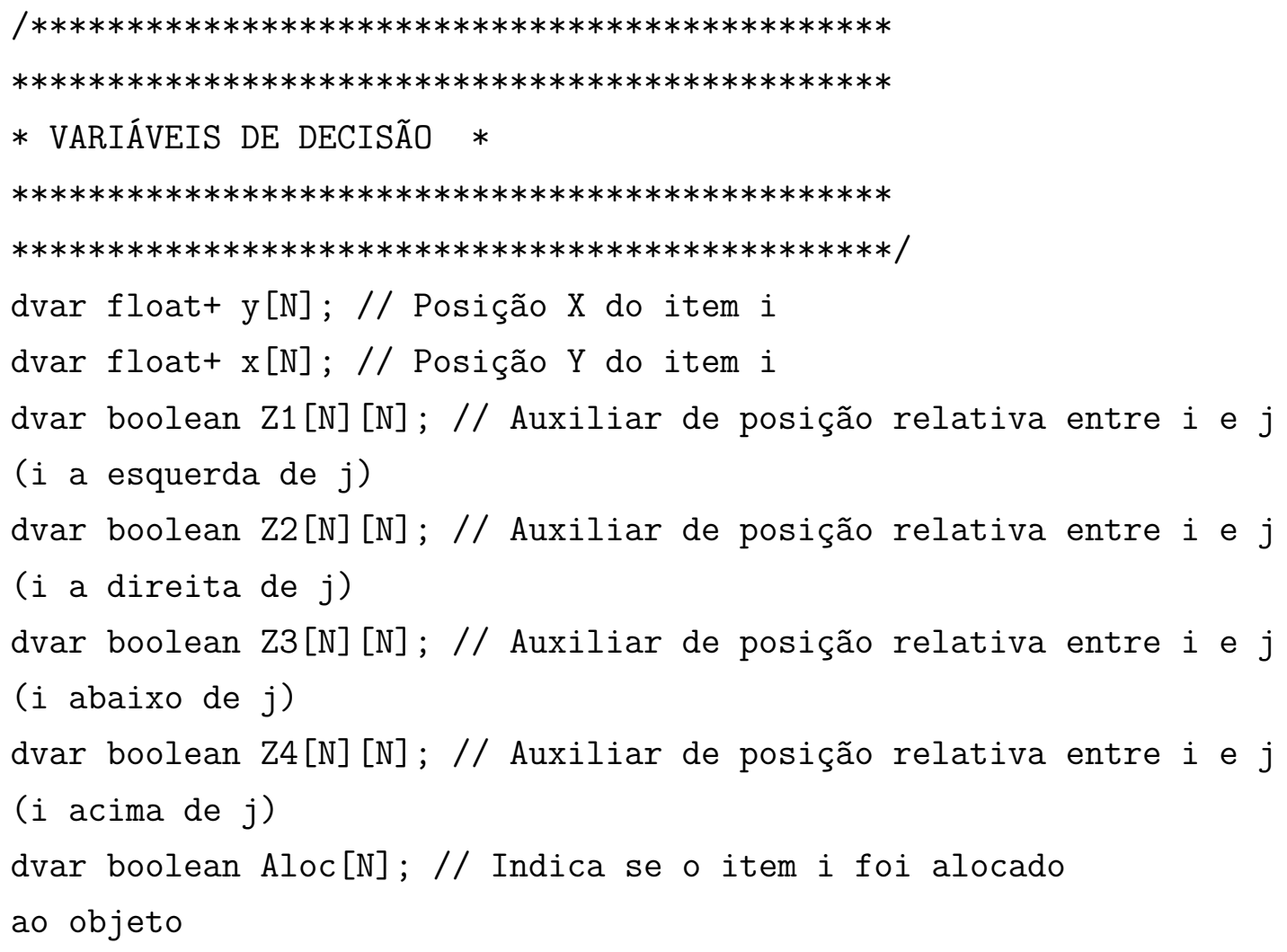


// Restrição de não-sobreposição - i está a direita de j forall ( $i$ in $N, j$ in $N: i<j$ )

ct2: $x[i]-x[j]-L_{-} \operatorname{Item}[j]+(1-Z 2[i][j]) * M>=0$;

// Restrição de não-sobreposição - i está abaixo de j

forall ( $i$ in $N, j$ in $N: i<j$ )

ct3: $y[j]-y[i]-W_{-}$Item $[i]+(1-Z 3[i][j]) * M>=0$;

// Restrição de não-soobreposição - i está acima de j

forall ( $i$ in $N, j$ in $N: i<j$ )

ct4: $y[i]-y[j]-W_{-} \operatorname{Item}[j]+(1-Z 4[i][j]) * M>=0$;

// Consolidação das restrições de não-sobreposição

forall ( $i$ in $N, j$ in $N: i<j$ )

ct5: $\mathrm{Z} 1[\mathrm{i}][j]+\mathrm{Z} 2[\mathrm{i}][\mathrm{j}]+\mathrm{Z} 3[\mathrm{i}][\mathrm{j}]+\mathrm{Z} 4[\mathrm{i}][\mathrm{j}]-\mathrm{Aloc}[\mathrm{i}]-\mathrm{Aloc}[\mathrm{j}]>=-1$;

// Limite de posição no eixo horizontal

forall ( $i$ in $N$ )

ct6: $0<=x[i]$;

forall ( $i$ in $N$ )

ct7: $x[i]<=\left(L_{-}\right.$Objeto - L_Item $\left.[i]\right)$;

// Limite de posição no eixo vertical

forall ( $\mathrm{i}$ in $\mathrm{N}$ )

ct8: $0<=y[i]$;

forall ( $\mathrm{i}$ in $\mathrm{N}$ )

ct9: $y[i]<=$ (W_Objeto - W_Item $[i]$ ); 


\section{APÊNDICE C - Implementação do Matemático Modificado}

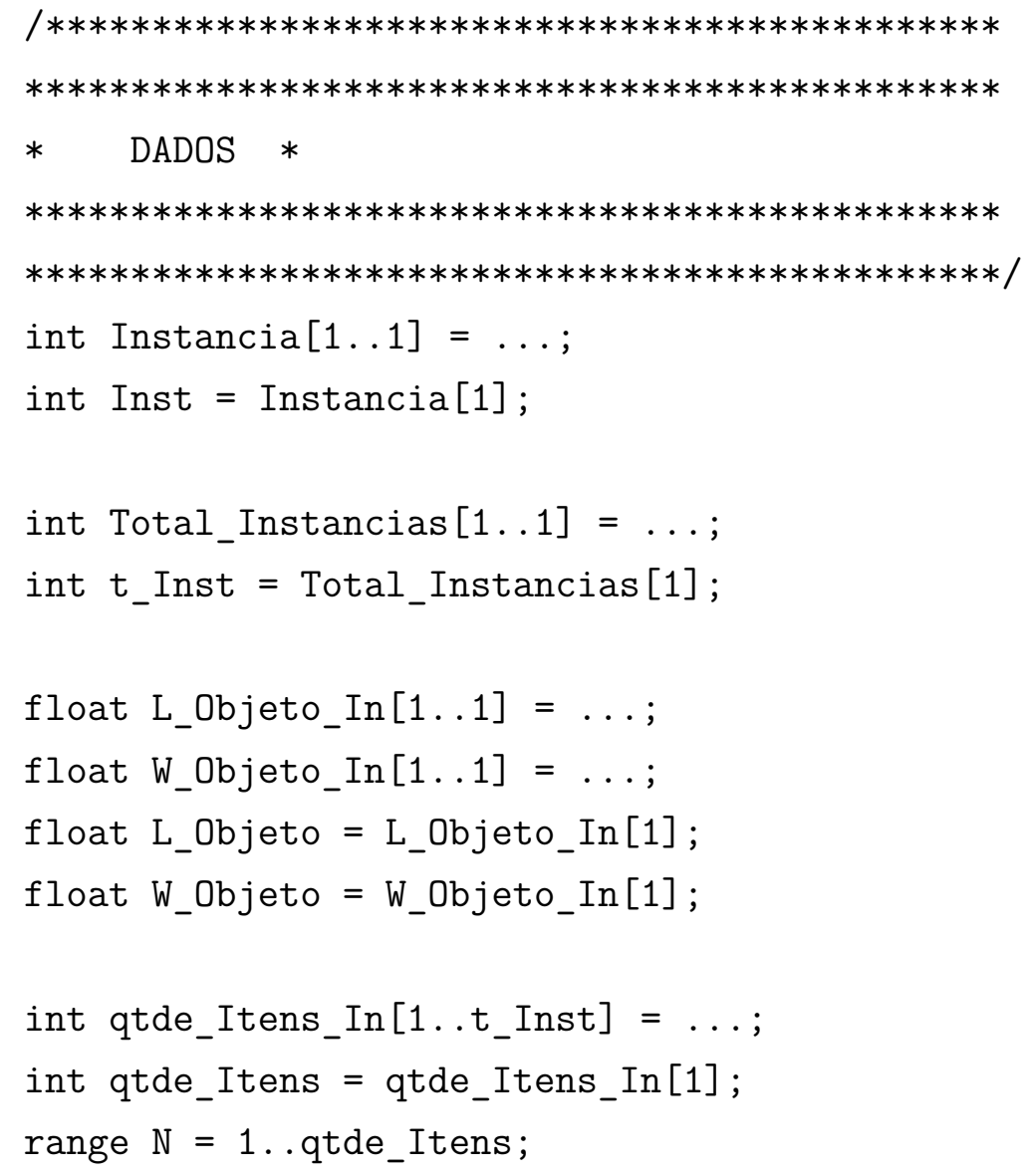




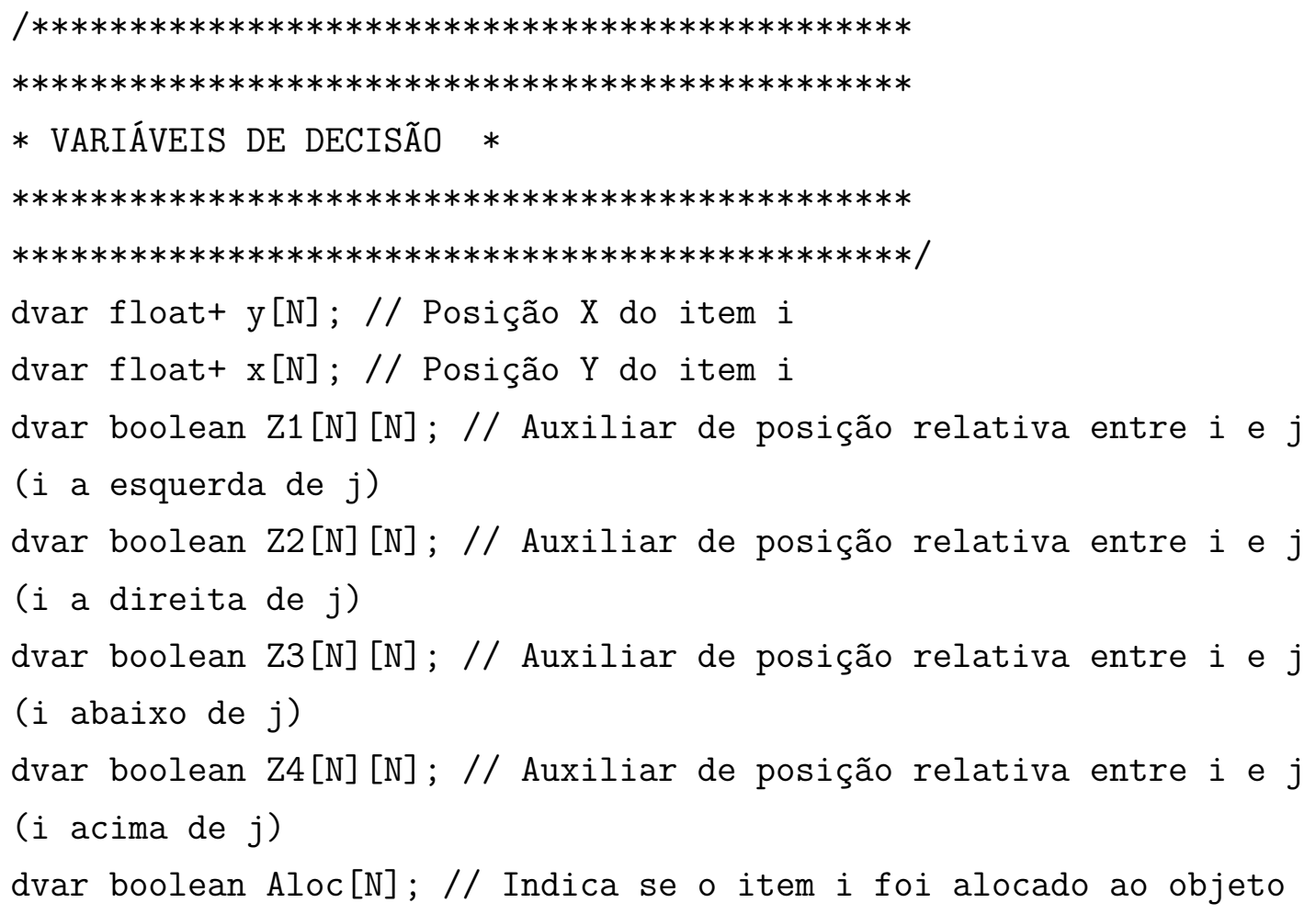




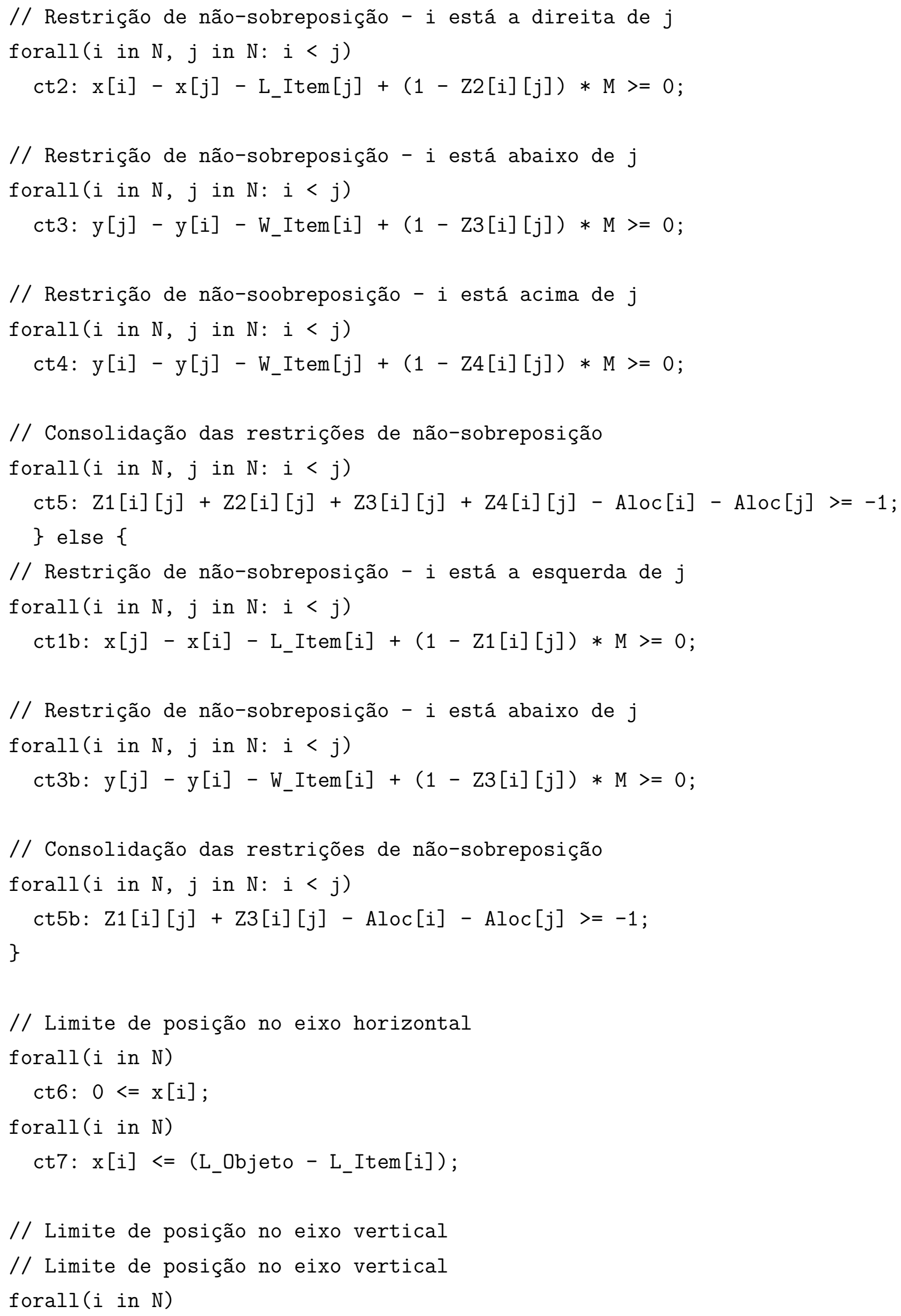


ct8: $0<=y[i]$;

forall ( $i$ in $N$ )

ct9: $y[i]<=\left(W_{-}\right.$Objeto - W_Item $\left.[i]\right)$; 


\section{APÊNDICE D - Implementação do Método Iterativo de Solução}

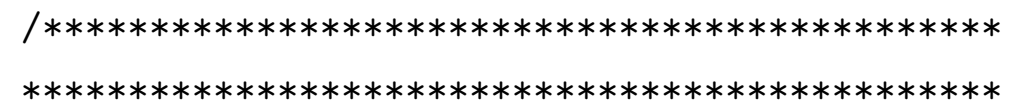

* FLOW CONTROL *

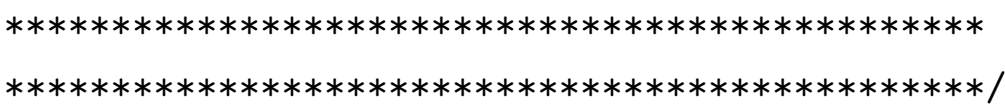

main \{

// Habilita end() no CPLEX IDE

thisOplModel.settings.mainEndEnabled = true;

// Criação do modelo com dados de entrada originais

var data = new IloOplDataSource ("PEUC.dat");

var source $=$ new IloOplModelSource ("PEUC_CF.mod");

var def = new IloOplModelDefinition(source);

var model = new IloOplModel (def,cplex);

model.addDataSource (data);

// Variáveis auxiliares

var log_mod = new IloOplOutputFile("Log.txt");

var stow = new IloOplOutputFile("Stowplan.txt");

var $\mathrm{k}=1 ; / /$ Variável de controle das instâncias

var qtde_Instancias $=20 ; / /$ Quantidade total de instâncias

a serem solucionadas

// Loop de controle de instâncias

while ( $\mathrm{k}<=$ qtde_Instancias) \{

var dataEl = model.dataElements; // Variável auxiliar para referenciar dataElements

dataEl.Instancia[1] = k; // Passa a instância atual para o modelo

var area = dataEl.L_Objeto_In[1]*dataEl.W_Objeto_In[1]; // Área total do objeto 
var $t=1 ; / /$ Variável de controle das iterações

var best $=0 ; / /$ Variável com 0 OBJ da melhor instância

var $\operatorname{curr}=0 ; / /$ Variável com 0 OBJ da instância atual

var exaustao $=1 ; / /$ Variável auxiliar que controla a exaustão

das iterações da instância

// Tempo limite para resolução

var tilim $=60 ; / /$ Variável com o tempo limite para resolução de cada iteração

cplex.tilim = (tilim); // Atualiza parâmetro do CPLEX

// Loop de controle das iterações

while (1) \{

// Matriz de itens disponíveis para a próxima iteração

var counter_familia $=1$;

var counter_itens $=1$;

var counter_total $=1$;

var max_familia $=6 ; / /$ Verifica o número de famílias diferentes

var total_itens $=0 ; / /$ Variável com o máximo de itens total

// Loop para geração de cada família de itens

while (counter_familia $<=\max _{-}$familia) \{

var dataEl = model.dataElements; // Variável auxiliar para referenciar dataElements

// Verifica os itens de cada família que foram alocados na última iteração $\operatorname{var} j=1 ; / /$ Variável auxiliar de índice

var maximo_itens $=0 ; / /$ Variável com o máximo de itens para a família

while $(j<=$ model.qtde_Itens) \{

if (model.F_Aux $[j]==$ counter_familia) \{

maximo_itens $=$ maximo_itens $+\left(1 * \operatorname{model} . A l o c_{-} A u x[j]\right)$;

\}

j++;

\}

// Se for a primeira iteração, garante um mínimo de itens

if (maximo_itens $==0$ ) \{ 


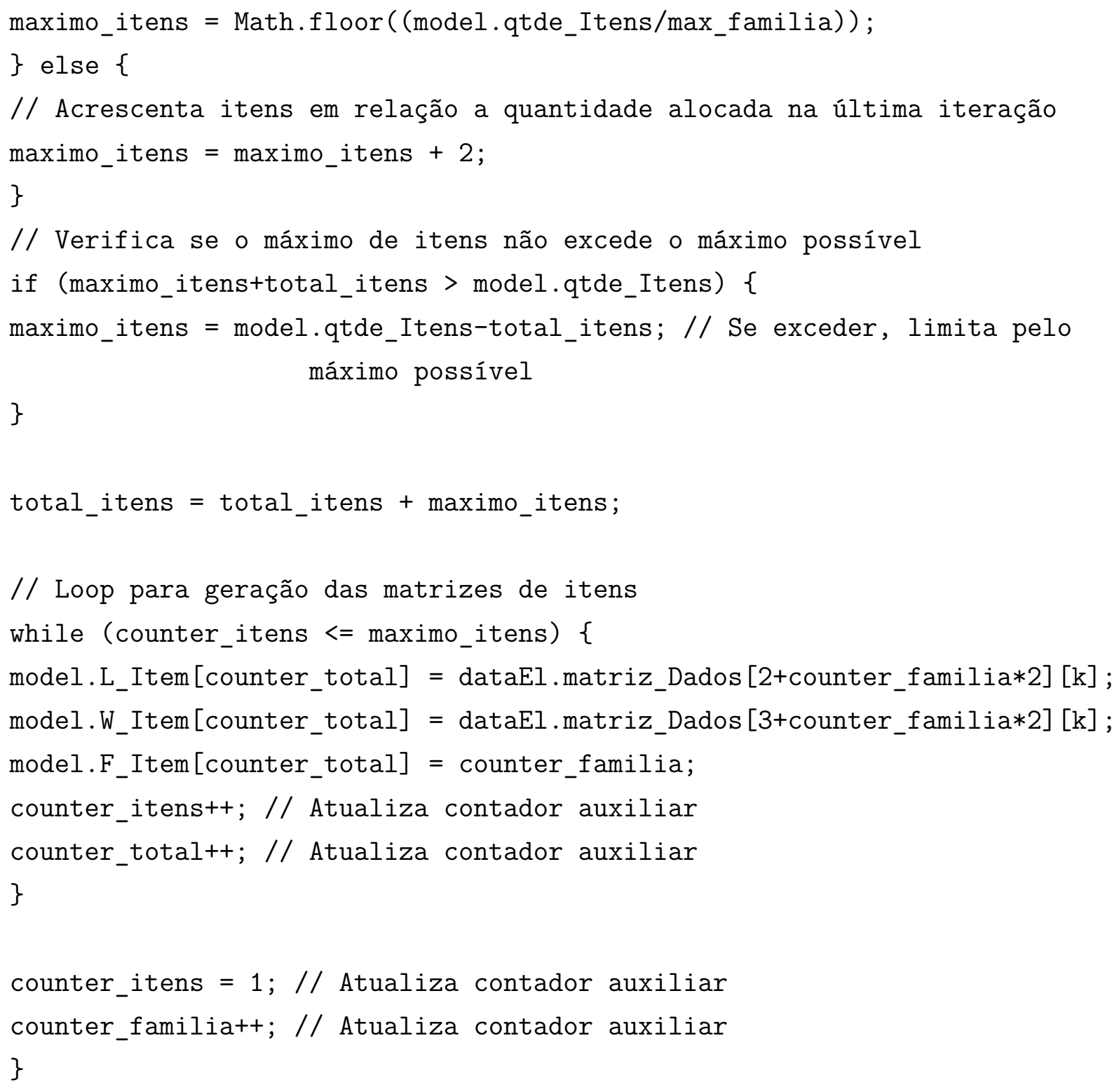




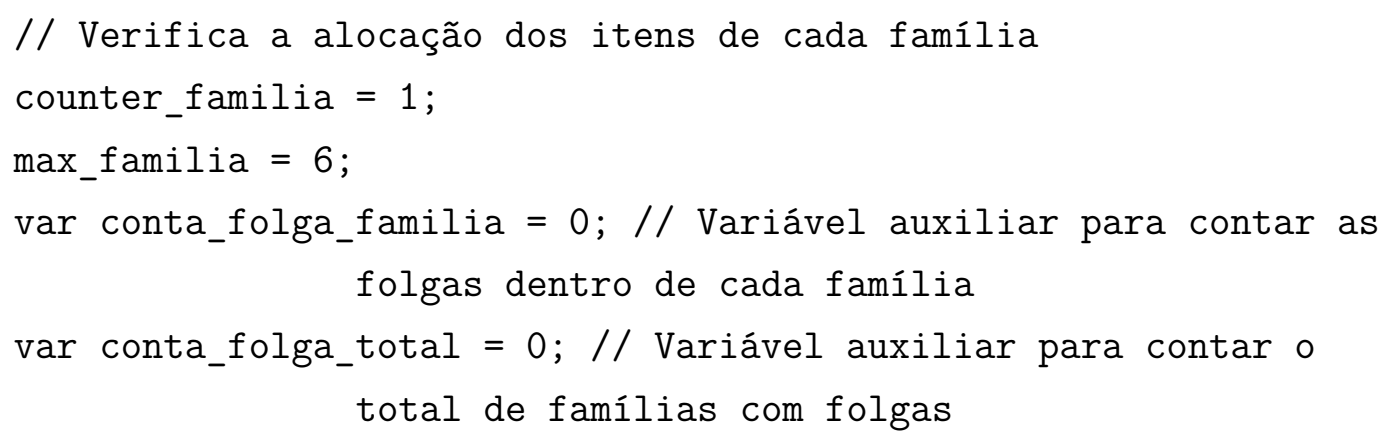

// Escreve dados da iteração para arquivo de Log do Modelo log_mod.writeln(k +";"+ t +";"+ cplex.getObjValue() +";"+ area +" ;"+ 


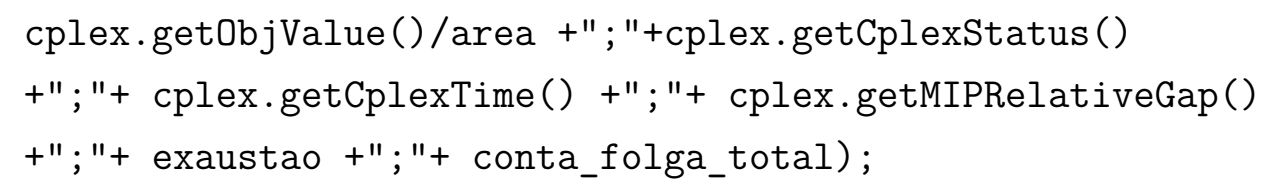

// Tempo padrão de resolução das iterações

tilim $=60$;

// Verifica qualidade da solução atual

if (curr > best) \{ // Se a solução atual for superior a melhor até

o momento

best $=$ curr; // Atualiza a variável com o melhor OBJ até o momento exaustao $=1 ; / /$ Zera o contador de exaustão

\} else $\{/ /$ Se não houve melhora na solução

exaustao++; // Incrementa o contador de exaustão

\}

// Escreve plano de estivagem para arquivo de saída

for ( $\operatorname{var} z=1 ; z<=$ model.qtde_Itens; $z^{++}$) \{

stow.writeln $(k+" ; "+\mathrm{t}+" ; "+\operatorname{model} \cdot \mathrm{x}[\mathrm{z}]+"$;"+ model.y[z] +";"+ model.L_Item[z] $+" ; "+\operatorname{model}$.W_Item $[z]+" ; "+\operatorname{model}$.Aloc $[z])$;

\}

// Controle das iterações de acordo com a folga

if (conta_folga_total $==6$ ) \{

tilim $=180 ; / / 1.800$ segundos $=30$ minutos

\}

// Controle das iterações se não houver melhorias

var gap_curr $=$ cplex.getMIPRelativeGap () ;

if (exaustao $>5||$ best $==$ area || gap_curr < 0.05) $\{/ /$ Triggers para encerrar o modelo

break; // Encerra instância atual

\}

cplex.tilim = (tilim); // Atualiza parâmetro do CPLEX t++; // Atualiza contador de controle das iterações 
// Gera novo modelo para próxima iteração.

model = new IloOplModel (def, $\mathrm{cplex})$;

model. addDataSource (dataEl);

\}

// Insere separador no log para resultados da próxima instância writeln("-----------------------------------------");

// Limpa as matrizes para a próxima instância

$\operatorname{var} \mathrm{w}=1$;

while ( $<<=$ model.qtde_Itens) \{

model.Aloc_Aux $[\mathrm{w}]=0$;

model.F_Aux $[\mathrm{w}]=0$;

$\mathrm{w}^{++}$;

\}

// Atualiza dimensões do objeto para a próxima instância.

dataEl.L_Objeto_In[1] = dataEl.matriz_Dados[2] [k+1];// Length

dataEl.W_Objeto_In[1] = dataEl.matriz_Dados [3] [k+1];// Height

k++; // Atualiza contador de controle de instâncias

// Gera novo modelo para próxima instância.

model = new IloOplModel (def, $\mathrm{cplex})$;

model. addDataSource (dataEl);

\}

\} 